\begin{abstract}
Aus der Klinik für
Unfallchirurgie, Orthopädie und Plastische Chirurgie

(Prof. Dr. med. W. Lehmann)

der Medizinischen Fakultät der Universität Göttingen

\section{Vorbeugender Gesundheitsschutz für das Personal vor Infektionen mit übertragbaren Erregern}

\author{
INAUGURAL-DISSERTATION \\ zur Erlangung des Doktorgrades \\ der Medizinischen Fakultät der \\ Georg-August-Universität zu Göttingen
}

vorgelegt von

Lara Katharina Reinmuth

aus

Freiburg im Breisgau

Göttingen 2017 
Dekan: $\quad$ Prof. Dr. rer. nat. H. K. Kroemer

Referent: $\quad$ Prof. Dr. med. Klaus Dresing

Ko-Referentin: Prof. Dr. med Simone Scheithauer

Datum der mündlichen Prüfung: 05.03.2018 
Hiermit erkläre ich, die Dissertation mit dem Titel "Vorbeugender Gesundheitsschutz für das Personal vor Infektionen mit übertragbaren Erregern" eigenständig angefertigt und keine anderen als die von mir angegebenen Quellen und Hilfsmittel verwendet zu haben.

Göttingen, den 24.02.2018 Lara Katharina Reinmuth 
Inhalt

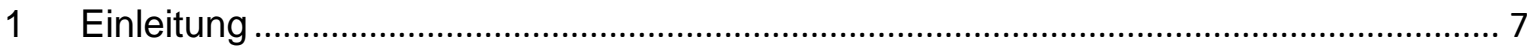

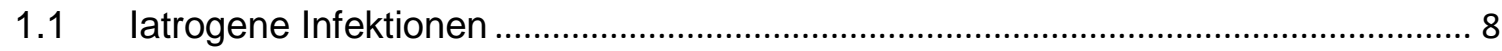

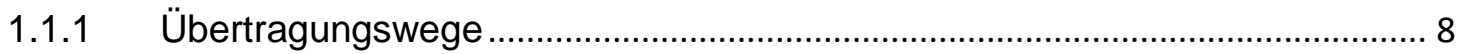

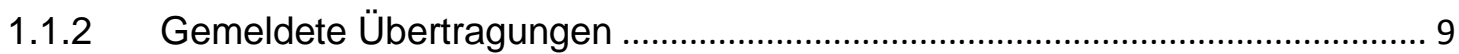

1.1.3 Infektionen von Personal im Gesundheitswesen ............................................ 9

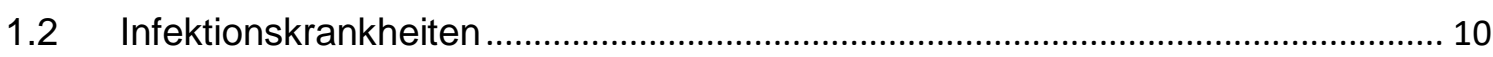

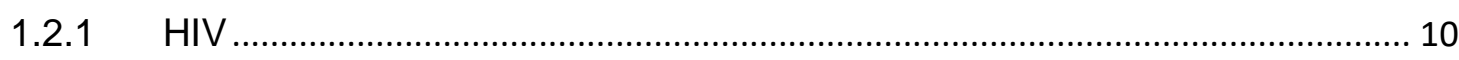

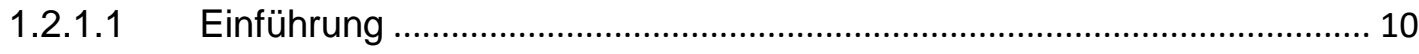

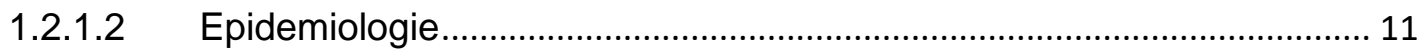

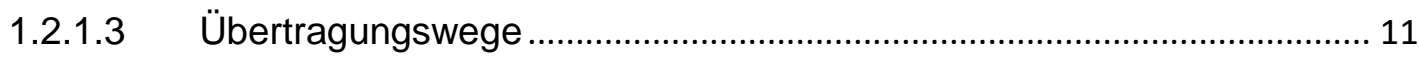

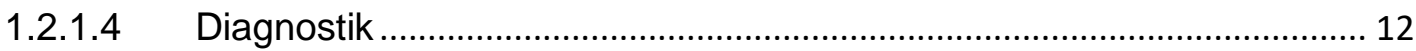

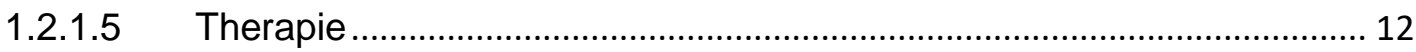

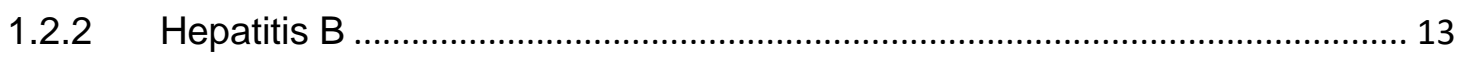

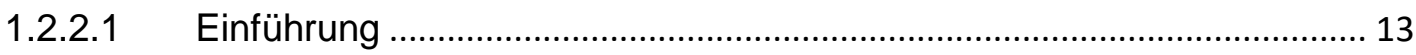

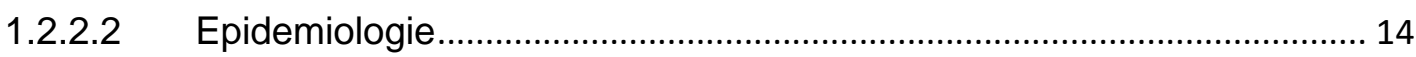

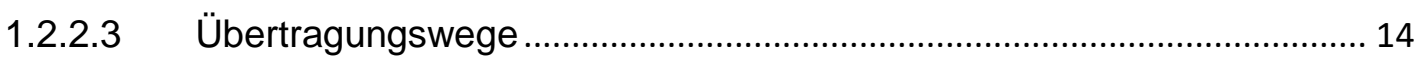

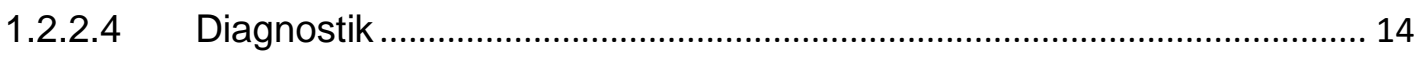

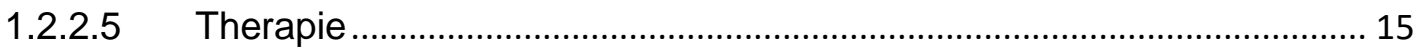

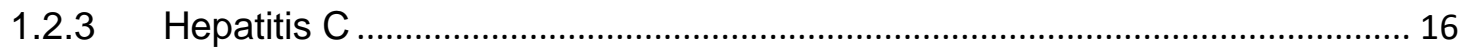

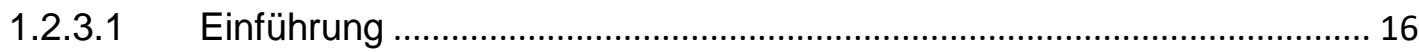

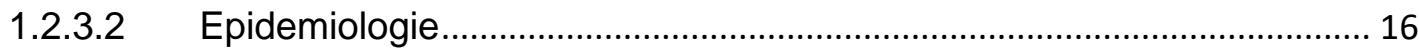

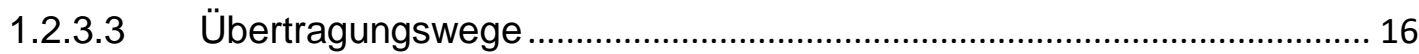

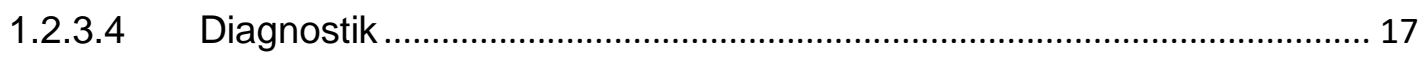

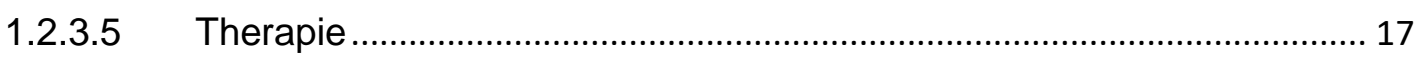

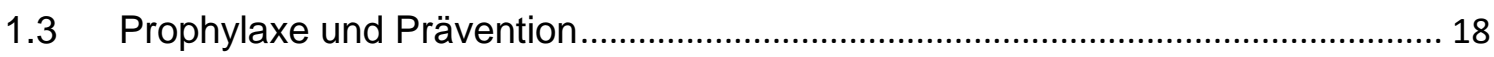

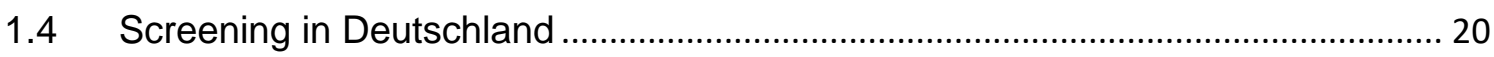

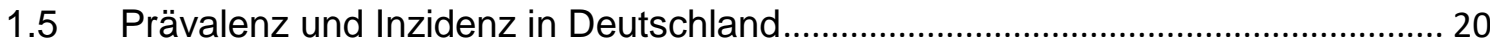

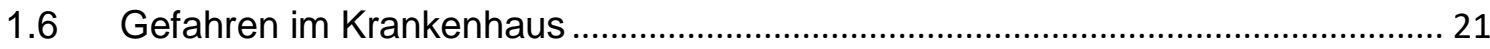

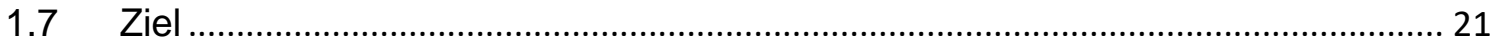

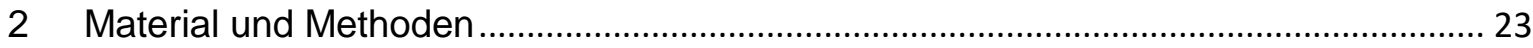

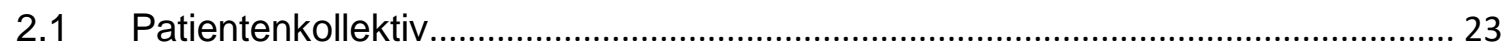

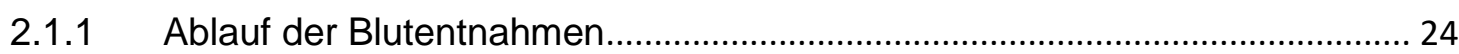

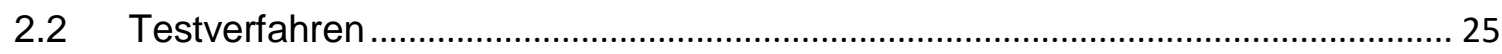

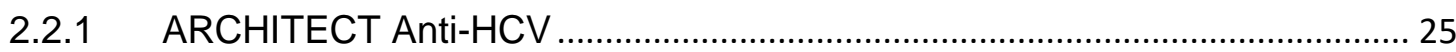




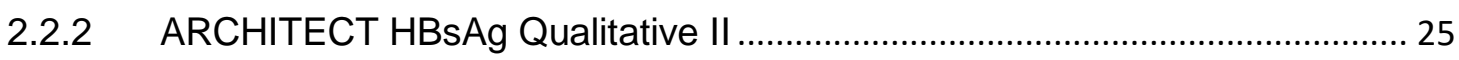

2.2.3 ARCHITECT HIV Ag/Ab Combo …................................................................... 25

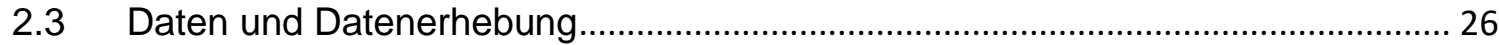

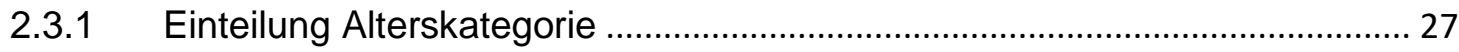

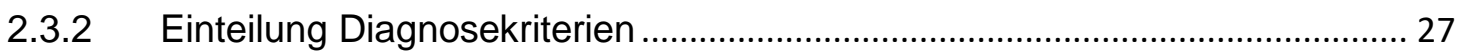

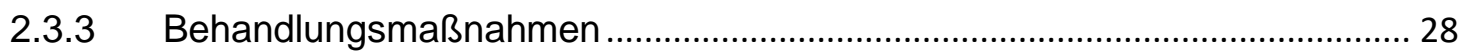

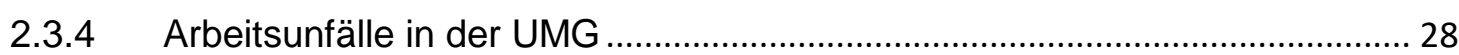

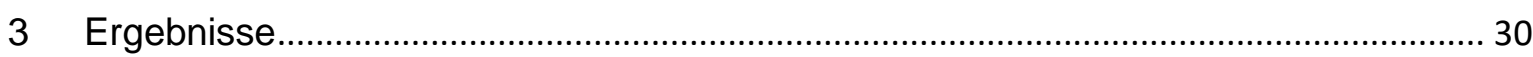

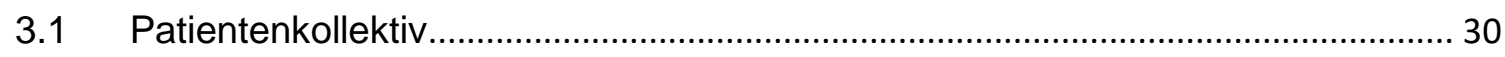

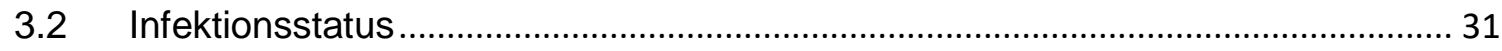

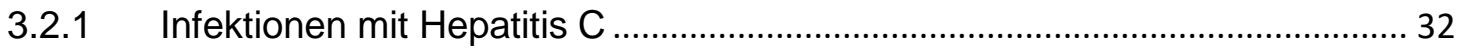

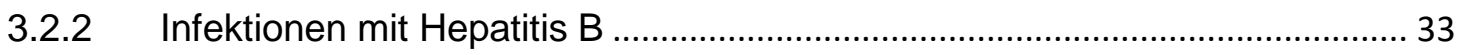

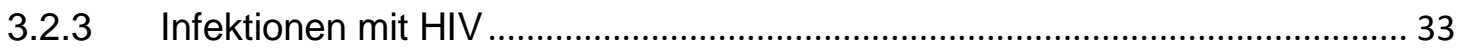

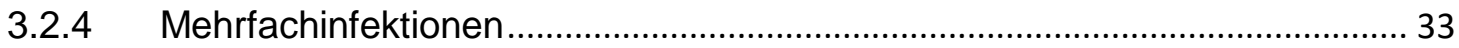

3.2.5 Patienten und Infektionsaufkommen pro Jahr .............................................. 34

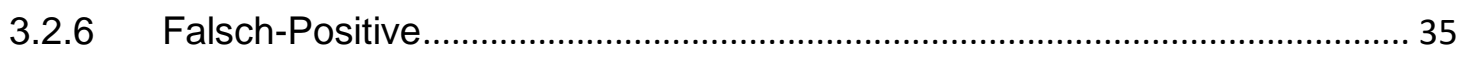

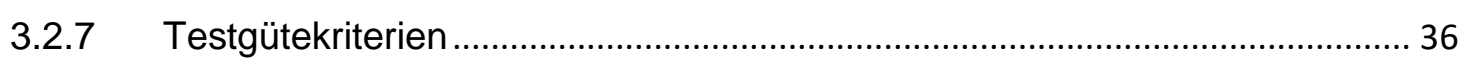

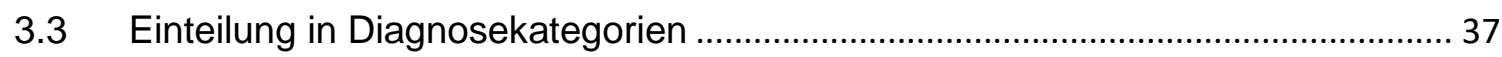

3.3.1 Kategorie A - Patienten mit Verletzungen im Kopf- und Gesichtsbereich .... 37

3.3.2 Kategorie B - Patienten mit thorakalen Verletzungen...................................... 37

3.3.3 Kategorie C - Patienten mit Abdominalverletzungen ....................................... 37

3.3.4 Kategorie D - Patienten mit Beckenverletzungen........................................... 37

3.3.5 Kategorie E - Patienten mit Extremitätenverletzungen.................................... 38

3.3.6 Kategorie F - Patienten mit Wirbelsäulenverletzungen ................................... 38

3.3.7 Kategorie G - Polytrauma-Patienten................................................................. 38

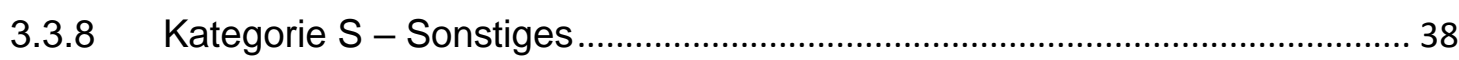

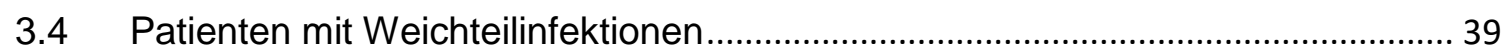

3.5 Hauptkategorie E, Extremitätenverletzungen ....................................................... 40

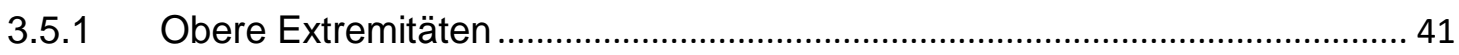

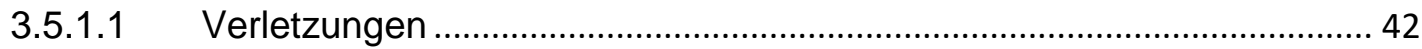

3.5.1.2 Lokalisation der Verletzungen und Infektionsstatus............................... 42

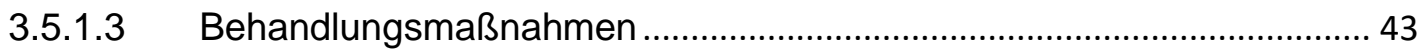

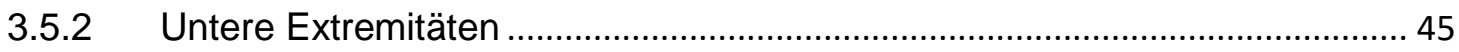

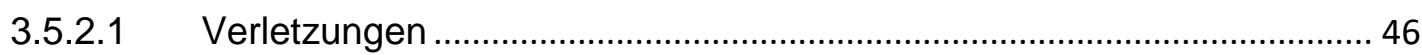

3.5.2.2 Lokalisation der Verletzungen und Infektionsstatus............................... 46 


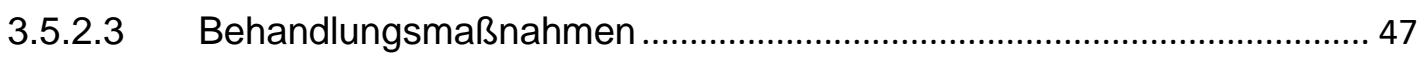

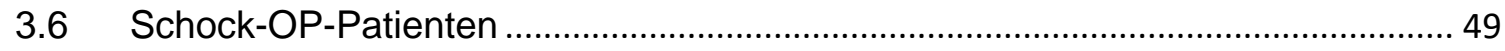

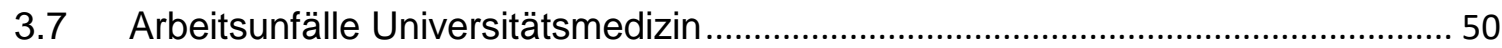

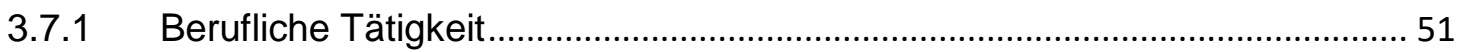

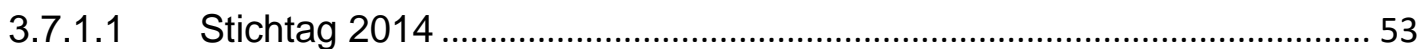

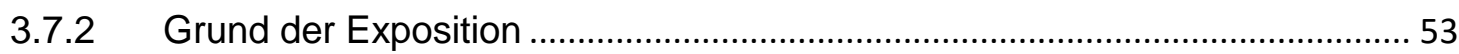

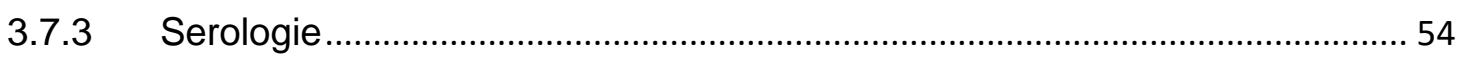

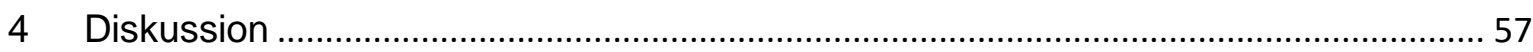

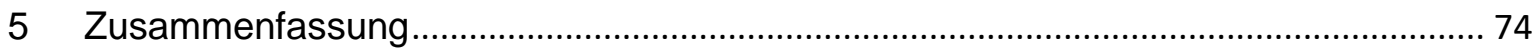

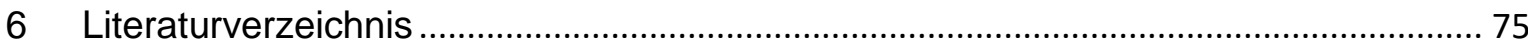

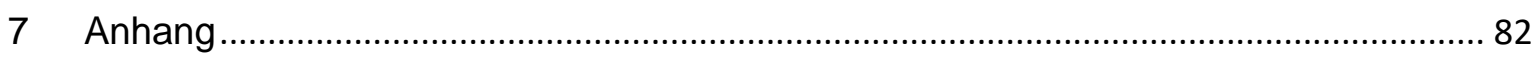

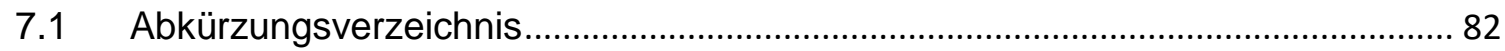

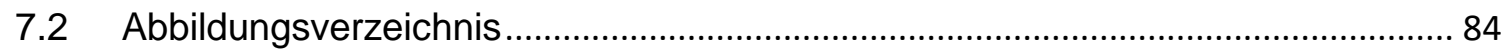

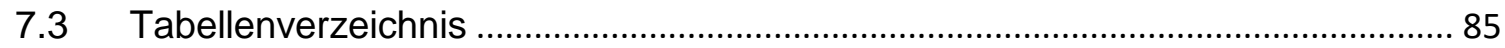

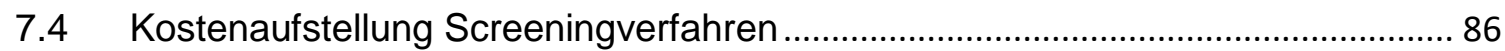




\section{Einleitung}

Unfallchirurgen und medizinisches Personal sind in ihrem beruflichen Umfeld vermehrt dem Kontakt mit infizierten Körperflüssigkeiten ausgesetzt, ohne über die möglichen Gefahren umfassend Kenntnis zu haben. Auch bei größter Vorsicht im Umgang mit Patienten kommt es in Krankenhaus und Praxis immer wieder zu Verletzungen des medizinischen Personals mit der potentiellen Infektionsmöglichkeit durch blutübertragbare Erkrankungen wie HIV (human immunodeficiency virus) und Hepatitis B und C.

Ein einheitliches Screening aller Patienten und damit vorbeugender Gesundheitsschutz für das Personal existiert nicht.

Hepatitis B und C sowie HIV sind auch heute schwere Erkrankungen, die nicht durch banale Therapiemaßnahmen beherrscht werden können oder zur Ausheilung zu bringen sind. In Krankenhäusern sind Ärzte und Pflegemitarbeiter und -mitarbeiterinnen täglich Gefahren durch infizierte Patienten ausgesetzt (Schell 2002). Hierbei können z. B. Nadelstichverletzungen zur Infektion mit blutübertragbaren Erkrankungen wie Hepatitis und HIV führen. Auch in der Ambulanz, Notaufnahme und insbesondere im Operationssaal können diese Infektionen durch scharfe Instrumente und Implantate, Knochen und Aerosole, z. B. bei der Jet-Lavage, übertragen werden.

Hepatitis B, C und HIV werden durch Viren übertragen, die im Rahmen der Biostoffverordnung $\S 2$ Abs. 3 zu den Mikroorganismen gezählt werden, die eine gesundheitsschädigende Wirkung haben können (BGBI I 2013, S. 2514). Unter dem Begriff Mikroorganismen werden alle biologischen Einheiten zusammengefasst, die zur Weitergabe ihres genetischen Materials befähigt sind. Die hier genannten Viren werden der Kategorie 3 der Biostoffverordnung zugeteilt und zählen somit zu Stoffen, die schwere Krankheiten verursachen und eine Gefahr für den Menschen darstellen können. Des Weiteren beinhaltet diese Kategorie, dass eine Verbreitungsgefahr in der Bevölkerung bestehen kann, diese jedoch durch vorbeugende Maßnahmen oder Behandlungen minimiert werden kann. Die Biostoffverordnung gilt nach $\S 2$ Absatz 7, 2. für Tätigkeiten mit Kontakt und Umgang mit Biomaterialien, dazu zählen alle Arbeiten, bei denen die Stoffe auftreten können und ein Kontakt von Beschäftigten entstehen könnte (BGBII 2013, S. 2514).

In der Richtlinie 2000/54/EG des Europäischen Parlaments und des Rates wird darauf hingewiesen, dass eine Exposition der Viren nicht über Luftwege stattfindet. 
Weiter wird ausgeführt, dass für Hepatitis B eine wirksame Impfprophylaxe vorhanden ist. Ein Verzeichnis mit Angaben über Exposition eines Arbeitnehmers gegenüber dem Biostoff, muss bis zu 10 Jahre nach Exposition aufbewahrt werden (Richtlinie Nr.54/2000/EG, ABI. EU Nr. L 262 S. 21).

In der vorliegenden Arbeit werden die Ausdrücke Patient und Personal für beide Geschlechter verwendet.

\section{1 latrogene Infektionen}

\subsection{1 Übertragungswege}

Potentielle Infektionsgefahren im Krankenhaus bestehen einerseits durch infiziertes Personal, aber auch durch kontagiöse Flüssigkeiten von Patienten sowie (äußerst selten) kontaminierte Blutprodukte von infizierten Blutspendern. Blutprodukte wurden vor der Transfusion ab 1970 auf HBV (Hepatitis-B-Virus), ab 1985 auf HIV und ab den frühen 90er Jahren auch auf HCV (Hepatitis-C-Virus) getestet (Offergeld et al. 2003). Die größte Infektionsgefahr besteht weiterhin für Hepatitis B mit einer Wahrscheinlichkeit von 1:200.000 bei Bluttransfusionen. Hepatitis $C$ und HIV dagegen haben Übertragungswahrscheinlichkeiten von weniger als 1:1.000.000 (Offergeld et al. 2003). Dies ist auf die Infektiosität der einzelnen Viren und die notwendige kritische Menge an erregerhaltigem Material zurückzuführen (Berger et al. 2012). Durch immer sensibler werdende Testverfahren verringern sich diese Zahlen weiterhin deutlich.

Die Übertragung von Viren von medizinischem Personal auf Patienten, hierbei vor allem durch chirurgisch tätiges Personal, erfolgt in den meisten Fällen über perkutane Verletzungen (Fry 1993). Wichtig für eine mögliche Übertragung durch infektiöses Material sind unter anderem die Faktoren Viruslast, Menge des Materials und Zustand der Haut, da intakte Haut besseren Schutz bietet als verletzte. Ebenso spielt die Eindringtiefe des infektiösen Materials eine Rolle (Sarrazin et al. 2003). 


\subsubsection{Gemeldete Übertragungen}

Bis zum Jahr 2012 gab es für das HI-Virus keinen gemeldeten Transmissionsvorgang von medizinischem Personal auf Patienten innerhalb Deutschlands, bei ca. 5000 im Gesundheitswesen tätigen HIV-Infizierten (Rabenau et al. 2012). Das parenterale Übertragungsrisiko durch blutige Instrumente liegt hierbei bei $0,3 \%$, bei mukosaler Übertragung sogar nur bei 0,03\% (Rabenau et al. 2012).

Für Hepatitis $C$ wurden 14 infizierte, im Gesundheitswesen tätige Personen gemeldet, die das Virus auf insgesamt 55 Patienten weiter übertragen haben (Deterding 2014). Die Infektionsgefahr für Hepatitis $C$ beträgt bei Nadelstichverletzungen $3 \%$, für das Hepatitis-B-Virus liegt die Übertragungswahrscheinlichkeit bei einem Zehnfachen davon (Sarrazin et al. 2005). Die Virustransmission ist auch hier wiederum von vielen Faktoren abhängig, unter anderem spielen die Viruslast und die AntigenArt des Trägers sowie das Verletzungsmuster bei der Übertragung eine Rolle (Hasselhorn und Hofmann 2000).

Die iatrogene Übertragung kann im Falle von Hepatitis B durch eine prophylaktische Impfung des Personals verhindert werden (Gerlich 2004). Für Deutschland gab es von 1968-2013 insgesamt 16 gemeldete Fälle (Hofmann 2015). Bei diesen Zahlen konnte eine direkte Korrelation zwischen Patient und Arzt nachgewiesen werden und gilt somit als arbeitsplatzbezogene Infektion.

\subsubsection{Infektionen von Personal im Gesundheitswesen}

Bis zum Ende des Jahres 2013 gab es 82 anerkannte Fälle von HIV als Berufskrankheit, dazu zählten 45 pflegerisch tätige Personen, drei Arzthelfer und 20 Ärzte, von denen sich vier die Infektion erwiesenermaßen im Ausland zugezogen hatten (Robert Koch-Institut 2014a).

2013 wurden 24 Hepatitis-B-Fälle von der Deutschen gesetzlichen Unfallversicherung als berufsbedingt anerkannt (Robert Koch-Institut 2015c), ebenso 34 HepatitisC-Fälle (Robert Koch-Institut 2015d). 


\subsection{Infektionskrankheiten}

\subsubsection{HIV}

\subsubsection{Einführung}

Das human immunodeficiency virus gehört zur Familie der Retroviren und kommt in mindestens zwei bekannten Subtypen, nämlich HIV-1, welches für die meisten Infektionen verantwortlich ist und erstmals 1981 entdeckt wurde, sowie HIV-2 vor (Barasa 2011). HIV dringt mit Hilfe der Glykoproteine gp120 und gp41 in seine Zielzellen ein, welche CD4 (cluster of differentiation 4) exprimieren (Kwong et al. 1998). Dieser Rezeptor führt aufgrund seiner überwiegenden Expression auf CD4-Helferzellen dazu, dass vorwiegend T-Helferzellen befallen werden, welche als Folge der Infektion absterben und so die Immunschwäche AIDS (acquired immune deficiency syndrome) auslösen (Chan und Kim 1998). T-Helferzellen gehören zum immunologischen Gedächtnis und helfen dem Körper bei der Abwehr von Krankheitserregern. Ohne diese Zellen enden die meisten erworbenen Immundefekte tödlich (Kamradt und Ferrari-Kühne 2011).

HIV-2 war initial vor allem in Westafrika zu finden und scheint eine niedrigere Viruslast als HIV-1 aufzuweisen, was auf den Ursprung aus einem anderen Lentivirus zurückführbar sein könnte und die geringere Übertragungsrate erklären würde (Sharp et al. 2001).

Nach Eintritt in das Zytoplasma der Zielzellen wird die virale RNA (ribonucleic acid) durch die Reverse Transkriptase des HI-Virus in Doppelstrang-DNA (dsDNA, deoxyribonucleic acid) umgeschrieben (Peliska und Benkovic 1992) und durch Integrase in das Genom der Wirtszelle integriert (Hoffmann und Rockstroh 2011). Dadurch stellen sich die T-Helferzellen auf Virusproduktion um und halten den eigenen Zellzyklus nicht mehr in Gang, wodurch es zu gesteigerter Apoptose und vermehrtem Untergang der Zellen sowie anschließendem Verlust der Immunabwehr kommt (Engelman und Cherepanov 2012).

AIDS ist das Endstadium der HIV-Infektion und mit pathognomonischen Erkrankungen wie beispielsweise dem Kaposi-Sarkom verbunden (Plettenberg et al. 1990).

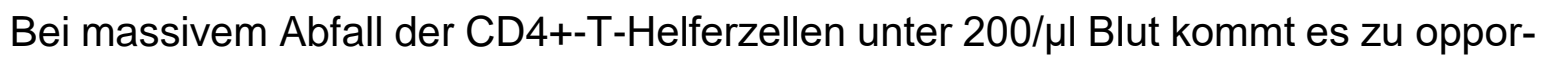
tunistischen Infektionen wie Candidosen und Pneumonien, die für den Patienten häufig letal enden (Potthoff und Brockmeyer 2007). 
Die HIV-Infektion verläuft in drei Stadien (Robert Koch-Institut 2006):

- Der akuten Phase (null bis sechs Wochen), in welcher sich das Virus im Körper ausbreitet,

- der Latenz- oder asymptomatischen Phase (bis zu mehreren Jahren)

- sowie der symptomatischen Phase, die das Vollbild der Erkrankung mit sich bringt.

HIV wird nach der CDC-Klassifikation in drei klinische Kategorien und analog drei CD4-Zellzahlbereiche eingeteilt (Centers for Disease Control (CDC) 1992):
A: Asymptomatisches Stadium, $\geq 500$ CD4+- T-Zellen/ $\mu$ l Blut

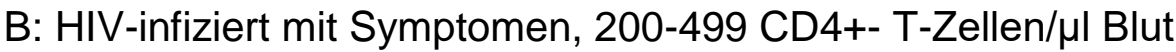
C: AIDS (Vollbild) <200 CD4+- T-Zellen/ $\mu$ Blut

\subsubsection{Epidemiologie}

Weltweit lebten laut World Health Organization Ende 2015 36,7 Millionen Menschen mit HIV, wovon 2,1 Millionen Neuninfektionen waren (World Health Organization 2016c). 2,4 Millionen der weltweit Infizierten leben in West- und Zentraleuropa sowie Nord-Amerika (UNAids 2016). In Deutschland liegt die Prävalenz laut Robert KochInstitut (Stand Ende 2014) bei ungefähr 83.400 mit HIV/AIDS infizierten Bundesbürgern, die Inzidenz betrug bundesweit etwa 3200 Personen (Robert Koch-Institut 2014b). Seit Beginn der Erfassung gab es geschätzt 27.600 Tote unter den Infizierten in Deutschland, für das Jahr 2014 wurden 480 Tote registriert (Robert KochInstitut 2014b). Für Niedersachsen ergab sich eine geschätzte Anzahl von 4.200 Infizierten für das Jahr 2014 (Robert Koch-Institut 2014c). Diese Zahlen beruhen auf geschätzten Angaben des RKI aus unterschiedlich zusammengetragenen Quellen und Daten. Es werden jährlich neue Berechnungen erstellt, die aber keine Fortführung alter Berechnungen darstellen. Seit 1982 gibt es ein freiwilliges AIDS-Register und seit 1987 eine Labormeldepflicht nach Infektionsschutzgesetz. Weltweit verzeichnet UNAids etwa 35 Millionen Tote im Zusammenhang mit AIDS seit Entdeckung der Krankheit (UNAids 2016).

\subsubsection{3 Übertragungswege}

Für eine Infektion mit HI-Viren gibt es drei mögliche Übertragungswege. Die Infektion kann durch mukosale, parenterale und vertikale Übertragung erfolgen. 
- Die mukosale Übertragung über Schleimhäute geschieht durch den Austausch von Körperflüssigkeiten bei ungeschütztem Geschlechtsverkehr, was die Bedeutung von AIDS als sexuell übertragbare Krankheit verdeutlicht (Royce et al. 1997).

- Zur parenteralen Übertragung zählt man die Infektion durch Transfusionen von Blutprodukten sowie Blutübertragung bei intravenösem Drogenmissbrauch mit verunreinigtem Besteck. Akzidentielle Nadelstichverletzungen od. Verletzungen mit chirurgischem Besteck bei medizinischem Personal können ebenfalls zur Infektion führen, wobei das Risiko abhängig von Art der Verletzung, verwendeter Nadel oder Instrument sowie Einstichtiefe ist. Diese Art der Übertragung wird ebenfalls dem parenteralen Weg zugerechnet (Baggaley et al. 2006).

- Vertikale Übertragung steht für die Weitergabe der Infektion von Mutter auf Kind, entweder in utero oder während der Geburt. Der überwiegende Teil der Infektionen kommt durch perinatale Übertragung zu Stande, was jedoch durch Kaiserschnittentbindung weitgehend vermieden werden kann (Read und Newell 2005).

\subsubsection{Diagnostik}

Der Nachweis des Virus erfolgt über serologische und direkte Nachweisverfahren als Stufentest, wobei zu Beginn ein ELISA-Suchtest (enzyme linked immunosorbent assay) durchgeführt wird, bei welchem nach HIV-1 und 2- Antikörpern im Serum oder Plasma gesucht wird und bei positivem Ergebnis mittels Immunoblot verifiziert wird (Rabenau et al. 2015). In der Stufendiagnostik muss ein zweites positives Ergebnis mit einer weiteren neuen Plasma- oder Serumprobe bestätigt werden, um eine eindeutige Diagnose stellen zu können (Rabenau et al. 2015).

\subsubsection{Therapie}

Die medikamentöse Therapie erfolgt nach dem 1996 eingeführten HAART-Schema (highly active antiretroviral therapy) mit dem Ziel, die Virusreplikation zu verlangsamen, eine Regeneration des Immunsystems zu ermöglichen und die Lebenserwartung der Patienten zu verlängern (Deutsche Aids-Gesellschaft e.V 2014). Sie beinhaltet einen kombinierten Einsatz aus mindestens drei antiviralen Medikamenten. 
Dazu zählen Nukleosid-/Nukleotidanaloga, nicht-nukleosidische Reverse-Transkriptase-Inhibitoren, Proteaseinhibitoren und Integrase-Inhibitoren, die das Virus an unterschiedlichen Stadien seiner Replikation sowie Integration in das Wirtsgenom hemmen (Deutsche Aids-Gesellschaft e.V 2014).

Die Therapie sollte bei einem Abfall der CD4-Helferzellen unter $350 \mu$ begonnen und die Virus-RNA dauerhaft unter eine Nachweisgrenze von 20-50 Kopien/ml gesenkt werden (Vogel et al. 2010). Bei Therapiebeginn innerhalb von 24 Wochen, in denen noch keine Manifestationen eines Stadium B oder C stattgefunden hat, ergibt sich eine annähernd gleiche Lebenszeitprognose zu Nicht-Infizierten (van Sighem et al. 2010).

\subsubsection{Hepatitis B}

\subsubsection{Einführung}

Der Begriff Hepatitis beschreibt eine Entzündung der Leberzellen. Es soll an dieser Stelle auf die viral bedingten Formen eingegangen werden. Unberücksichtigt bleiben somit unter anderem toxische und autoimmunologische Hepatitiden sowie Begleithepatitiden.

Das Hepatitis-B-Virus zählt zur Gruppe der Hepadnaviren und besteht im Gegensatz zu den anderen bekannten viralen Hepatitiden aus DNA (Seeger und Mason 2000). Es ist ein behülltes Virus mit multiplen Oberflächenproteinen wie dem HBsAg (hepatitis $B$ surface antigen) und wird aus drei Hüllproteinen zusammengesetzt (Hildt et al. 2003). Das Nukleokapsid im Inneren wird durch das HBcAg (hepatitis $B$ core antigen) gebildet und umgibt die Virus-DNA (Schädler und Hildt 2009). Zielzellen des Hepatitis-B-Virus sind die Hepatozyten, in denen es sich repliziert (Grimm et al. 2011). Das Hepatitis-B-Virus selbst ist nicht zytopathogen und kann bei stabilem Immunsystem vom menschlichen Körper adäquat bekämpft werden (Bundesgesundheitsblatt Hepatitis-B-Virus (HBV) 2000). Die Erkrankung hat mehrere Erscheinungsbilder. Sie kann unentdeckt verlaufen und vollständig ausheilen, bei 0,5$1 \%$ der Fälle zu Leberversagen oder bei bis zu 10\% der Infizierten zu einer chronischen Erkrankung führen (Robert Koch-Institut 2015c). 


\subsubsection{Epidemiologie}

Laut World Health Organization leiden weltweit ungefähr 240 Millionen Menschen unter chronischen Lebererkrankungen, ausgelöst durch das Hepatitis-B-Virus, wovon jährlich etwa 686.000 Menschen an den Folgen versterben (World Health Organization 2016a).

Die Durchseuchungsrate im Sinne einer durchgemachten Infektion mit Immunität, mit Nachweis von Anti-HBc Antikörpern liegt dabei in Deutschland bei 5,1\%, wobei es aber mit einer HBsAg-Prävalenz von unter $0,3 \%$ als Zeichen für eine vorhandene oder chronische Infektion, zu den gefährdungsärmeren Ländern gehört (PoethkoMüller et al. 2013).

\subsubsection{3 Übertragungswege}

Da sich das Hepatitis-B-Virus in fast allen Körperflüssigkeiten befindet, kann es wie HIV mukosal, parenteral oder vertikal übertragen werden (Shepard et al. 2006). Im Gegensatz zu HIV und Hepatitis C gibt es jedoch eine von der STIKO (Ständige Impfkommission) empfohlene Hepatitis-B-Impfung (Robert Koch-Institut 2016). Die Impfempfehlung bezieht sich bei Erwachsenen auf Personen mit geschwächtem Immunsystem, Personen mit Kontakt zu Infizierten, beruflichem Expositionsrisiko und im Rahmen einer Reiseindikation. Für Säuglinge und Kleinkinder gibt es eine ständige Empfehlung (Robert Koch-Institut 2016). 2013 zeigte sich bei Schuleingangsuntersuchungen von Kindern im Alter von fünf bis sieben Jahren eine bundesweite Hepatitis-B-Impfquote von 88\% (Robert Koch-Institut 2015b).

\subsubsection{Diagnostik}

Die Diagnostik erfolgt je nach Verdacht auf eine akute oder chronische Infektion initial mit dem Nachweis von HBsAg und Anti-HBc im Serum und Plasma des Patienten (Cornberg et al. 2011). Während HBsAg eine chronische Infektion nachweist, dient Anti-HBc zum Nachweis einer stattgefundenen oder vorhandenen aktuellen Infektion, wobei bei vorliegendem Verdacht auf eine akute Hepatitis-B-Infektion initial der Nachweis von HBsAg und Anti-HBc erfolgt (Cornberg et al. 2011). Abhängig vom Ausgang des ersten Screenings erfolgen weitere Tests auf $\mathrm{HBeAg}$ (hepatitis $B$ envelope antigen), Anti-HBe (HBe-Antikörper) und Anti-HBc-IgM (Immunglobuline). Die aktuelle S3-Leitlinie gibt als diagnostische Kriterien für eine akute Hepatitis-B- 
Infektion einen positiven Nachweis von HBsAg und Anti-HBc-IgM an, sowie das Vorhandensein von HBeAg und HBV-DNA bei fehlendem HBsAg und einem zeitlichen Verlauf unter sechs Monaten (Cornberg et al. 2011). Für eine chronische Infektion spricht ein über sechs Monate bestehendes HBsAg, veränderte Leberwerte, eine initial nachgewiesene HBV-DNA über $2000 \mathrm{IU} / \mathrm{ml}$, sowie eine Leberbiopsie mit Zeichen einer chronischen Veränderung (Cornberg et al. 2011).

\subsubsection{Therapie}

Durch Vorhandensein einer empfohlenen Impfung gegen das Hepatitis-B-Virus ist eine Prophylaxe durch regelrecht durchgeführte Impfung möglich (Jilg 2000). Aufgrund der guten Ausheilungstendenzen bei suffizientem Immunsystem, wird die akute unkomplizierte HBV-Infektion nicht therapiert (Girke et al. 2008). Der Ablauf der Therapie hängt von vielen Faktoren ab, wie beispielsweise der Frage ob ein positiver HBeAg-Status besteht und inwieweit eine Leberschädigung bereits fortgeschritten ist (Sundaram und Kowdley 2015). Bei der chronischen Infektion werden drei Medikamentengruppen zur Hinderung der Virusreplikation verwendet, dazu gehören Alpha-Interferone zur Hemmung der Virussynthese, sowie Nukleosid- und Nukleotid-Analoga, die zum Strangbruch und somit zur fehlerhaften Virusreplikation führen (Sundaram und Kowdley 2015).

Wahl des Medikamentes und Dauer des Einsatzes müssen individuell überprüft werden. Bei fortschreitendem Leberversagen ohne Therapieerfolg muss eine Transplantation in Betracht gezogen werden (Bundesärztekammer 2016). Bei durch Hepatitis B ausgelöstem Leberversagen muss als Indikationsstellung eine dritt- oder viertgradige Enzephalopathie oder ein altersabhängig erniedrigter Faktor V-Gerinnungsstatus vorliegen (Bundesärztekammer 2016). 


\subsubsection{Hepatitis C}

\subsubsection{Einführung}

Hepatitis C ist ein RNA-Virus aus der Gruppe der Flaviviren (Hugle et al. 2001). Es kommt wie bei Hepatitis B zu einer Immunantwort gegen die infizierten Hepatozyten (Schirmacher et al. 2004).

Wie bei Hepatitis B gibt es eine Einteilung in akute und chronische Verlaufsform, wobei bis zu $80 \%$ der Fälle nicht entdeckt werden, da die Patienten keine spezifischen Symptome aufweisen (World Health Organization 2016b). 15-45\% der infizierten Personen überstehen die Infektion innerhalb von sechs Monaten ohne Therapie, bis zu 85\% der Infektionen können in eine chronische Form übergehen, wovon 15-30\% im Verlauf der Erkrankung eine Leberzirrhose ausbilden können (World Health Organization 2016b). Unter diesen wiederum besteht bei einigen wenigen Prozent die Gefahr, ein Leberzellkarzinom zu entwickeln (World Health Organization 2016b).

\subsubsection{Epidemiologie}

Weltweit sind über 170 Millionen Menschen chronisch mit Hepatitis C infiziert, drei bis vier Millionen Menschen infizieren sich jährlich neu und pro Jahr werden 350.000 Todesfälle mit dem Virus in Verbindung gebracht (Mohd Hanafiah et al. 2013). In Europa gibt es ungefähr 14 Millionen chronisch Infizierte mit jährlich 84.000 Toten aufgrund von Leberzirrhose oder hepatozellulärem Karzinom, wobei Deutschland mit einer Prävalenz von unter 1\% zu den Niedrig-Prävalenz Ländern gehört (World Health Organization 2015).

\subsubsection{3 Übertragungswege}

Der parenterale Übertragungsweg über Blut ist der relevanteste, jedoch sind prinzipiell alle Übertragungswege möglich (Lauer und Walker 2001). Die mukosale Übertragung ist aufgrund der hohen Virusmenge, die für eine Infektion notwendig ist, sowie der niedrigeren Konzentration des Virus in Körperflüssigkeiten, weitaus seltener (Lavanchy 2009). Das prä- oder perinatale vertikale Übertragungsrisiko von Mutter auf Kind ist, mit 3 bis 5\%, abhängig von der mütterlichen Viruslast, ebenfalls 
möglich, aber weniger wahrscheinlich als bei Hepatitis B (Robert Koch-Institut 2007).

\subsubsection{Diagnostik}

Für die Diagnose des Hepatitis-C-Virus stehen zwei Testverfahren zur Verfügung (Li und Lo 2015):

- Der direkte Nachweis von viraler RNA erfolgt beispielsweise durch Rt-PCR (Reverse Transkriptase-Polymerase-Kettenreaktion), welche auch eine Quantifizierung der Virus-RNA ermöglicht oder durch Nachweis des CoreAntigenes durch ein Enzym-Immuno-Assay.

- Der indirekte Nachweis erfolgt durch Testung auf Anti-HCV durch EnzymImmuno-Assay oder Point-of-care Test. Dieser Test erkennt innerhalb von 20-40 Minuten Anti-HCV-Antikörper in menschlichen Körperflüssigkeiten und kann außerhalb eines Labors durchgeführt werden.

Ein Bestätigungstest erfolgt mit rekombinanten Immuno-Blot Assays zum Nachweis von vorhandenen Anti-HCV-Antikörpern (Li und Lo 2015).

\subsubsection{Therapie}

Bis März 2015 wurden Patienten mit chronischer Hepatitis C standardmäßig mit Interferon therapiert (Sarrazin et al. 2015). Abweichend davon sieht die neue Behandlungsleitlinie keine standardisierte Interferon-Therapie mehr vor, stattdessen stehen für die Behandlung Interferon und Ribavirin als konventionelle Substanzen zur Verfügung, ergänzt durch Proteaseinhibitoren, NS5A-Inhibitoren (nonstructural protein $5 A$ ), nicht nukleosidische Polymerase (NS5B)-Inhibitoren (nonstructural protein 5B ) und Nukleos(t)idische Polymerase (NS5B)-Inhibitoren (Sarrazin et al. 2015). Die Wahl des geeigneten Behandlungsschemas wird für jeden Patienten individuell erstellt und orientiert sich am Genotypus des Virus, den Begleiterkrankungen des Patienten und der Dauer der Therapie (Sarrazin et al. 2015). 


\subsection{Prophylaxe und Prävention}

1991 zeigte eine Studie, dass bei 28\% der überprüften Operationen in unterschiedlichen Fachrichtungen ein Kontakt zwischen Patientenblut und Chirurgenhaut zustande kam (Popejoy und Fry 1991). Somit stellt sich schon vor Beginn operativer Maßnahmen die Frage nach Prävention von möglichen Verletzungen des Personals und der Patienten. Dazu gehört bereits die betriebsärztliche Untersuchung bei Stellenantritt und das Screening auf blutübertragbare Infektionskrankheiten (Deutsche Gesetzliche Unfallversicherung 2010), sowie eine Hepatitis-B-Impfung. Bei positiv getestetem Personal empfiehlt die Deutsche Vereinigung zur Bekämpfung der Viruskrankheiten e.V. eine engmaschige Kontrolle der Virämie anhand von Grenzwerten. Bei Überschreitung sollte über das Einstellen der ausgeübten Tätigkeit nachgedacht werden, um eine Gefährdung weiterer Personen auszuschließen (DVV 2007). Bei HIV ist unter laufender antiretroviraler Therapie weiterhin ein Arbeitseinsatz möglich, sofern auch hier regelmäßige Kontrollen durchgeführt werden (Rabenau et al. 2012).

Vor Operationen stellt sich für den Operateur die Frage, ob der Patient zu einer möglichen Risikogruppe gehört. Zu den Gruppen mit Risikoprofilen für die erwähnten Viruserkrankungen gehören in erster Linie Personen, die intravenös Drogen konsumieren, Männer, die Sex mit Männern praktizieren und Personen, die aus Hochprävalenz-Ländern stammen (Wild und Dellinger 2013).

Bereits bei Verdacht sollten besondere Vorsichtsmaßnahmen getroffen werden. Für derartige Eingriffe gilt, dass scharfe Gegenstände nur unter Augenkontakt gereicht und nach Verwendung in dafür vorgesehene Abwurfbehälter entsorgt werden (Joint Working Party 1992).

Bei Operationen in beengtem OP-Feld, mit langer Dauer, nicht dauerhaft möglicher Sicht sowie Operationen, bei denen der Operateur die Nadel manuell führt und somit in Kontakt zu scharfen bzw. spitzen Geräten ist, ist besondere Vorsicht zu wahren (Hofmann 2015). Der Einsatz von Jet-Lavage sollte aufgrund der Verteilung von Aerosolen vermieden werden (Dresing et al. 2005). 
Ein wichtiger Punkt der Expositionsprophylaxe ist die persönliche Schutzausrüstung des Personals. Dazu gehört bereits die tägliche Hautpflege außerhalb des tätigen Bereiches im Alltag. Laut der Joint Working Party der Hospital Infection Society gab es im Jahre 1987 bei drei im Gesundheitswesen tätigen Personen mit ekzematösen Hautveränderungen, die ohne Schutzmaßnahmen arbeiteten, eine HIV-Infektion ohne Verletzung (Joint Working Party 1992). Hygienische Händedesinfektion vor Beginn therapeutischer Maßnahmen sollte selbstverständlich sein (Thurau et al. 2010), wasserdichte Operationskittel und Plastikschürzen können vor Blutkontakt schützen (Sitzmann 2014). Des Weiteren sollte ein Augenmerk auf dem Schutz der Füße und Unterarme liegen, da diese Bereiche oftmals nur schlecht geschützt werden und bei Operationen mit großem Blutverlust Expositionsstellen bieten (Fry 2005). Ein wichtiger Faktor zum Eigenschutz stellen Handschuhe dar. In einigen Studien wurde gezeigt, dass viele Handschuhperforationen während der Operation unentdeckt bleiben (Thomas et al. 2001). Aus diesem Grund sollte bei Verdacht auf eine blutübertragbare Infektionskrankheit das Doppel-Lagen Verfahren angewandt werden, bei dem zwei Handschuhpaare übereinander getragen werden, am besten in Form von Indikatorhandschuhen, bei denen eine Perforation zu einer Farbänderung der Handschuhe führt. Eine Studie zeigte, dass in $82 \%$ der Fälle, bei denen der äußere Handschuh perforiert war, der Innere weiterhin vor einer Kontamination mit Körperflüssigkeiten schützte (Thomas et al. 2001). Eine retrospektive Auswertung, in der 34 randomisierte kontrollierte Studien miteinander verglichen wurden, ergab, dass das Tragen von zwei Paar Handschuhen im Vergleich zu einem Paar, die Gefahr der Hautperforation verringert, die Perforation des inneren Paar Handschuhes um 71\% reduziert und die Gefahr des Kontaktes der Hand mit Blut um 65\% reduziert werden konnte (Mischke et al. 2014).

In einer 2007 veröffentlichten Studie zeigten die Untersuchungen, dass bei 384 begutachteten Operationen unterschiedlicher Fachrichtungen bei 45,2\% der Eingriffe die Operateure durch Patientenblut oder Körperflüssigkeiten verunreinigte Schutzbrillen trugen. Unter den getragenen Mundschutzen ergab sich eine Verunreinigung von $24,2 \%$. Von 23 untersuchten Amputationsvorgängen (Akren, Unterschenkelamputationen ober- und unterhalb des Kniegelenks) zeigten 100\% der Schutzbrillen und $78 \%$ der Mundschutze eine Verunreinigung. Somit sollte das operativ tätige Personal, zusätzlich zum standardmäßigen Mundschutz, Schutzbrillen tragen, um eine Inokulation mit infektiösem Material zu vermeiden (Davies et al. 2007). 


\subsection{Screening in Deutschland}

Unter Screening versteht man im medizinischen Bereich eine Vorsorgeuntersuchung auf Krankheiten (Becker 2002). Ziel dieser Untersuchungen sind ein frühzeitiges Entdecken einer der hier relevanten Infektionskrankheiten und die Einleitung einer rechtzeitigen medizinischen Behandlung um Spät- oder Folgeschäden zu minimieren oder zu vermeiden. Da HIV, Hepatitis B und C auch durch Geschlechtsverkehr und Blutkontakte übertragbar sind, kann durch eine Screeninguntersuchung eine mögliche Übertragung auf weitere Personen verringert werden. Screeninguntersuchungen auf HIV, Hepatitis B und C gehören in Deutschland aufgrund der geringen Durchseuchungsraten nicht zur allgemeinen Vorsorgediagnostik (Marcus et al. 2010). Wenn überhaupt werden Risikogruppen wie i.v. Drogenkonsumenten oder Männer, die Sex mit Männern praktizieren, gescreent (Sadlowski et al. 2011).

Patienten-Screening zum Schutz von Mitarbeitern im Gesundheitswesen ist in Deutschland nicht Standard.

\subsection{Prävalenz und Inzidenz in Deutschland}

Unter Prävalenz versteht man die Häufigkeit einer Erkrankung in einer Bevölkerungsgruppe zu einem bestimmten Zeitpunkt. Die Inzidenz beschreibt die Zahl der Neuerkrankten an einer bestimmten Krankheit in einem definierten Zeitintervall.

Im Rahmen eines deutschlandweiten Gesundheitsmonitorings wurde von 2008 bis 2011 die Studie "Studie zur Gesundheit Erwachsener in Deutschland (DEGS1)“ durchgeführt. Es nahmen 8152 Personen im Alter von 18 bis 79 Jahren aus ganz Deutschland teil, wobei 7.047 Teilnehmer auf ihren Hepatitis-C-Status untersucht wurden. Es ergab sich eine Anti-HCV-Prävalenz von 0,3\% (95\%-Konfidenzintervall (KI) 0,1- 0,5\%) (Poethko-Müller et al. 2013). In Deutschland wurden im Jahr 2014 5817 neu diagnostizierte Hepatitis-C-Fälle gemeldet, was eine Inzidenz von 7,2 pro 100.000 Personen ergibt (Robert Koch-Institut 2015d). Für Niedersachsen ergaben sich 232 Neuerkrankungen mit einer Inzidenz von 0,3 pro 100.000 Personen (Robert Koch-Institut 2015d). 
Für Hepatitis B gibt das Robert Koch-Institut Prävalenzen von weniger als $1 \%$ in der deutschen Bevölkerung an. Dies variiert prozentual anhand der positiven AntigenMarker. Die Inzidenz im Jahre 2014 wird mit 0,9 pro 100.000 angegeben (Robert Koch-Institut 2015c). In Niedersachsen wurden 201437 Neuerkrankungen mit einer Inzidenz von 0,5 pro 100.000 Personen gemeldet (Robert Koch-Institut 2015a).

HIV-Infektionen zeigten zum Ende 2014 eine Prävalenz von 0,1\% mit ca. 83000 Infizierten in Deutschland (Robert Koch-Institut 2015e). Im Jahre 2014 gab es 3525 Neuerkrankungen mit einer deutschlandweiten Inzidenz von 4,4 pro 100.000 Einwohnern. (Robert Koch-Institut 2015a). Für Niedersachsen wurden 195 Neuinfektionen mit einer Inzidenz von 2,5/100.000 Personen gemeldet (Robert Koch-Institut 2015a).

\subsection{Gefahren im Krankenhaus}

In Krankenhäusern haben je nach Verletzungsmuster unterschiedlich viele Berufsgruppen Kontakt zum Patienten. Bei Verletzungen mit notwendiger operativer Versorgung treffen nicht nur das Pflegepersonal der chirurgischen Notaufnahme und die Chirurgen selbst auf den Patienten, sondern auch die OP-Pflege, Anästhesie, der Transportdienst, das Personal im Aufwachraum und anschließend das weiterbehandelnde Team auf Station. Somit besteht durch Kontakt zu kontagiösen Flüssigkeiten bei reaktivem Status eine potentielle Möglichkeit zur Übertragung der Viren.

\section{$1.7 \quad$ Ziel}

Ziel der Arbeit war es, im Rahmen einer Qualitätssicherungsmaßnahme herauszufinden,

- welche potentielle Gefahr für das medizinische Personal in der Notfallversorgung (Notaufnahme und Operationssaal) besteht.

- Es soll die Inzidenz und Prävalenz der Patienten in der Unfallchirurgie abgeklärt werden.

- Der vorbeugende Gesundheitsschutz für pflegerisches und ärztliches Personal soll evaluiert werden. 
- Des Weiteren soll überprüft werden, wie Behandlungsabläufe von Verletzungen und Frakturen bei Vorliegen einer reaktiven Blutprobe geändert werden können, ohne die Qualität der Versorgung zu vernachlässigen.

- Eine Analyse der Patienten mit HIV- oder Hepatitis-Nachweis sollte durchgeführt und ein statistischer Vergleich der Infektionsdaten im bundesweiten Vergleich vorgenommen werden, um eventuell vorhandene Unterschiede in der Region Göttingen zu ermitteln.

- Faktoren sollten gefunden werden, die als Indikatoren für eine Belastung der Patienten dienen können. 


\section{Material und Methoden}

Die Untersuchungen wurden unter der Antragsnummer Dok_336_2015 bei der Ethikkommission der Universitätsmedizin Göttingen angemeldet und akzeptiert.

Im Text werden die Begriffe Patienten und Blutentnahme synonym verwendet, wobei hier die Zahl der Blutentnahmen als relevante Größe gilt und die Gesamtzahl der getesteten Patienten übersteigt.

\subsection{Patientenkollektiv}

Das Patientenkollektiv setzt sich aus Notfallpatienten der unfallchirurgischen Notaufnahme der Universitätsmedizin Göttingen zusammen. Von Oktober 2001 bis Januar 2015 wurden sämtliche Patienten per Schnelltest, siehe dazu Punkt 2.2., auf die möglichen Infektionskrankheiten Hepatitis B, Hepatitis C und HIV getestet. Nach $\S 630$ e (1) des Bundesgesetzbuches muss seitens des behandelnden Arztes verpflichtend eine Aufklärung über die geplanten Maßnahmen, in diesem Fall die Blutentnahme mit Screening auf HIV, Hepatitis B und C, stattfinden. Der Patient kann dieser Behandlung nach § 630d (1) BGB (Bürgerliches Gesetzbuch) zustimmen. Ist es nicht möglich, die Einwilligung zeitnah einzuholen, wie bei bewusstlosen Patienten, so darf diese vorausgesetzt werden, wenn sie dem mutmaßlichen Willen entspricht (BGBI I 2002, S. 42, 2909; 2003 I S. 738).

In der UMG (Universitätsmedizin Göttingen) der Universität Göttingen ist der „Umgang mit der serologischen Testung von Patienten auf blutübertragbare Krankheiten einschließlich der rechtlichen Rahmenbedingungen und Definition der Patientengruppen, die einem routinemäßigen Screening unterzogen werden“, geregelt. In der Version 1.0 von Mai 2002 wird auf die besonderen gesetzlichen Auflagen (§ 49 ArztR) hingewiesen, die zur Berücksichtigung des Screenings bei Verdacht auf HIV eingehalten werden müssen. Somit galten folgende Indikationen als Einschlusskriterium für das Screening:

- Bei der Testung von elektiven Patienten gilt, dass sie nach Aufklärung und Einwilligung auf HIV getestet werden können, wenn der elektive Eingriff mit einer erhöhten Übertragungsgefahr von Viren auf das Personal einhergeht. 
Darunter fallen länger dauernde Eingriffe, Eingriffe mit erhöhtem Gefahrenpotential sowie Eingriffe, die eine Umgebungskontamination herbeiführen könnten.

- Einwilligungsfähige Notfallpatienten können nach Aufklärung und Einwilligung unter den gleichen Voraussetzungen wie elektive Patienten auf HIV getestet werden.

- Für die Testung von nichteinwilligungsfähigen Patienten gilt, dass diese mit Rücksichtnahme auf ein erhöhtes Schutzbedürfnis des medizinischen Personals unter mutmaßlicher Einwilligung getestet werden dürfen.

Dies ist analog auf Infektionen mit Hepatitis B und C zu verwenden. Willigt ein Patient nicht in die Testung ein, so darf der zuständige Arzt nach ärztlichem Ermessen über die Fortführung der Behandlung entscheiden und diese gegebenenfalls ändern oder ablehnen.

Ein Ausschlusskriterium für die Blutentnahme besteht grundsätzlich für Kinder, Ausnahme gilt hierbei aber bei bekannter familiärer Belastung.

Daraus folgend bekamen die Patienten- primär aus Gründen des Personalschutzesnach Aufklärung und Einwilligung, ein Screening auf Hepatitis C, Hepatitis B und HIV.

\subsubsection{Ablauf der Blutentnahmen}

Das Prozedere der Blutentnahme richtet sich nach dem Modus der Patienteneinweisung:

Ablauf bei Notfallpatienten:

- Ankunft Schockraum oder Poliklinik

- Aufklärung und Einholen der Einwilligung, falls möglich

- Blutentnahme

- Einsendung des Materials in Notfalllabor

- Ca. 30 Minuten später Information über Status des Patienten

Ablauf bei elektiven Patienten:

- Aufnahme in Universitätsmedizin 
- Aufklärung und Einholen der Einwilligung

- Blutentnahme

- Einsendung des Materials an Mikrobiologie

- Ca. 2-3 Tage später Information über Status des Patienten

\subsection{Testverfahren}

Für das Screening wurden Tests der Firma Abbot, Wiesbaden, verwendet. Diese wurden im Laufe der Jahre nicht gewechselt. Dazu zählen ARCHITECT Anti-HCV, ARCHITECT HBsAg Qualitative II und ARCHITECT HIV Ag/Ab Combo.

\subsubsection{ARCHITECT Anti-HCV}

Dieser Test weist anti-HCV-Antikörper mittels Chemilumineszenz-Mikropartikel- Immunoassay im Serum und Plasma nach. Dies geschieht als Variante eines Enzymimmunoassays auf dem Grundprinzip einer ELISA-Testung, im Sinne einer AntigenAntikörper-Reaktion zum Nachweis von Viruspartikeln. Die Gesamtspezifität liegt bei diesem Test bei 99,60\% (KI 99,45\%-99,71\%) mit einer Gesamtsensitivität von 99,19\%, bei einem 95\%-Konfidenzintervall zwischen 96,77\% und 99,89\% (Abbott Laboratories 2009)

\subsubsection{ARCHITECT HBsAg Qualitative II}

Mittels Chemilumineszenz-Mikropartikel-Immunoassay (siehe Punkt 2.2.1) können durch diesen Test Hepatitis-B-Surface-Antigene im menschlichen Serum und Plasma nachgewiesen werden. Er weist eine Gesamtspezifität von 99,91\% (95\%Konfidenzintervall 99,78\%-99,97\%) bei Blutspendern auf, mit einer Gesamtsensitivität von $99,09 \%$ bei Patienten mit unbekanntem Krankheitsstatus (95\% Konfidenzintervall 99,09-100\%) (Abbott Laboratories 2011b).

\subsubsection{ARCHITECT HIV Ag/Ab Combo}

Per Chemilumineszenz-Mikropartikel-Immunoassay (Siehe Punkt 2.2.1) kann gleichzeitig ein qualitativer Nachweis von Antigenen und Antikörpern gegen HIV Typ 1 sowie HIV Typ 2 im Serum oder Plasma des Patienten nachgewiesen werden. Bei Blutspendern wies er eine Spezifität von 99,89\% (95\%-KI 99,77\%-99,96\%) auf. Die 
Sensitivität wurde in einer Studie anhand von bereits diagnostizierten HIV-Patienten mit 100\% ermittelt (Abbott Laboratories 2011a).

\subsection{Daten und Datenerhebung}

Die Ergebnisse der Blutentnahmen und Daten der klinischen Chemie wurden, nach Überprüfung durch die Virologie der Universitätsmedizin bei positivem Ergebnis, verarbeitet und mit dem Tabellenkalkulationsprogramm Microsoft Excel bearbeitet und sortiert.

Mit Hilfe der klinikeigenen Programme SAP, IXserv, OPAS und des medizinischen Archivs war es möglich, bei den als reaktiv gekennzeichneten Patienten genauere Daten zum Klinikaufenthalt und der medizinischen Versorgung zu ermitteln. Daraufhin erfolgte anhand der tabellarischen Darstellung eine einheitliche Gliederung und Überprüfung der darin gezeigten Inhalte.

Wurde ein Patient im Screening-Test als reaktiv getestet, so konnten durch das SAP-Programm genauere Informationen herangezogen werden, um Aufnahmedatum, Diagnose, Behandlung und stationäre oder ambulante Behandlungsdauer zu ermitteln. Es erfolgte ein Abgleich über das IXserv-Programm, um die Untersuchungsergebnisse der klinischen Chemie zuzuordnen. Das Blut eines im Schnelltest reaktiven Patienten, wurde zur Verifizierung des Ergebnisses in der Virologie erneut getestet. Wurde die Infektion nicht bestätigt, so galt der Patient als falsch positiv und wurde aus dem Kollektiv der Reaktiven entfernt. Wurde der Patient als positiv bestätigt, so schloss sich eine Suche nach früheren Vorstellungen im Klinikum an und es wurde überprüft, ob frühere Blutentnahmen erfolgt waren, die bereits eine Infektion gezeigt hatten. War dies der Fall, so bekam der Patient den Infektionsstatus „bekannt“, woraufhin der Grund der Klinikvorstellung untersucht wurde. Die Informationen dazu ließen sich aus den bereits erwähnten Klinik-Software-Programmen ziehen oder mussten durch Aktenforschung im medizinischen Archiv zusammengetragen werden. Alle Daten wurden danach pseudonymisiert.

Die statistische Auswertung erfolgte in Zusammenarbeit mit dem Institut für Statistik der Universität Göttingen. Hierzu wurden die, aus mehreren Quellen zusammenge- 
tragenen und in der Excel-Tabelle gelisteten Daten, verwendet und dem Statistikprogramm Statistica zugeführt. Es wurden dabei unter anderem Werte der zentralen Tendenz, Mittelwert, Standardabweichung, Minimum und Maximum erhoben.

\subsubsection{Einteilung Alterskategorie}

Eine Einteilung des Alters erfolgte zur besseren Übersicht in elf Kategorien:

- Kategorie 1: 0,00-9,99 Jahre

- Kategorie 2: 10,00-19,99 Jahre

- Kategorie 3: 20,00-29,99 Jahre

- Kategorie 4: 30,00-39,99 Jahre

- Kategorie 5: 40,00-49,99 Jahre

- Kategorie 6: 50,00-59,99 Jahre

- Kategorie 7: 60,00-69,99 Jahre

- Kategorie 8: 70,00-79,99 Jahre

- Kategorie 9: 80,00-89,99 Jahre

- Kategorie 10: 90,00-99,99 Jahre

- Kategorie 11: 100,00-109,99 Jahre

\subsubsection{Einteilung Diagnosekriterien}

Nachdem von allen Blutentnahmen mit reaktivem Infektionsstatus die erforderlichen Daten zusammengetragen worden waren, wurde eine Unterteilung der Diagnosen vorgenommen. Diese Diagnosen wurden in Kategorien von A-S unterteilt:

- Kategorie A: Patienten mit Verletzungen im Kopf- und Gesichtsbereich

- Kategorie B: Patienten mit thorakalen Verletzungen

- Kategorie C: Patienten mit Abdominalverletzungen

- Kategorie D: Patienten mit Beckenverletzungen

- Kategorie E: unfallchirurgische Patienten mit Extremitätenverletzungen bzw. behandlungsbedürftigen Erkrankungen der Extremitäten, unterteilt in obere und untere Extremität

- Kategorie F: solitäre Wirbelsäulenverletzungen 
- Kategorie G: Polytrauma-Patienten als Extrakategorie, da sich ein Polytrauma als multiple schwerwiegende Verletzungen definiert, von denen sich eine oder die Kombination mehrerer als tödlich erweisen kann.

- Kategorie S: Sonstiges

Exemplarisch wurde die Kategorie E (Extremitätenverletzungen) herausgegriffen, um Einflüsse auf das therapeutische Vorgehen zu erfassen.

Nach Indikationsstellung zu einer weiterführenden invasiven Maßnahme, wie Operationen oder anderweitigen chirurgischen Therapien, ergibt sich die Fragestellung einer möglicherweise vorliegenden Infektionskrankheit des Patienten, wodurch ein Übertragungsrisiko für das behandelnde medizinische Personal bei invasiven Prozeduren vorliegt.

\subsubsection{Behandlungsmaßnahmen}

Es erfolgte eine Aufteilung in die erfolgten Behandlungsmaßnahmen. Dies umfasst entweder eine normalerweise folgende operative Versorgung, eine konservative Behandlung oder die Möglichkeit, eine der beiden Optionen zu wählen.

\subsubsection{Arbeitsunfälle in der UMG}

Im Rahmen von Verletzungen unter medizinischem Personal wird ein Durchgangsarzt-Arzt Verfahren eingeleitet, die Mitarbeiter werden danach D-ärztlich betreut. Sämtliche gemeldeten Stichverletzungen und weiteren Verletzungen wurden in der Unfallchirurgie D-ärztlich erfasst. Diese Daten beziehen sich auf alle Mitarbeiter der Universitätsmedizin Göttingen. Von 2002 bis 2014 wurden Informationen zu Stichverletzung, mit Ausnahme der Jahre 2012 und 2013, gesammelt und in Kategorien eingeordnet. Zu diesen vorgelegten Kategorien zählten das Material, mit dem die Verletzung zustande kam, das betroffene Personal und die Serologie des übertragenen Materials. Vom Jahre 2009 gab es nur eine Übersicht über den Grund der Verletzung, nicht jedoch über die berufliche Tätigkeit des Personals (Betriebsmedizin Göttingen 2016).

Als ärztliches Personal wurden Ärzte, Studenten im Praktischen Jahr sowie Medizin- und Zahnmedizinstudenten zusammengefasst. Von 2002-2004 galten auch 
Ärzte im Praktikum als Ärzte. OP-Personal, examinierte Pflegekräfte und Krankenpflegeschüler wurden als pflegerisch tätiges Personal zusammengefasst. 


\section{Ergebnisse}

\subsection{Patientenkollektiv}

Es wurden in den Jahren 2001 bis Januar 2015 insgesamt 18569 Blutproben entnommen. Das mittlere Alter der gescreenten Patienten betrug 52,73 $\pm 21,93[0,18$ 102,45] Jahre. Von den untersuchten Personen waren 7728 (41,62\%) weiblich mit einem mittleren Alter von 59,01 $\pm 22,86$ [0,18-102,45] Jahren.

Bei den männlichen Patienten waren es 10841 (58,28\%) Entnahmen mit einem Altersschnitt von 48,23 $\pm 20,07$ [0,41-20,07] Jahren.

Abbildung 1 zeigt die Verteilung der Patienten in die Alterskategorien.

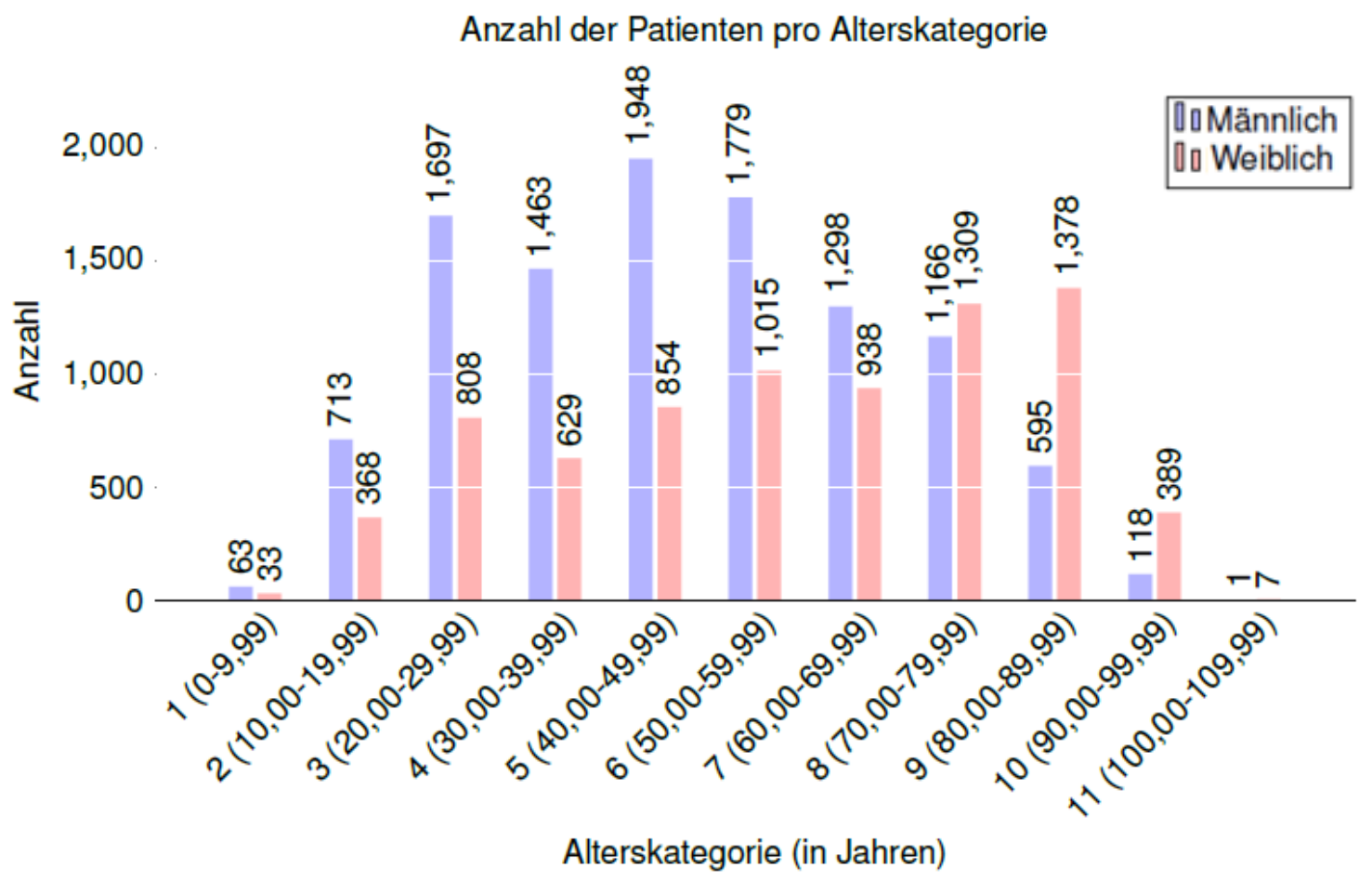

Abbildung 1: Unterteilung des Gesamtkollektives von 18569 Untersuchungen nach Geschlecht auf Alterskategorie 


\subsection{Infektionsstatus}

Bei 593 (3,19\%) der Blutentnahmen zeigte sich ein reaktiver Infektionsstatus. Davon waren 198 (33,39\%) weiblich und 395 (66,61\%) männlich. Der Altersschnitt betrug für alle Entnahmen 49,42 $\pm 18,79$ [7,14-98,18] Jahre. Bei der Betrachtung des Gesamtkollektivs in Hinblick auf Geschlecht und Alter zeigte sich in Bezug auf die absolute Häufigkeit nachgewiesener Infektionen unterschiedliche Peaks. So wurden für das männliche Geschlecht im Alter von 30- bis 40 Jahren 111 und für die Altersgruppe der 40-bis 50-Jährigen 113 Infektionen festgestellt. In den gleichen Alterskategorien fanden sich bei den Frauen nur 31 bzw. 35 positive Testergebnisse. Lediglich in den Gruppen der über 80-Jährigen sowie den unter 20-Jährigen wurden mehr weibliche Patienten als männliche positiv getestet. Die graphische Darstellung findet sich in Abbildung 2.

\section{Verteilung Alter und Geschlecht}

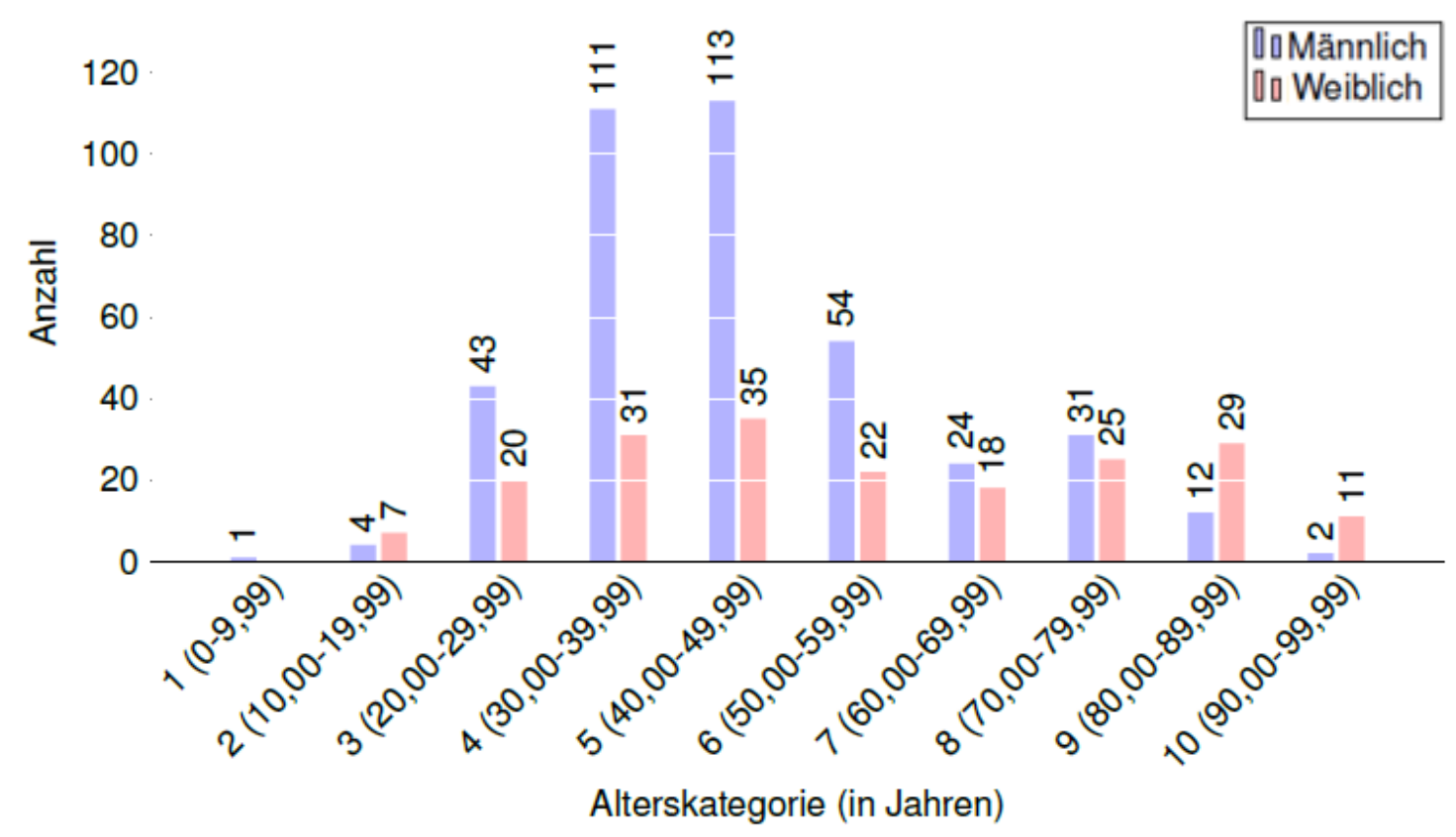

Abbildung 2: Verteilung der reaktiven Ergebnisse nach Alter und Geschlecht 
Die Infektionen teilten sich auf in Hepatitis C, Hepatitis B und HIV sowie mögliche Kombinationen der drei Infektionen. Abbildung 3 verdeutlicht die erhaltenen reaktiven Proben in Bezug auf die Infektionen.

\section{Anzahl der Infektionen}

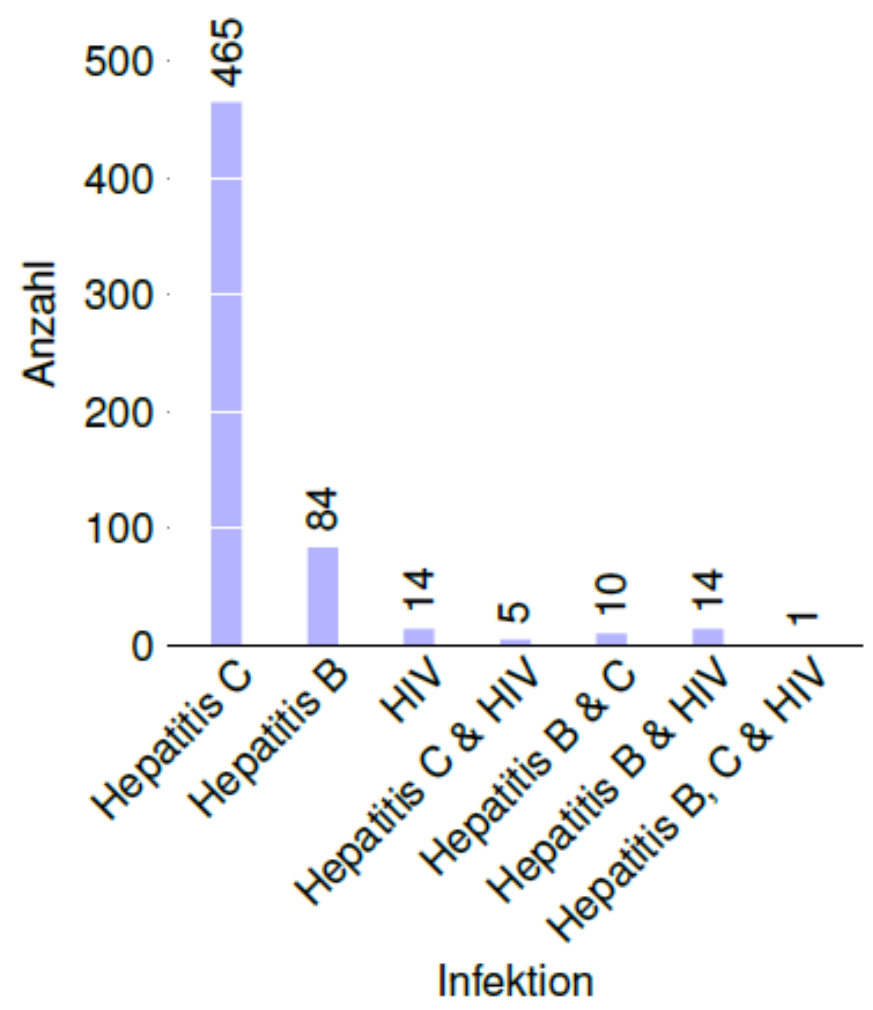

Abbildung 3: Anzahl der reaktiven Blutentnahmen, Mono- und Mehrfachinfektionen

\subsubsection{Infektionen mit Hepatitis C}

465 (78,41\% aller reaktiven Proben) Blutentnahmen wurden positiv auf Hepatitis C getestet, davon waren 153 weiblich mit einem Durchschnittsalter von 56,18 $\pm 22,26$ [17,05-98,18] Jahren und 312 männlich mit einem Durchschnittsalter von $46,15 \pm 15,79$ [7,14-98,12] Jahren. Sowohl bei den Frauen mit 26 reaktiven Proben als auch den Männern mit 95 reaktiven Proben gab es die häufigsten Blutentnahmen in der Altersspanne von 30,00-39,99 Jahren. 


\subsubsection{Infektionen mit Hepatitis B}

84 (14,17\% aller reaktiven Proben) der Entnahmen waren Hepatitis-B-reaktiv, davon 30 Frauen mit einem Durchschnittsalter von 59,46 $\pm 23,72$ [17,16-96,70] Jahren, wovon sich mit sechs Proben die höchste Rate in der Altersspanne zwischen 80,00 und 89,99 Jahren zeigte. Bei 54 reaktiv getesteten Männern mit einem durchschnittlichen Alter von 46,43 \pm 17,18 [15,10-87,47] Jahren lag die höchste Rate mit 13 Entnahmen in der Altersspanne von 50,00-59,99 Jahren.

\subsubsection{Infektionen mit HIV}

HIV-Infektionen zeigten sich bei 14 (2,36\% aller reaktiven Proben) Entnahmen, wobei vier davon weiblich waren im Alter von 37,61 \pm 14,25 [26,16-56,67| Jahren mit zwei reaktiven Testergebnissen in der Altersspanne von 20,00-29,99 Jahren, zehn männlich mit einem Durchschnittsalter von $64,55 \pm 13,52$ [22,66-61,62] Jahren sowie zwei reaktiven Proben im Altersbereich von 40,00-59,99 Jahren.

\subsubsection{Mehrfachinfektionen}

Doppelinfektionen mit Hepatitis C und B zeigte sich bei zehn (1,69\% aller reaktiven Proben) Patienten. Drei davon waren weiblich mit einem Durchschnittsalter von 45,06 $\pm 10,33$ [34,88-55,53] Jahren und sieben männlich im Altersschnitt von $37,17 \pm 3,93[30,70-44,05]$ Jahren.

Fünf $(0,84 \%$ aller reaktiven Proben) der Entnahmen waren reaktiv für Hepatitis $C$ und HIV, wovon eine Patientin weiblich war im Alter von 36,52 Jahren und vier $\mathrm{Pa}$ tienten männlich mit durchschnittlich 43,14 $\pm 6,22$ [38,65-53,35] Jahren.

Bei 14 (2,36\% aller reaktiven Proben) der Blutentnahmen konnte ein reaktiver Status für Hepatitis B und HIV festgestellt werden. Die Verteilung hierbei waren sieben weibliche Doppelinfektionsträgerinnen im Alter von 55,14 $\pm 22,91$ [25,51-85,93] Jahren sowie sieben männliche Doppelinfizierte im Alter von $50,78 \pm 19,70[16,00$ $73,80]$.

Die Probe eines männlichen Patienten, 57,09 Jahre alt, war für alle drei getesteten Infektionen reaktiv.

Prozentual gesehen waren von den 18569 Blutentnahmen 17976 (96,81\%) negativ für jegliche Infektion. Bei Hepatitis $C$ betrug der Anteil in Bezug auf alle untersuchten 
Proben 2,50\%, 0,45\% bei Hepatitis B sowie 0,08\% bei HIV. Die Kombinationen aus zwei oder mehreren Infektionen, anteilig an allen getätigten Blutentnahmen, betrugen bei Hepatitis C und B 0,05\%, Hepatitis C und HIV 0,03\% und Hepatitis B und HIV 0,08\%. Die einzige dreifach positive Blutentnahme, gesehen an der Gesamtzahl der Proben, hat einen Prozentwert von 0,005\%. Abbildung 4 gibt als Box Plot die Altersverteilung in Bezug auf das Geschlecht mit unterschiedlichen Infektionsstatus wieder.

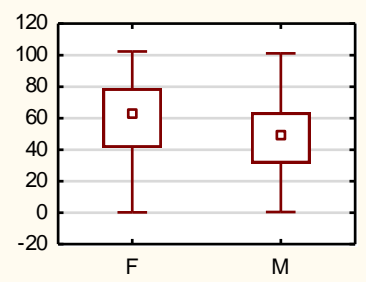

Aufstellung Infektion, Alter, Geschlecht
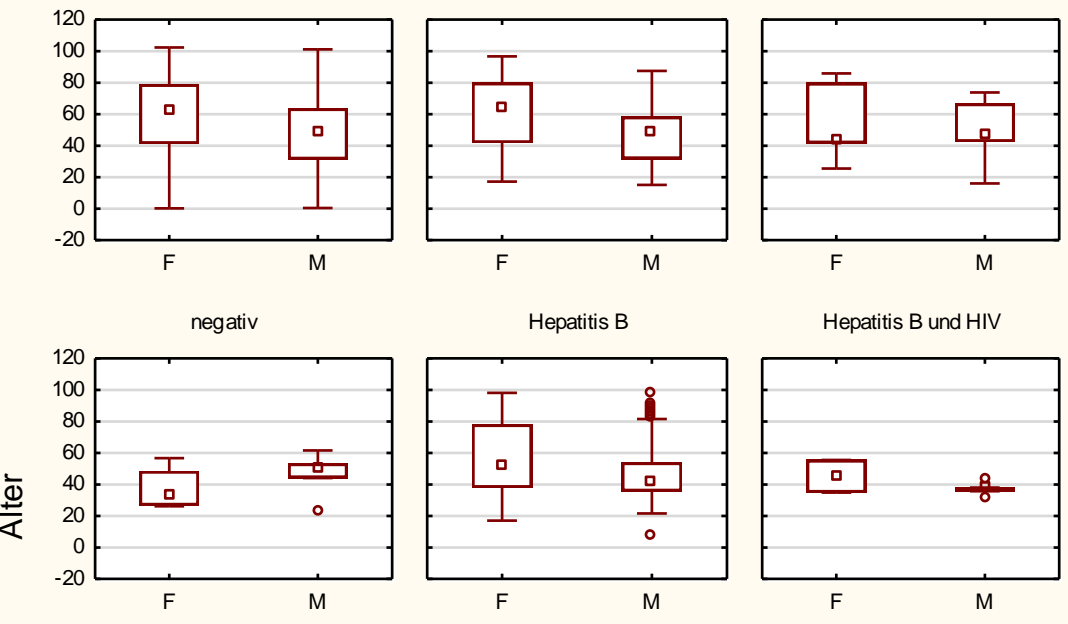

Hepatitis B und HIV
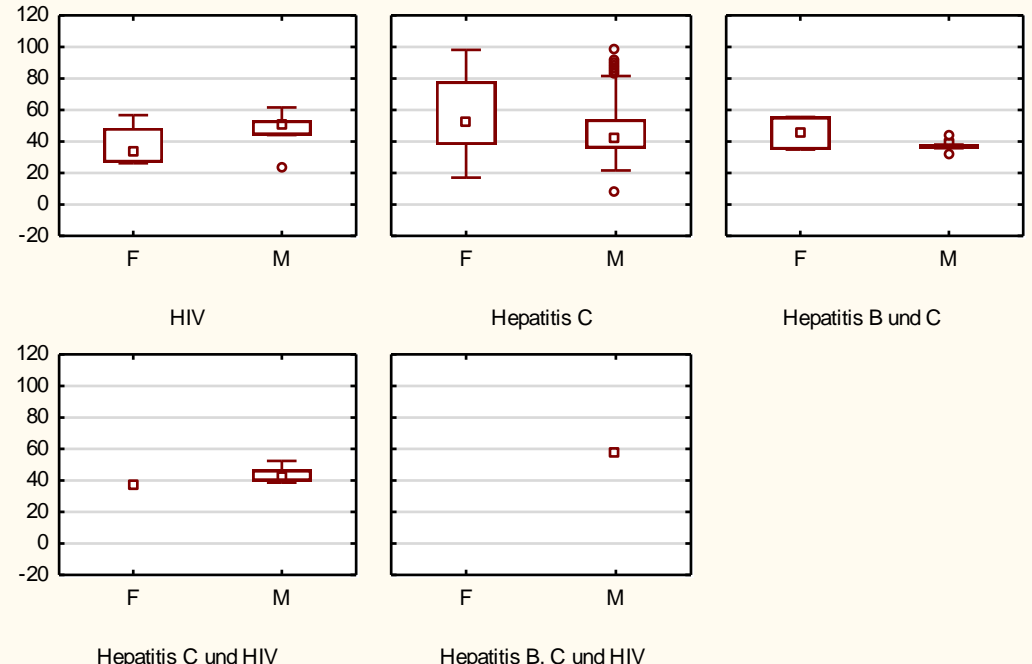

Hepatitis B und C

Geschlecht

Abbildung 4: Box Plot, Gesamtverteilung des Infektionsstatus von 593 Blutentnahmen auf Alter und Geschlecht

\subsubsection{Patienten und Infektionsaufkommen pro Jahr}

Die insgesamt 18569 Entnahmen verteilen sich auf die Jahre Oktober 2001 bis Januar 2015. Im Schnitt wurden jährlich (ganze Jahre von 2002-2014) 1398,62 \pm 528,60 [920-2359] Blutproben abgenommen. Davon waren im Mittel für ganze Jahre $44,85 \pm 17,60$ [32-98] Proben reaktiv für eine Infektion. 
Tabelle 1 listet die genaue Verteilung der positiv und negativ getesteten Blutproben verteilt auf die einzelnen Jahre auf.

Tabelle 1: Unterteilung der Status auf die Jahre 2001 bis 2015

\begin{tabular}{|c|c|c|c|c|c|c|c|c|}
\hline Jahr & Negativ & $\begin{array}{l}\text { Hepatitis } \\
\text { C }\end{array}$ & $\begin{array}{l}\text { Hepatitis } \\
\text { B }\end{array}$ & HIV & $\begin{array}{l}\text { Hepatitis } \\
\text { B \& C }\end{array}$ & $\begin{array}{l}\text { Hepatitis } \\
\text { C \& HIV }\end{array}$ & $\begin{array}{l}\text { Hepatitis } \\
\text { B \& HIV }\end{array}$ & $\begin{array}{l}\text { Hepatitis } \\
\text { B, C \& } \\
\text { HIV }\end{array}$ \\
\hline 2001 & 181 & 6 & & & & & & \\
\hline 2002 & 926 & 32 & & & & & & \\
\hline 2003 & 887 & 33 & & & & & & \\
\hline 2004 & 985 & 37 & 1 & 1 & & & & \\
\hline 2005 & 869 & 39 & 45 & 1 & 1 & & 12 & \\
\hline 2006 & 894 & 34 & & & & & & \\
\hline 2007 & 1062 & 32 & & & & & & \\
\hline 2008 & 1054 & 38 & & & & & & \\
\hline 2009 & 1260 & 41 & 5 & 2 & 2 & & & \\
\hline 2010 & 1253 & 19 & 7 & 2 & 3 & & 1 & \\
\hline 2011 & 1765 & 31 & 8 & 1 & & 1 & & \\
\hline 2012 & 2067 & 42 & 7 & 4 & 3 & 2 & & 1 \\
\hline 2013 & 2273 & 28 & 7 & 1 & 1 & 2 & 1 & \\
\hline 2014 & 2304 & 49 & 4 & 2 & & & & \\
\hline 2015 & 196 & 4 & & & & & & \\
\hline Gesar & 17976 & 465 & 84 & 14 & 10 & 5 & 14 & 1 \\
\hline
\end{tabular}

\subsubsection{Falsch-Positive}

Unter allen untersuchten Blutproben zeigte sich bei 102 Fällen ein falsch-positives Testergebnis, ersichtlich in Abbildung 5. 23 der falsch-positiven Proben kamen von Patienten, die über den Schockraum eingeliefert wurden.

Es ergab sich eine Verteilung von 17 falsch-positiven HIV-Ergebnissen (0,092\%) bei vier Frauen im Alter von 58,03 \pm 10,97 [48,14-68,75] Jahren und 13 Männern mit einem mittleren Alter von 47,57 $\pm 30,78[10,61-87,61]$ Jahren. Auf Hepatitis C wurden 67 Proben falsch-positiv getestet $(0,361 \%)$, wovon 25 weiblich im Altersschnitt von 59,69 $\pm 22,21$ [22,08-94,46] sowie 42 männlich, im Alter von 48,98 \pm 21,94 [16,97-90,55] Jahren, waren. Hepatitis B wurde bei 14 Proben fälschlicherweise angenommen (0,075\%), mit einer Verteilung von acht Frauen im Alter von durchschnittlich 65,04 \pm 24,15 [25,94-86,49] Jahren und sechs Männern mit einem mittleren Alter von 60,00 $\pm 21,83$ [22,19-86,58] Jahren. Vier Patientinnen waren in der Nachtestung weder für Hepatitis B noch HIV positiv $(0,022 \%)$. Diese hatten ein 
durchschnittliches Alter von 76,17 $\pm 15,59$ [55,21-88,05] Jahren. Insgesamt ergab sich, dass bei einem Prozentsatz von $0,55 \%$ aller getätigten Blutentnahmen initial im Schnelltest ein reaktiver Infektionsstatus festgestellt wurde, der sich in weiterführenden Test als negativ herausstellte.

\section{Falsch-Positive}

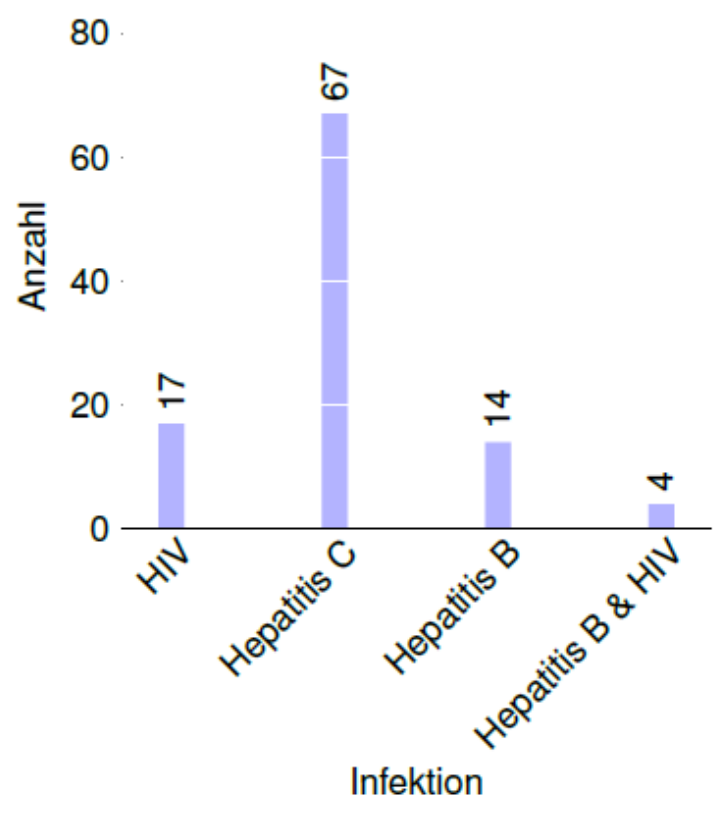

Abbildung 5: Anzahl der falsch-positiven Testergebnisse bezogen auf die im Schnelltest initial festgestellte Infektion

\subsubsection{Testgütekriterien}

Insgesamt wurden 18569 Blutentnahmen getätigt. Davon waren 17874 negativ für jegliche Infektion. Bei 695 wurde im Schnelltest ein reaktiver Status auf eine oder mehrere Infektionen festgestellt. Davon bestätigten sich in weiterführenden Untersuchungen 593 Infektionen, 102 wurden als falsch-positiv ausgeschlossen. Es ergab sich somit eine Spezifität von 99,43\%. Dies gibt an, dass Gesunde, die nicht an einer Infektion leiden, auch tatsächlich als gesund gescreent werden.

Es ließ sich ein positiver prädiktiver Wert von $85,32 \%$ ermitteln. Dieser Wert gibt an, wie viele Personen, bei denen mittels Test eine Krankheit festgestellt wurde, auch wirklich an der Krankheit leiden. Er lässt sich ermitteln aus der Anzahl aller Infizierten geteilt durch die Summe aus richtig positiven und falsch positiv Getesteten. 
Mittels der Daten war es nicht möglich, die Sensitivität des Screeningverfahrens zu ermitteln, da initial negativ getestete Patienten nicht nochmalig verifiziert wurden.

\subsection{Einteilung in Diagnosekategorien}

Die reaktiven Status wurden in sieben Diagnosekategorien (siehe 2.3.2.) unterteilt. Anhand der Tabelle 2 zeigt sich die Verteilung der Verletzungskategorie auf die unterschiedlichen Altersgruppierungen.

\subsubsection{Kategorie A - Patienten mit Verletzungen im Kopf- und Gesichtsbereich}

Die Diagnosekategorie A umfasste 149 Patienten, wovon 48 weiblich und 101 männlich waren. Die Männer hatten einen Altersschnitt von 47,82 \pm 16,36 [15,1089,24] Jahren, wovon 30 Patienten in der Alterskategorie der 40- bis 50-Jährigen vorkamen. Bei den Frauen lagen in den Alterskategorien Vier bis Sieben $(30,00-$ 69,99 Jahre) jeweils sieben Proben vor, bei einem Altersschnitt von 57,98 $\pm 22,38$ [17,76-98,18] Jahren.

\subsubsection{Kategorie B - Patienten mit thorakalen Verletzungen}

Kategorie B umfasste mit 38 Entnahmen 29 Männer und neun Frauen. Die Männer wiesen einen Altersschnitt von 46,31 $\pm 13,55$ [22,66-72,10] Jahren auf, die Frauen von $46,77 \pm 21,74[18,65-80,75]$ Jahren.

\subsubsection{Kategorie C - Patienten mit Abdominalverletzungen}

Kategorie C umfasste 33 Abnahmen, verteilt auf 25 Männer und acht Frauen. Das Alter betrug bei den Männern durchschnittlich 46,99 $\pm 13,56$ [29,70-78,22], bei den Frauen durchschnittlich $39,40 \pm 16,12[23,95-65,46]$ Jahre.

\subsubsection{Kategorie D - Patienten mit Beckenverletzungen}

In Kategorie D gab es Blutentnahmen bei sechs männlichen, im Durchschnittsalter von $60,58 \pm 17,19[30,13-79,76]$ Jahren sowie zwei weiblichen Patienten. Bei den Frauen betrug der Altersschnitt 67,24 $\pm 34,96$ [42,52-91,96] Jahre. 


\subsubsection{Kategorie E - Patienten mit Extremitätenverletzungen}

Die Kategorie E war mit 318 Blutentnahmen die größte Gruppe. Davon waren 198 Patienten männlich und 120 weiblich. Bei den Männern gab es 56 Verletzungen in der Alterskategorie der 30- bis 40-Jährigen und 55 Verletzungen in der Kategorie der 40- bis 50-Jährigen. Es ergab sich ein Altersdurchschnitt von 44,99 \pm 15,49 [7,14-91,33] Jahren. Bei Frauen mit einem Altersschnitt von 57,69 $\pm 22,27$ [17,16$96,70]$ Jahren gab es in den selben Alterskategorien jeweils 21 Proben, ebenso wie in den Kategorien der 70- bis 80-Jährigen und 80- bis 90-Jährigen mit 21 und 20 Entnahmen.

\subsubsection{Kategorie F - Patienten mit Wirbelsäulenverletzungen}

Wirbelsäulenverletzungen waren bei 17 Entnahmen als Diagnose dokumentiert, wovon elf männlich im Alter von 55,36 $\pm 23,28[21,66-98,12]$ und sechs weiblich mit dem Durchschnittsalter 47,49 $\pm 21,77[19,72-82,14]$ Jahre waren.

\subsubsection{Kategorie G - Polytrauma-Patienten}

Unter den Patienten mit multiplen, potentiell lebensbedrohenden Verletzungen gab es elf Entnahmen, davon neun Männer und zwei Frauen. Bei den Männern waren sechs der Patienten unter 39,99 Jahren mit einem Altersschnitt von 38,91 $\pm 14,44$ $[23,58-66,19]$ Jahren. Bei den Frauen ergab sich ein Altersschnitt von $31,80 \pm 20,85$ $[17,05-46,54]$ Jahren.

\subsubsection{Kategorie S - Sonstiges}

Die Kategorie $S$ beinhaltete psychisch erkrankte Patienten, die im Verlauf an die Psychiatrie überwiesen wurden. Dies traf für zehn Patienten zu. Acht davon waren männlich mit einem Gipfel im Bereich von 40,00-49,99 Jahren und zwei weiblich. Der Altersdurchschnitt bei den Männern betrug 35,81 $\pm 5,52$ [28,63-43,36] und bei den Frauen 46,85 \pm 11,71 [38,56-55,13] Jahre.

Die weiteren Kategorien, bei denen keine der genannten Hauptdiagnosen zugeordnet werden konnten, beinhalteten 9 Entnahmen. 
Tabelle 2: Verteilung Geschlecht, Alterskategorie (in Jahren) und Diagnosekategorien A-S (Definition siehe 2.3.2) Werte über Zehn wurden rot markiert

\begin{tabular}{llllllllll} 
Geschlecht & Altersgruppe & A & B & C & D & E & F & G & S \\
\hline \multirow{5}{*}{ Männlich } & $1(0-9,99)$ & 0 & 0 & 0 & 0 & 1 & 0 & 0 & 0 \\
& $2(10,00-19,99)$ & 2 & 0 & 0 & 0 & 2 & 0 & 0 & 0 \\
& $3(20,00-29,99)$ & 7 & 2 & 1 & 0 & 27 & 1 & 3 & 1 \\
& $4(30,00-39,99)$ & 27 & 9 & 7 & 1 & 56 & 2 & 3 & 5 \\
& $5(40,00-49,99)$ & 30 & 7 & 9 & 0 & 55 & 4 & 1 & 2 \\
& $6(50,00-59,99)$ & 17 & 6 & 4 & 2 & 23 & 1 & 1 & 0 \\
& $7(60,00-69,99)$ & 4 & 2 & 2 & 1 & 14 & 0 & 1 & 0 \\
& $8(70,00-79,99)$ & 8 & 3 & 2 & 2 & 14 & 1 & 0 & 0 \\
& $9(80,00-89,99)$ & 6 & 0 & 0 & 0 & 5 & 1 & 0 & 0 \\
& $10(90,00-99,99)$ & 0 & 0 & 0 & 0 & 1 & 1 & 0 & 0 \\
\hline \multirow{5}{*}{ Weiblich } & $1(0-9,99)$ & 0 & 0 & 0 & 0 & 0 & 0 & 0 & 0 \\
& $2(10,00-19,99)$ & 1 & 2 & 0 & 0 & 2 & 1 & 1 & 0 \\
& $3(20,00-29,99)$ & 5 & 0 & 4 & 0 & 10 & 1 & 0 & 0 \\
& $4(30,00-39,99)$ & 7 & 2 & 0 & 0 & 21 & 0 & 0 & 1 \\
& $5(40,00-49,99)$ & 7 & 2 & 2 & 1 & 21 & 1 & 1 & 0 \\
& $6(50,00-59,99)$ & 7 & 0 & 1 & 0 & 11 & 2 & 0 & 1 \\
& $7(60,00-69,99)$ & 7 & 1 & 1 & 0 & 8 & 0 & 0 & 0 \\
& $8(70,00-79,99)$ & 3 & 1 & 0 & 0 & 21 & 0 & 0 & 0 \\
& $9(80,00-89,99)$ & 7 & 1 & 0 & 0 & 20 & 1 & 0 & 0 \\
& $10(90,00-99,99)$ & 4 & 0 & 0 & 1 & 6 & 0 & 0 & 0
\end{tabular}

\subsection{Patienten mit Weichteilinfektionen}

Bei 49 Patienten erfolgte eine Behandlung aufgrund von Infektionen des Weichteilgewebes. Abbildung 6 zeigt die Anzahl der reaktiven Blutproben in Bezug auf das Vorstellungsjahr. Die Blutentnahmen waren alle positiv für Hepatitis $\mathrm{C}$, zwei davon gleichzeitig für HIV. Elf der Entnahmen gehörten zu Frauen, 38 zu Männern. Es ergab sich ein Altersschnitt von 38,37 $\pm 10,10$ [22,34-82,06] Jahren. Die Altersspanne umfasste die Alterskategorien der 20- bis 60- Jährigen sowie die der 80 - bis 90-Jährigen, wobei bei den Männern 15 sowie 16 Entnahmen in den Altersklassen der 30- bis 40-Jährigen und 40- bis 50-Jährigen lagen. Die Männer hatten ein durchschnittliches Alter von 39,34 \pm 9,97 [23,68-82,06] Jahren. Bei den Frauen betrug der Altersschnitt 35,03 \pm 10,29 [22,34-50,12] Jahre. 47 der Abszesse ließen sich der Kategorie E (Extremitäten) zuordnen, die weiteren Zwei befanden sich an der Halsregion von jeweils einer männlichen und einer weiblichen Blutentnahme (Kategorie A). Bei 35 der Entnahmen war der Status im IXserv Programm bekannt, davon 
fielen acht bekannte Status auf weibliche und 27 auf männliche Entnahmen. Die beiden Doppelinfektionen mit HIV und Hepatitis $C$ waren ebenfalls bekannt und werden zu den bekannten Infektionsstatus bei männlichen Entnahmen gezählt. Bei 21 der Entnahmen konnte durch Dokumentation ein direkter Zusammenhang mit Drogenabusus erstellt werden.

Bei den 49 reaktiven Blutentnahmen wurde ein Patient sieben Mal in der Universitätsmedizin vorstellig. Drei Patienten waren dreimal vorstellig und zwei zweimalig im Krankenhaus.

\section{Anzahl Abszesspatienten pro Jahr}

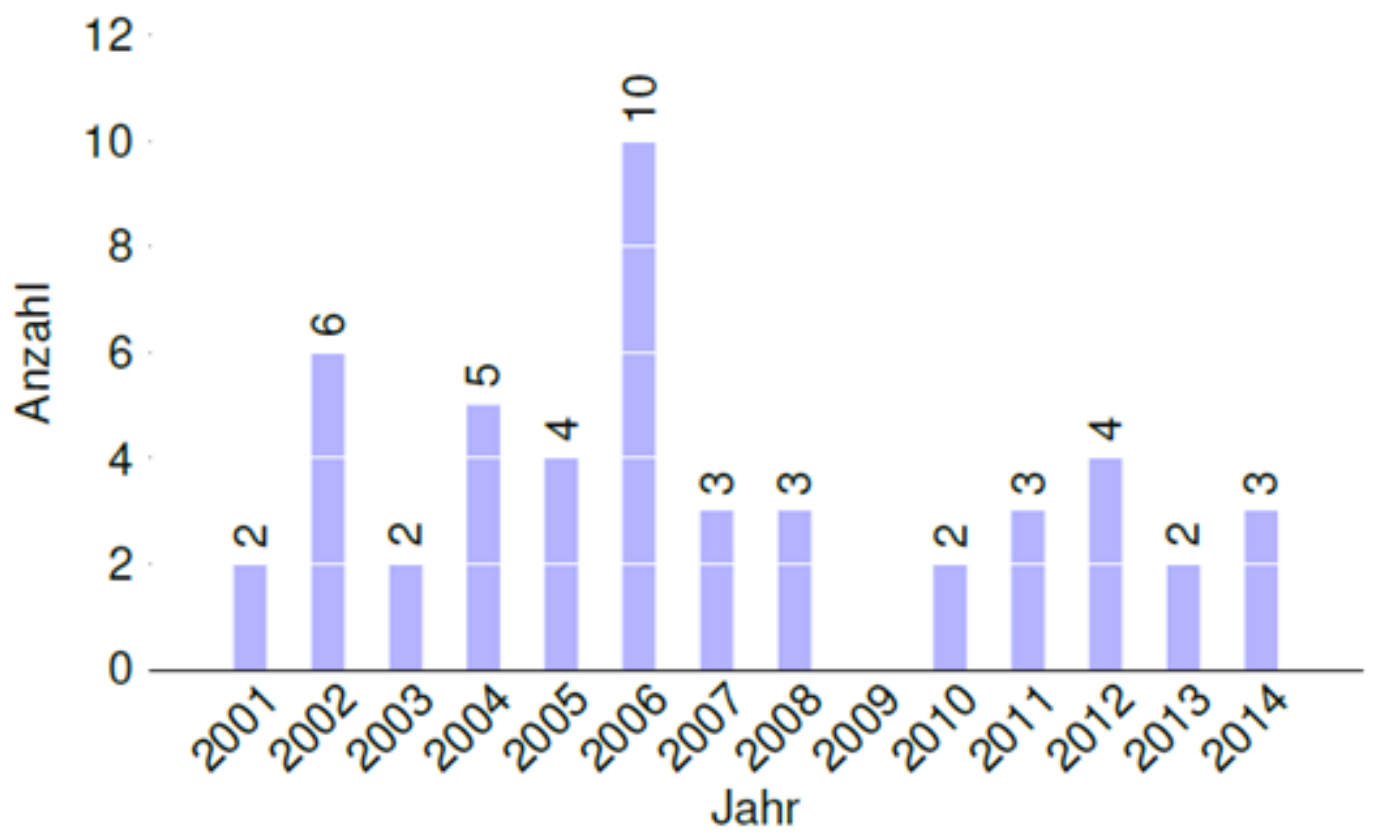

Abbildung 6: Anzahl der Patienten mit Weichteilinfektionen (Abszessen) in Bezug auf die Jahre 2001-2014, aufgrund fehlender Dokumentation keine Zahlen aus dem Jahr 2009

\subsection{Hauptkategorie E, Extremitätenverletzungen}

Dieser Kategorie wurden 318 Entnahmen zugeordnet. Davon waren 308 als unfallchirurgische Patienten anzusehen, die restlichen wurden anderen Fachrichtungen zugewiesen. Die 308 Patienten wurden daraufhin in die Kategorien Verletzungen der oberen und unteren Extremitäten aufgeteilt. Anhand der Abbildung 7 verdeutlicht sich die Lokalisation der Verletzungen. 


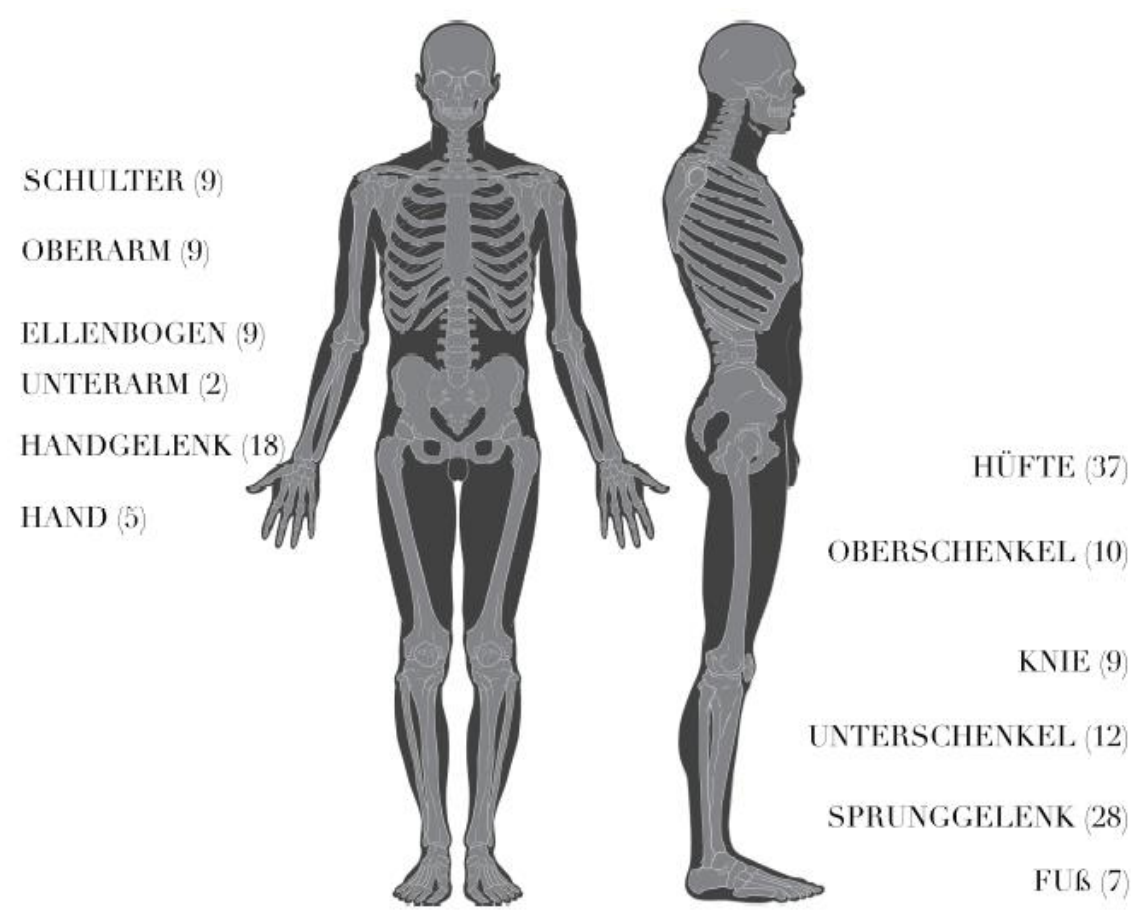

Abbildung 7: Lokalisation der Extremitätenverletzungen (Quelle: By Patrick J. Lynch, medical illustrator [CC BY 2.5 (http://creativecommons.org/licenses/by/2.5)], via Wikimedia Commons, Modifiziert durch Autorin)

\subsubsection{Obere Extremitäten}

137 Patienten konnten Verletzungen der oberen Extremitäten zugeordnet werden, wovon 96 Männer (70,07\%) und 41 Frauen (29,93\%) waren. Es wurde ersichtlich, dass 52 der Patienten eine Fraktur der oberen Extremität vorweisen konnten. Darunter waren 33 Männer und 19 Frauen mit einem Altersschnitt von 55,38 \pm 20,02 [7,14-91,33] Jahren. Bei den Männern gab es mit zehn Proben die höchste Entnahmerate in der Alterskategorie der 40- bis 50-Jährigen und bei den Frauen sechs Entnahmen in der Alterskategorie der 80- bis 90-Jährigen. Unter den Männern waren 25 reaktiv für Hepatitis C (48,08\%), vier für Hepatitis $\mathrm{B}(7,69 \%)$ und zwei für HIV $(3,85 \%)$. Reaktiv für Hepatitis C und B sowie Hepatitis B und HIV war jeweils einer der männlichen Patienten (1,92\%; 1,92\%)

Unter den weiblichen Patienten der Kategorie Extremitätenverletzungen waren elf reaktiv für Hepatitis C $(21,15 \%)$, sieben für Hepatitis B $(13,46 \%)$, eine Patientin war doppelt reaktiv für Hepatitis C und B (1,92\%) 
Der reaktive Infektionsstatus war bei 17 (32,69\%) von 52 Entnahmen bekannt. Ein Patient war viermal im Krankenhaus vorstellig, zwei jeweils zweimal. In drei Operationsberichten wurde der reaktive Infektionsstatus dokumentiert.

\subsubsection{Verletzungen}

Die Verletzungen der oberen Extremität wurden in sechs Unterkategorien eingeteilt:

- Kategorie S: Schulter- und schulternahe Frakturen

- Kategorie OA: Frakturen des Oberarmschafts

- Kategorie EB: Ellenbogen- und ellenbogennahe Frakturen wie Radiusköpfchenfrakturen, supra- oder intrakondyläre Frakturen

- Kategorie UA: Frakturen des Unterarms

- Kategorie HG: handgelenksnahe Frakturen wie distale Ulna- oder Radiusfrakturen

- Kategorie X: Frakturen der Hand

Es ergaben sich 18 Frakturen in Kategorie HG (34,62\%), jeweils neun Verletzungen in den Kategorien EB, S und OA (je 17,31\%) sowie fünf Verletzungen in Kategorie $X(9,62 \%)$ und zwei in Kategorie UA (3,85\%).

Abbildung 8 verdeutlicht die Art der Verletzung, unterteilt in die einzelnen Unterkategorien, in Bezug auf die festgestellten Infektionskrankheiten.

\subsubsection{Lokalisation der Verletzungen und Infektionsstatus}

Von den 18 Verletzungen in Kategorie HG wiesen elf einen reaktiven Hepatitis CStatus auf, vier waren Hepatitis-B-reaktiv, zwei HIV- und eine Verletzung HepatitisB- und C-reaktiv.

Die Kategorie EB war achtmal für Hepatitis-C- und einmal für Hepatitis-B-reaktiv. In der Kategorie OA gab es sechs Hepatitis-C-Infektionen, zwei Hepatitis-B-Fälle und eine Doppelinfektion Hepatitis B und C.

Bei Patienten mit Schulterverletzungen gab es sieben Hepatitis-C- und eine Hepatitis-B-Infektion sowie eine Doppelinfektion mit Hepatitis B und HIV. 
Die Verletzungen in der Kategorie $X$ wiesen vier Hepatitis-C- und eine Hepatitis-BInfektion auf.

Beide Unterarmverletzungen waren reaktiv für Hepatitis B.

\section{Verletzungen und Infektion obere Extremität}

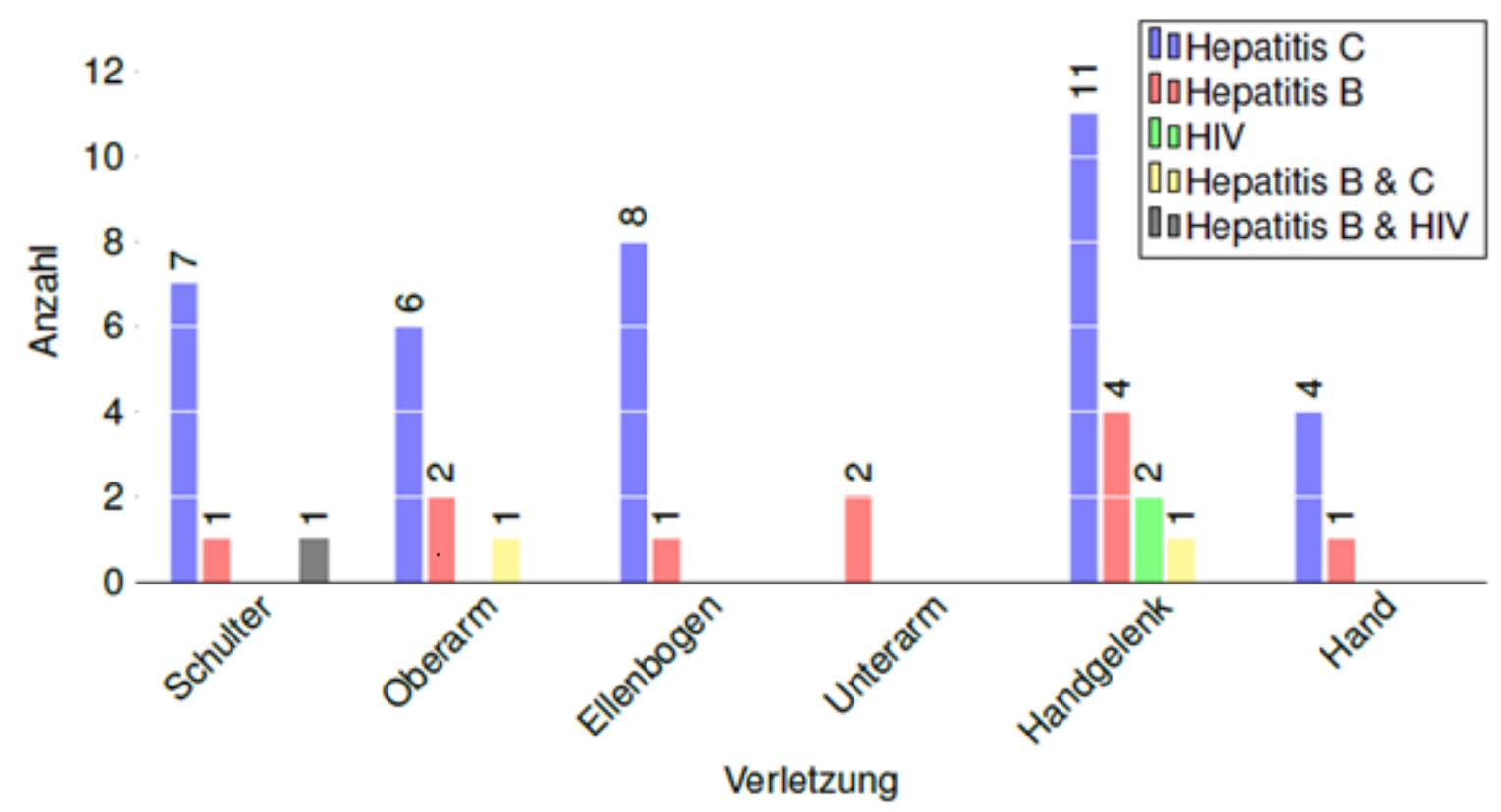

Abbildung 8: Verteilung der Infektionen in Bezug auf Verletzungen der oberen Extremität

\subsubsection{Behandlungsmaßnahmen}

Nach Indikation wären 44 Verletzungen (84,62\%) operativ versorgt worden, sechs $(11,53 \%)$ entweder operativ oder konservativ und zwei konservativ (3,85\%). 40 der Verletzungen $(76,92)$ wurden operativ versorgt, wovon vier $(7,49 \%)$ der Operationen minimalinvasiv durchgeführt wurden. Zwölf Verletzungen $(23,08 \%)$ wurden konservativ versorgt.

Anhand der Tabelle 3 zeigt sich das empfohlene Behandlungsregime der unterschiedlichen Verletzungen in Bezug auf die tatsächlich durchgeführte Behandlung.

Bei den 18 Handgelenksverletzungen wurden elf von 15 operativ versorgt. Eine Verletzung wurde operativ statt konservativ versorgt und zwei Verletzungen, bei denen beide Behandlungsoptionen möglich gewesen wären, wurden konservativ behandelt. 
Von den neun üblicherweise operativ zu versorgenden Ellenbogen-Verletzungen wurden acht operiert und eine konservativ versorgt.

In der Kategorie Schulter mit neun Verletzungen wären sieben Verletzungen operativ zu versorgen gewesen, wovon eine konservativ versorgt wurde. Zwei Verletzungen wurden konservativ versorgt in der Kategorie, in der beide Behandlungsoptionen möglich gewesen wären.

Sieben von neun Oberarmschaftfrakturen erforderten eine operative Behandlung und wurden dementsprechend versorgt. Eine Fraktur, aus der Kategorie mit beiden Behandlungsmöglichkeiten, wurde konservativ versorgt und eine Verletzung wurde wie üblich konservativ behandelt.

Die beiden Unterarmfrakturen wurden gemäß dem Therapieregime der Universitätsmedizin operativ versorgt.

Vier Handverletzungen aus der Kategorie X (fünf Verletzungen) wurden, wie erwartet, operativ versorgt. Eine Verletzung, bei der beide Behandlungen möglich gewesen wären, wurde konservativ versorgt. 
Tabelle 3: Obere Extremität, Vergleich Maßnahmen in Bezug auf übliche Behandlung und Verletzungskategorie

\begin{tabular}{|c|c|c|c|c|c|}
\hline \multirow{2}{*}{ Verletzungskategorie } & \multirow{2}{*}{$\begin{array}{l}\text { Behandlungsoption } \\
\text { üblicherweise }\end{array}$} & \multicolumn{3}{|c|}{ Behandlung } & \multirow{2}{*}{ Gesamt } \\
\hline & & operativ & minimalinvasiv & konservativ & \\
\hline \multirow{3}{*}{ Schulter } & Operation & 5 & 1 & 1 & 7 \\
\hline & Operation oder konservativ & 0 & 0 & 2 & 2 \\
\hline & konservativ & 0 & 0 & 0 & 0 \\
\hline \multirow{4}{*}{ Oberarm } & & 5 & 1 & 3 & 9 \\
\hline & Operation & 7 & 0 & 0 & 7 \\
\hline & Operation oder konservativ & 0 & 0 & 1 & 1 \\
\hline & konservativ & 1 & 0 & 0 & 1 \\
\hline \multirow{4}{*}{ Ellenbogen } & & 8 & 0 & 1 & 9 \\
\hline & Operation & 8 & 0 & 1 & 9 \\
\hline & Operation oder konservativ & 0 & 0 & 0 & 0 \\
\hline & konservativ & 0 & 0 & 0 & 0 \\
\hline \multirow{4}{*}{ Unterarm } & & 8 & 0 & 1 & 9 \\
\hline & Operation & 2 & 0 & 0 & 2 \\
\hline & Operation oder konservativ & 0 & 0 & 0 & 0 \\
\hline & konservativ & 0 & 0 & 0 & 0 \\
\hline \multirow{4}{*}{ Handgelenk } & & 2 & 0 & 0 & 2 \\
\hline & Operation & 10 & 1 & 4 & 15 \\
\hline & Operation oder konservativ & 0 & 0 & 2 & 2 \\
\hline & konservativ & 1 & 0 & 0 & 1 \\
\hline \multirow{4}{*}{ Hand } & & 11 & 1 & 6 & 18 \\
\hline & Operation & 2 & 2 & 0 & 4 \\
\hline & Operation oder konservativ & 0 & 0 & 1 & 1 \\
\hline & konservativ & 0 & 0 & 0 & 0 \\
\hline \multirow{2}{*}{\multicolumn{2}{|c|}{ Gesamt }} & 2 & 2 & 1 & 5 \\
\hline & & 36 & 4 & 12 & 52 \\
\hline
\end{tabular}

\subsubsection{Untere Extremitäten}

171 Patienten mit Verletzungen der unteren Extremitäten wurden ermittelt. Die Unterteilung erfolgte hierbei auf 94 Männer (54,97\%) und 77 Frauen (45,03\%). Die weitere Unterteilung ergab 103 Frakturen, davon 54 bei Männer und 49 bei Frauen mit einem Altersschnitt von 56,27 $\pm 20,76$ [16,00-94,81]. Bei den Männern gab es jeweils 16 und 15 Verletzungen in den Alterskategorien der 30 bis 40-Jährigen und 40 bis 50-Jährigen. 36 der männlichen Patienten wurden positiv auf Hepatitis $C$ getestet (34,95\%), elf waren Hepatitis-B-reaktiv (10,68\%) und zwei HIV-reaktiv (1,94\%). Fünf der Männer waren für je zwei Infektionen reaktiv, darunter vier für Hepatitis B und HIV (3,88\%) und einer für Hepatitis C und B $(0,97 \%)$.

Bei den Frauen gab es zwölf Probenentnahmen in den Alterskategorien der 70 bis 80-Jährigen und elf in der Gruppe der 80 bis 90 -Jährigen. Einen reaktiven Status 
wiesen 42 Entnahmen für Hepatitis C auf (40,78\%), fünf für Hepatitis B (4,85\%) und zwei Frauen waren jeweils Hepatitis-B- und HIV-reaktiv (1,94\%).

Bei 47 (45,63\%) von den 103 versorgungspflichtigen Verletzungen war ein positiver Reaktionsstatus bekannt. Darunter fielen Mehrfachvorstellungen der Patienten. Neun waren zweimalig in der Klinik und zwei dreimalig. In zwölf der 103 Behandlungsberichten wurde die betreffende Infektion erwähnt.

Abbildung 9 verdeutlicht die Art der Verletzung, unterteilt in die einzelnen Unterkategorien, in Bezug auf die festgestellten Infektionskrankheiten.

\subsubsection{Verletzungen}

Die Verletzungen der unteren Extremität wurden in sechs Unterkategorien eingeteilt.

- Kategorie OS: Oberschenkel

- Kategorie S: Sprunggelenk- und sprunggelenksnahe Frakturen

- Kategorie US: Frakturen des Unterschenkels

- Kategorie K: Knie- und kniegelenksnahen Verletzungen

- Kategorie H: Hüft- und hüftgelenksnahe Frakturen

- Kategorie X: Verletzungen des Fußes und der Zehen.

Es gab 37 Verletzungen in der Kategorie $\mathrm{H}(35,92 \%), 28$ in der Kategorie $\mathrm{S}$ $(27,18 \%)$ und zwölf in der Kategorie US $(11,65 \%)$. Zehn Verletzungen wurden der Kategorie OS zugeordnet $(9,71 \%)$, neun der Kategorie K $(8,74 \%)$ und sieben der Kategorie X (6,80\%).

\subsubsection{Lokalisation der Verletzungen und Infektionsstatus}

In der Kategorie $\mathrm{H}$ hatten 31 Patienten einen Nachweis von Hepatitis-C-Infektionen und jeweils drei von Hepatitis-B- und Hepatitis-B- und HIV-Doppelinfektionen.

In der Kategorie S gab es 19 Hepatitis-C-Infektionen, fünfmal Hepatitis B, einmal HIV und dreimal eine Doppelinfektion mit Hepatitis B und HIV.

Neun Hepatitis-C- und drei Hepatitis-B-Fälle waren in Kategorie US zu verzeichnen. 
Bei Verletzungen des Oberschenkels gab es neun Hepatitis-C- und eine HepatitisB-Infektion.

In Kategorie K zeigten sich sieben Hepatitis-C- und eine Hepatitis-B-Infektion sowie eine Hepatitis-B- und HIV-Infektion.

Von den sieben Fällen in Kategorie $X$ waren jeweils drei reaktiv für Hepatitis $C$ und $B$ und einmalig für HIV.

Infektionen bei Verletzungen der unteren Extremität

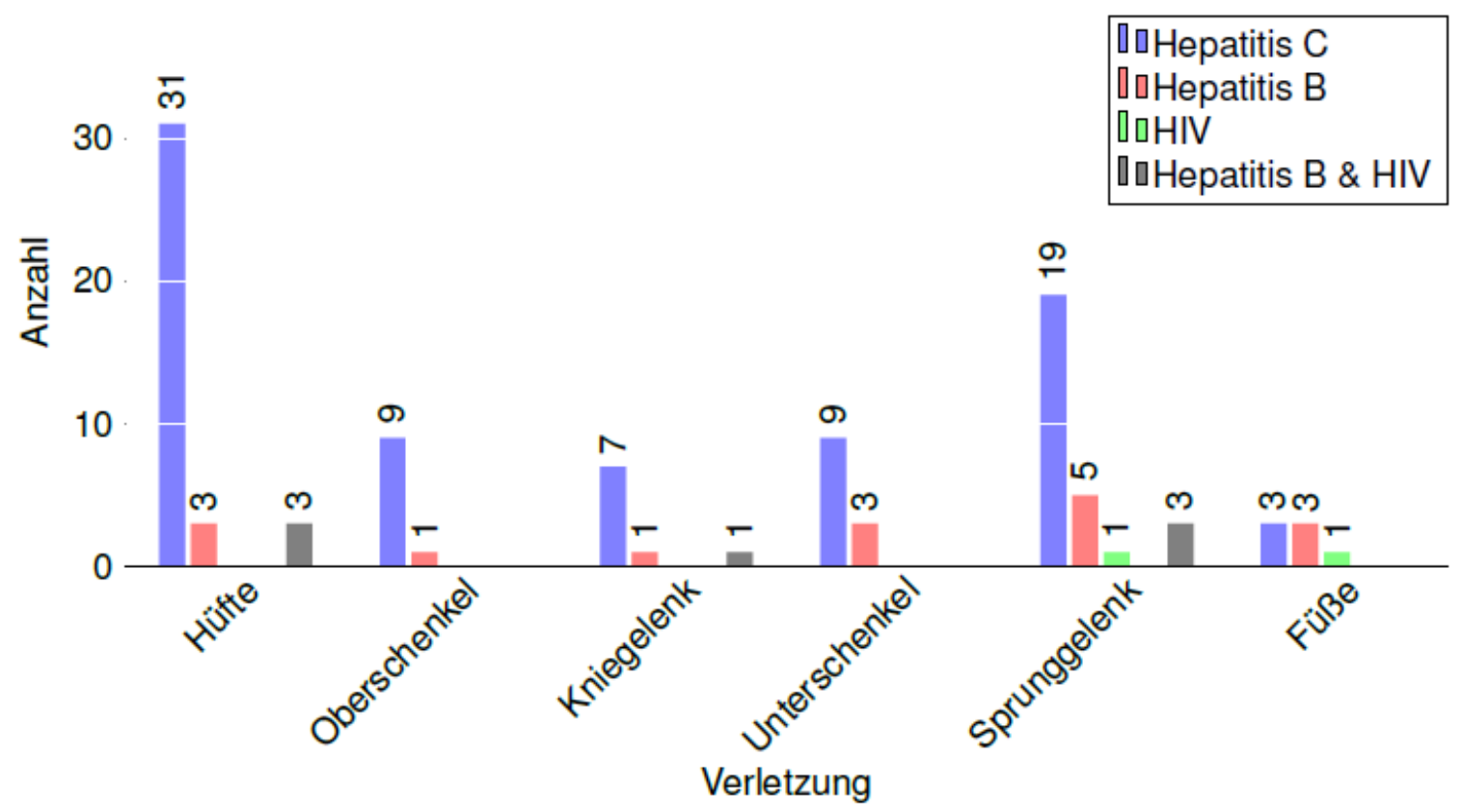

Abbildung 9: Infektionen bei Verletzungen der unteren Extremität

\subsubsection{Behandlungsmaßnahmen}

$92(89,32 \%)$ Verletzungen wären operativ zu versorgen gewesen, bei zehn $(9,71 \%)$ wären beide Behandlungsoptionen möglich gewesen und eine Verletzung (0,97\%) hätte konservativ behandelt werden können.

Insgesamt wurden 97 Verletzungen operativ versorgt (94,17\%) wovon bei 20 Operationen eine minimalinvasive Technik gewählt wurde (19,42\%). Sechs Verletzungen wurden konservativ behandelt $(5,82 \%)$.

Anhand der Tabelle 4 zeigt sich das empfohlene Behandlungsregime der unterschiedlichen Verletzungen in Bezug auf die tatsächlich durchgeführte Behandlung. 
In der Kategorie $\mathrm{H}$ wurden alle 35 operativ zu versorgenden Verletzungen entsprechend behandelt, zwei Verletzungen mit beiden Behandlungsoptionen wurden operativ versorgt.

Von den 22 operativ zu versorgenden Verletzungen aus der Kategorie der Sprunggelenksverletzungen wurden 21 operiert und einmal konservativ behandelt. Bei fünf der Verletzungen, die beide Behandlungsmöglichkeiten hatten, wurde viermal die Operation durchgeführt und einmal konservativ behandelt. Unter dem konservativ empfohlenen Behandlungsweg gab es eine Behandlung.

Alle Unterschenkelverletzungen wurden operiert, ferner hätte bei einer der Verletzungen der konservative Weg gewählt werden können.

Verletzungen des Oberschenkels wurden alle operiert.

Bei der Kategorie der Knie- und kniegelenksnahen Verletzungen gab es für sieben die operative Versorgungsempfehlung, davon wurden fünf operiert. Bei zwei Verletzungen wären beide Behandlungsoptionen möglich gewesen, hier wurde der operative Versorgungsweg gewählt.

In der Kategorie $\mathrm{X}$ gab es sieben Operationsempfehlungen, wovon sechs entsprechend operativ versorgt wurden. 
Tabelle 4: Untere Extremität, Vergleich Maßnahmen in Bezug auf übliche Behandlung und Verletzungskategorie, Werte über Zehn rot markiert

\begin{tabular}{|c|c|c|c|c|c|}
\hline \multirow{2}{*}{ Verletzungskategorie } & \multirow{2}{*}{$\begin{array}{l}\text { Behandlungsoption } \\
\text { üblicherweise }\end{array}$} & \multicolumn{3}{|c|}{ Behandlung } & \multirow{2}{*}{ Gesamt } \\
\hline & & operativ & minimalinvasiv & konservativ & \\
\hline \multirow{3}{*}{ Hūfte } & Operation & 26 & 9 & 0 & 35 \\
\hline & Operation oder konservativ & 2 & 0 & 0 & 2 \\
\hline & konservativ & 0 & 0 & 0 & 0 \\
\hline & & 28 & 9 & 0 & 37 \\
\hline \multirow{3}{*}{ Oberschenkel } & Operation & 8 & 2 & 0 & 10 \\
\hline & Operation oder konservativ & 0 & 0 & 0 & 0 \\
\hline & konservativ & 0 & 0 & 0 & 0 \\
\hline \multirow{4}{*}{ Kniegelenk } & & 8 & 2 & 0 & 10 \\
\hline & Operation & 4 & 1 & 2 & 7 \\
\hline & Operation oder konservativ & 2 & 0 & 0 & 2 \\
\hline & konservativ & 0 & 0 & 0 & 0 \\
\hline \multirow{4}{*}{ Unterschenkel } & & 6 & 1 & 2 & 9 \\
\hline & Operation & 5 & 6 & 0 & 11 \\
\hline & Operation oder konservativ & 0 & 1 & 0 & 1 \\
\hline & konservativ & 0 & 0 & 0 & 0 \\
\hline \multirow{4}{*}{ Sprunggelenk } & & 5 & 7 & 0 & 12 \\
\hline & Operation & 20 & 1 & 1 & 22 \\
\hline & Operation oder konservativ & 4 & 0 & 1 & 5 \\
\hline & konservativ & 0 & 0 & 1 & 1 \\
\hline \multirow{4}{*}{ Füße } & & 24 & 1 & 3 & 28 \\
\hline & Operation & 6 & 0 & 1 & 7 \\
\hline & Operation oder konservativ & 0 & 0 & 0 & 0 \\
\hline & konservativ & 0 & 0 & 0 & 0 \\
\hline \multirow{2}{*}{\multicolumn{2}{|c|}{ Gesamt }} & 6 & 0 & 1 & 7 \\
\hline & & 77 & 20 & 6 & 103 \\
\hline
\end{tabular}

\subsection{Schock-OP-Patienten}

Im folgenden Abschnitt werden Patienten besprochen, die durch Notarzt und Rettungsdienst als lebensbedrohlich Verletzte eingestuft wurden und über einen extra dafür vorhandenen Erstversorgungsraum in die Klinik eingeliefert wurden. $2886 \mathrm{der}$ 18659 (15,54\%) Blutentnahmen waren von Patienten, die über diesen Schockraum eingeliefert wurden.

Von diesen 2886 Blutentnahmen wiesen 51 (1,77\%) einen reaktiven Status auf. In Bezug auf die 593 reaktiven Abnahmen ergibt dies einen Prozentsatz von 8,60\% Die Aufteilung des reaktiven Status ist anhand Abbildung 10 ersichtlich. 
41 der Abnahmen aus dem Schockraum waren reaktiv für Hepatitis $C$, neun reaktiv für Hepatitis $B$ und eine Abnahme wies eine Doppelinfektion für Hepatitis $C$ und HIV auf.

\section{Schockraumpatienten}

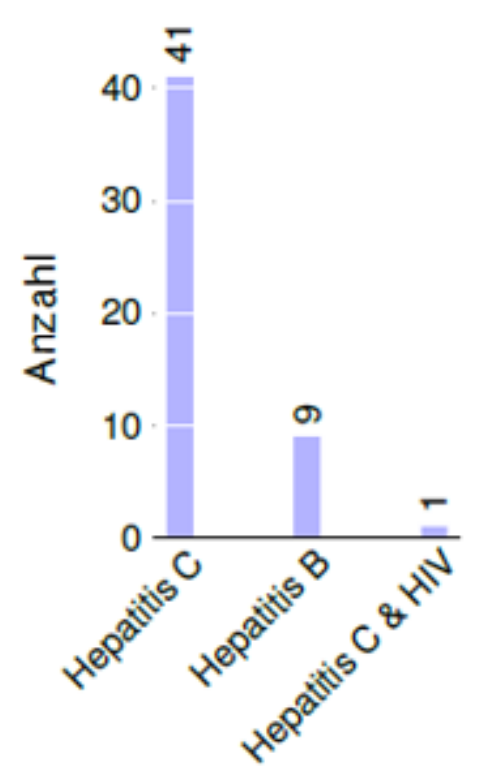

Abbildung 10: Anzahl der reaktiven Blutproben unter Schockraumpatienten

Die meisten (26) Entnahmen wurden der Diagnosekategorie A zugeordnet, gefolgt von je neun Entnahmen in Kategorie E und B sowie zwei in Kategorie C. Die restlichen fünf Entnahmen konnten keiner bestimmten Kategorie zugeordnet werden.

\subsection{Arbeitsunfälle Universitätsmedizin}

Insgesamt gab es in den elf Jahren 2385 Verletzungen, die D-ärztlich aufgenommen werden mussten. Diese Arbeitsunfälle beziehen sich auf Verletzungen mittels Gegenständen, die mit infektiösem Material verunreinigt waren. 


\subsubsection{Berufliche Tätigkeit}

599 Meldungen $(25,12 \%)$ von Verletzungen an infektiösem Material erfolgten von Ärzten, gefolgt von 432 Verletzungsmeldungen (18,13\%) von examinierten Pflegekräften. 233 (9,78\%) und 228 (9,75\%) Meldungen gab es von Studenten im Praktischen Jahr und Medizinstudenten einschließlich Zahnmedizin. Bei operativ tätigem Personal ereigneten sich 139 Verletzungen (5,83\%), das Wirtschafts- und Versorgungspersonal verzeichnete 108 Zwischenfälle (4,53\%).

Die übrigen Verletzungsmeldungen verteilen sich auf Berufsgruppen mit unter 100 Meldungen, wie Laborkräfte, Hilfspersonal, wissenschaftliche Mitarbeiter und Weitere.

Beim ärztlichen Personal gab es von 2002 bis 2014, exklusive 2009 und 2012 bis 2013, insgesamt 1058 Meldungen an den Betriebsärztlichen Dienst. Dazu zeigt Tabelle 5 die Anzahl der Meldungen durch die unterschiedlichen Berufsgruppen in den erwähnten Jahren.

Das pflegerisch tätige Personal hatte in den genannten Jahren 721 Meldungen.

Dies ergibt beim ärztlichen Personal prozentual an allen gesammelten Stichverletzungen einen Wert von $44,40 \%$ sowie einen Wert von $30,26 \%$ bei der Pflege. 
Tabelle 5: Anzahl der Stichverletzungen an der Universitätsmedizin Göttingen, unterteilt in Berufsgruppen (Betriebsmedizin Göttingen 2016). Für die Jahre 2012 und 2013 liegen keine Werte vor, für das Jahr 2009 ist nur die Gesamtanzahl an Verletzungen bekannt

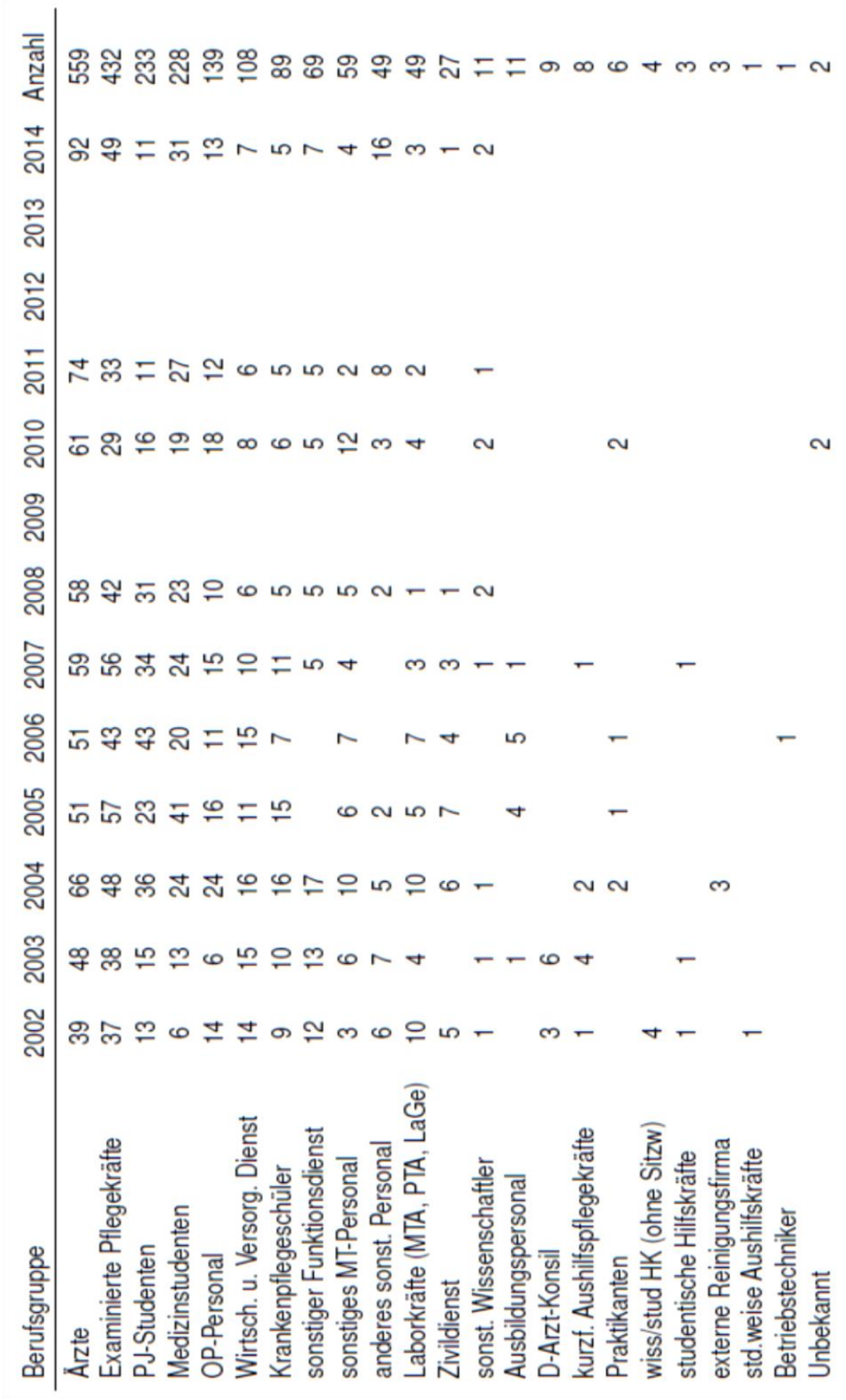




\subsubsection{Stichtag 2014}

Am 10.04.2015 wurde rückwirkend ein Stichtag für das Jahr 2014 festgelegt, anhand dessen festgestellt wurde, wie viele Beschäftigte der Universitätsmedizin prozentual im Jahr 2014 eine Verletzung gemeldet hatten. Daraus ist ersichtlich, dass sich im Jahr 201492 Ärzte (inklusive Zahnärzte) verletzt hatten, was am Stichtag 8,4\% des zu diesem Zeitpunkt tätigen Personals entspricht (1095 ärztliche Mitarbeiter). Unter den Studenten im Praktischen Jahr waren 11 Meldungen zu verzeichnen, was $10,7 \%$ der 103 tätigen Studenten ausmacht. Examinierte Pflegekräfte wiesen 49 Verletzungen auf, was einer Prozentzahl von $2,8 \%$ bei 1745 am Stichtag angestellten Personen entspricht. Unter den separat betrachteten Studierenden inklusive Zahnmedizin waren 31 Meldungen zu verzeichnen, was einen Wert von $0,9 \%$ bei 3517 Studierenden ergibt.

\subsubsection{Grund der Exposition}

Anhand von Aufzeichnungen des betriebsärztlichen Dienstes konnte nachgewiesen werden, bei welcher Tätigkeit sich einzelne Mitarbeiter durch welches Material verletzt hatten. Tabelle 6 zeigt das verwendete Material, durch welches sich die Verletzungen ereigneten in Bezug auf die Anzahl der Meldungen pro Jahr. Die Informationen wurden händisch zusammengetragen und ausgewertet. Insgesamt waren 2018 Einträge vorhanden, hierbei wurden die Jahre 2002, 2003, 2012 und 2013 nicht dokumentiert. 286 Verletzungen fanden durch Skalpelle statt (14,17\%), 274 durch Nahtnadeln (13,58\%), 209 durch Subkutan-Kanülen (10,36\%) und 206 weitere durch intravenöse Kanülen (10,21\%). Für 131 Meldungen waren Verletzungen mit Butterflynadeln verantwortlich (6,49\%) und bei 110 Einträgen war Blut oder Serum im Auge der Grund zur Meldung (5,45\%). Für die restlichen 820 Fälle gab es unter anderem Verletzungen durch Blutzuckerlanzetten (62, 3,07\%) sowie Bissverletzungen (vier, 0,2\%) und Materialien, die aus einem Abwurfbehälter ragten (14, 0,69\%). 128 Fälle wurden unter Sonstige aufgenommen (6,34\%). 
Tabelle 6: Material, anhand dessen es in der Universitätsmedizin Göttingen zu Stichverletzungen kam (>zehn Verletzungsmeldungen). Für die Jahre 2012 und 2013 liegen keine Werte vor (Betriebsmedizin Göttingen 2016).

\begin{tabular}{|c|c|c|c|c|c|c|c|c|c|c|}
\hline Material & 2004 & 2005 & 2006 & 2007 & 2008 & 2009 & 2010 & 2011 & 2014 & Anzahl \\
\hline Skalpell & 34 & 20 & 35 & 27 & 40 & 48 & 24 & 25 & 33 & 286 \\
\hline Nahtnadel & 20 & 34 & 20 & 31 & 20 & 40 & 28 & 38 & 43 & 274 \\
\hline sc-Kanüle & 29 & 36 & 17 & 23 & 23 & 28 & 19 & 8 & 26 & 209 \\
\hline iv-Kanüle & 43 & 40 & 22 & 26 & 15 & 16 & 9 & 11 & 24 & 206 \\
\hline Butterfly & 14 & 15 & 23 & 18 & 12 & 14 & 8 & 11 & 16 & 131 \\
\hline sonstige & 9 & 4 & 16 & 16 & 12 & 26 & 17 & 15 & 13 & 128 \\
\hline Blut \& Serum ins Auge & & & & 20 & 15 & 22 & 18 & 12 & 23 & 110 \\
\hline Instrument & 13 & 15 & 6 & 5 & 7 & 10 & 12 & 15 & 18 & 101 \\
\hline Kanüle (nicht weiter differenziert) & 14 & 7 & 8 & 7 & 4 & 6 & 15 & 12 & 10 & 83 \\
\hline Braunüle & 12 & 11 & 5 & 11 & 8 & 6 & 5 & & 8 & 66 \\
\hline BZ-Lanzette & 13 & 15 & 13 & 13 & 3 & 3 & & & 2 & 62 \\
\hline Pen & 2 & 4 & 3 & 2 & 2 & 6 & 7 & 7 & 13 & 46 \\
\hline Draht & 8 & 3 & 4 & 5 & 5 & 3 & 6 & 4 & 3 & 41 \\
\hline Blut auf Schleimhaut & 9 & 12 & 17 & & & & & & & 38 \\
\hline Blut auf Hautverletzung & 6 & 5 & & 4 & 4 & 4 & 5 & 4 & 3 & 35 \\
\hline Portkanüle & 5 & 2 & 4 & & 4 & 4 & & 6 & 2 & 27 \\
\hline unbekannt & 2 & 6 & 4 & 2 & 3 & 3 & & & & 20 \\
\hline Müllsack & 8 & & 2 & 5 & & & 4 & & & 19 \\
\hline ia-Kanüle & 2 & 1 & 3 & & 4 & & 5 & 3 & & 18 \\
\hline ZVK-Kanüle & 3 & & 3 & 2 & 2 & & & 4 & 1 & 15 \\
\hline Abwurfbehälter & 14 & & & & & & & & & 14 \\
\hline Schere & 2 & 5 & & 2 & 2 & & 2 & & & 13 \\
\hline
\end{tabular}

\subsubsection{Serologie}

In den Jahren 2004 bis 2008, 2010 und 2011, sowie 2014, wurden die Serologien der Proben händisch zusammengetragen. Insgesamt wurden 1773 Blutproben untersucht. Bei 1342 (75,69\%) war die Spenderserologie bekannt, bei den restlichen 431 Proben $(24,31 \%)$ unbekannt.

Daraufhin wurde eine Unterteilung der bekannten Serologien der Indexpatienten bzw. Spender vorgenommen. Von 1342 bekannten Serologien waren 1198 nicht infektiös (89,23\%). 104 der Proben waren reaktiv für Hepatitis C (7,75\%), 22 reaktiv für Hepatitis B $(1,64 \%)$, wovon zwei der Proben keinen Impfschutz aufwiesen, weitere 14 Proben waren reaktiv für HIV (1,04\%). Es gab vier Mischinfektionen, wovon zwei reaktiv für Hepatitis $C$ und HIV $(0,15 \%)$ und jeweils eine reaktiv für Hepatitis $B$ und HIV, sowie Hepatitis B und C, waren (je 0,07\%).

Die Summe aller infektiösen Stichverletzungen bei bekannter Serologie des Spenders, aufgeteilt auf die Jahre, ergab einen Mittelwert von 10,92\%. Das Augenmerk hierbei lag auf der Anzahl der Verletzungen gesehen auf die Gesamtverletzungen, unabhängig davon ob bei dem Spender eine oder mehrere Infektionen vorlagen. 2004 waren 17,86\% der Stichverletzungen infektiös, 2005 7,65\%, 2006 7,74\% und 
2007 9,73\%. Im Jahre 2008 waren 9,33\% der 150 bekannten Serologien infektiös, 2010 19,59\%, $20118,92 \%$ und 2014 6,56\%.

Betrachtet man die infektiösen Serologien (144) in Bezug auf die Gesamtstichverletzungen, bei denen Serologien erhoben wurden (1773), so ergibt sich ein prozentualer Wert von 8,20\% für eine infektiöse Serologie. Für das Jahr 2004 waren 10,49\% der Gesamtstichverletzungen infektiös, 2005 5,86\%, 2006 6,05\% und 2007 7,89\%. 2008 waren 7,33\% aller aufgenommenen Verletzungen infektiös, 2010 15,51\%, 2011 7,53 und 2014 4,98\%. Es ergibt sich eine mittlere Prävalenz von $0,08 \%$. Diese ergibt sich aus der jährlichen Prävalenz, errechnet durch die Anzahl der infektiösen Serologie, geteilt durch die Gesamtverletzungen. Tabelle 7 verdeutlicht die Anzahl der Serologien in Bezug auf die festgestellten Infektionen. 
Tabelle 7: Unterteilung der Serologien in Bezug auf Stichverletzungen an der Universitätsmedizin Göttingen. Für die Jahre 2009, 2012 und 2013 liegen keine Werte vor (Betriebsmedizin Göttingen 2016)

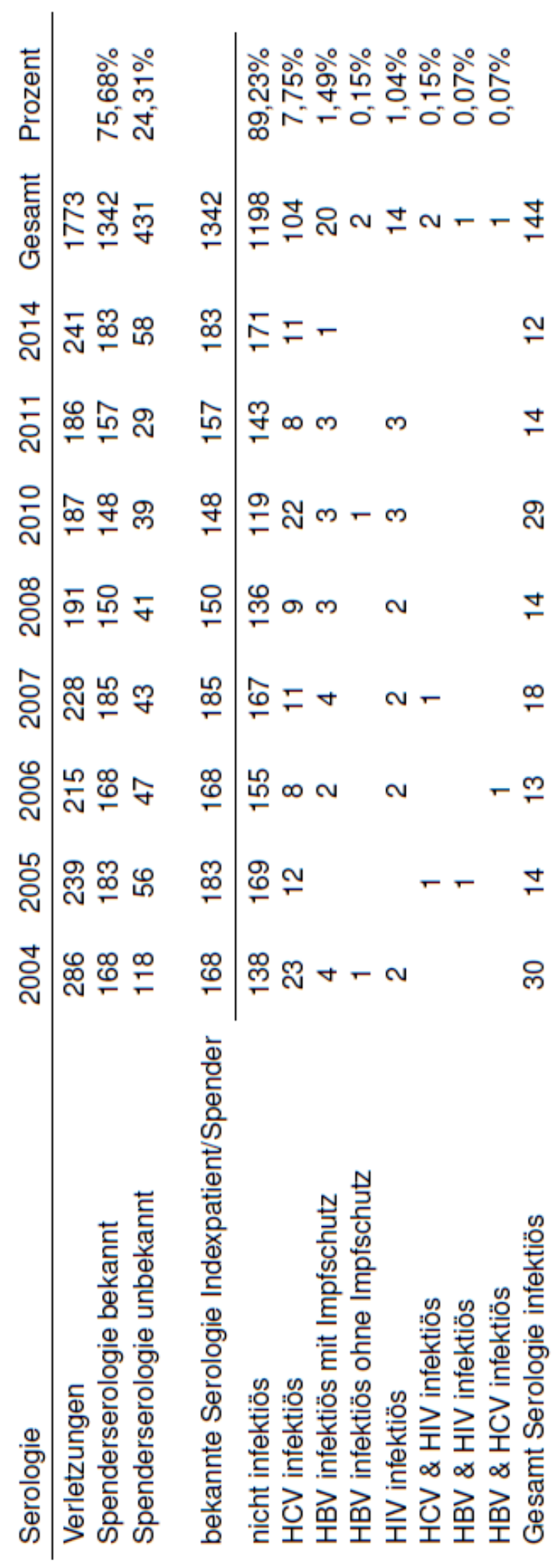




\section{Diskussion}

Auch heutzutage sind sich viele Menschen ihres reaktiven Infektionsstatus und damit der potentiellen Infektionsgefährdung anderer nicht bewusst. Dies erschwert die Arbeit im Krankenhaus mit eventuell gefährlichen Materialien, die in der Lage sind, gesundheitliche Schäden zu verursachen. Dazu zählt der Umgang mit Blut und weiteren infektiösen Flüssigkeiten zwischen dem Personal der Universitätsmedizin und den Patienten.

Umfragen durch die European Liver Patients Association (ELPA) im Jahr 2010 haben ergeben, dass bis zu 90\% der Patienten mit einer Hepatitis-B- oder C-Infektion innerhalb der Europäischen Union, HIV hierbei nicht berücksichtigt, sich ihres reaktiven Status vor Diagnosestellung nicht bewusst waren. Von diesen Patienten waren $27 \%$ sich nicht bewusst, dass sie einem hohen Transmissionsrisiko unterlagen (Hatzakis et al. 2011).

Von den Göttinger Patienten war der reaktive Status bei 271 Entnahmen im System und somit mutmaßlich auch dem Patienten bekannt. Prozentual gesehen beträgt der Anteil an bekannten Infektionen unter allen reaktiven Entnahmen 45,7\%. Dies ergibt sich möglicherweise durch bereits bekannte Patienten, die im Rahmen von Wiedervorstellung des Öfteren in Behandlung waren oder ihren reaktiven Status direkt bei erstmaliger Behandlung angaben. Aber dieser Zustand war häufig zum Zeitpunkt der Erstbehandlung nicht bekannt, da z. B. Patienten intubiert in den Schockraum eingeliefert wurden. Oder Patienten waren stark alkoholisiert, so dass sie keine adäquaten Antworten geben konnten. Von allen 18569 Entnahmen nehmen die im System bekannten reaktiven Entnahmen einen Prozentwert von 1,46\% ein.

Eine Prävalenz von 1,45\% ist im Kontext der weitreichenden Konsequenzen aus einer Infektion mit Hepatitis B, C oder HIV als hoch anzusehen. Daraus ergibt sich die Sinnhaftigkeit und Notwendigkeit von Screening-Tests bei Aufnahme ins Krankenhaus. Nach sorgfältiger Interessensabwägung und Aufklärung über die Notwendigkeit des Screenings wurde bei Patienten, die durch die vermutete oder diagnostizierte Verletzung potentiell weiterführender stationärer Behandlung im Klinikum bedurften, ein Screening auf Hepatitis B, C und HIV durchgeführt. Ferner wurde der Infektionsstatus bestimmt, wenn eine operative Versorgung notwendig wurde, oder 
bei klinischem oder anamnestischem Verdacht auf das Vorliegen einer Infektionskrankheit sowie beispielsweise im Kollektiv der Risikopatienten (Drogenabusus).

Indikation und Patientenbenefit

Bei einwilligungsfähigen Patienten erfolgte vor Abnahme der Blutproben eine vollständige Aufklärung. Bei nicht Einwilligungsfähigen ging man vom mutmaßlichen Willen der Patienten und somit von einem Einverständnis für weitere Untersuchungen aus. Es wurden bis auf die Abnahme bei Kindern- außer bei bekannter familiärer Belastung- keine Einschränkungen oder Ausschlusskriterien festgelegt. Bei einigen Patienten gab es mehrfach erforderliche Blutentnahmen. Da es aber aufgrund einer fehlenden elektronischen Patientenakte den aufnehmenden Ärzten nicht möglich ist, zeitnah relevante Informationen über ihnen unbekannte Patienten zu erlangen, war jede dieser Blutentnahmen medizinisch indiziert, um den Infektionsstatus definieren zu können. Ferner wurden auch Folgeblutentnahmen als sinnvoll erachtet, um Änderungen des Infektionsstatus feststellen und darauf adäquat reagieren zu können.

Sekundärer Benefit des Screenings auf Infektionskrankheiten ist für Patienten mit unbekanntem Status eine frühzeitige Diagnosestellung, die im Idealfall eine Behandlung der Infektion noch vor Ausbruch von Symptomen, ermöglichen würde.

Gefahrenpotential an der Universitätsmedizin Göttingen in Relation zur restlichen Bundesrepublik

An der Universitätsmedizin Göttingen, einem Klinikum der Maximalversorgung in Südniedersachsen, wurden von Oktober 2001 bis Januar 201518659 Blutentnahmen bei unfallchirurgischen Patienten durchgeführt. Die Klinik für Unfallchirurgie und Orthopädie, Abteilung Unfallchirurgie, Plastische- und Wiederherstellungschirurgie, jetzige Klinik für Unfallchirurgie, Orthopädie und Plastische Chirurgie, hat im Schnitt ein Patientenaufkommen von jährlich ca. 30.000 ambulanten und etwa 4.000 stationären Patienten, mit steigender Tendenz (Unfallchirurgie Göttingen 2017). Bei diesen hohen Patientenzahlen ergibt es sich, dass damit einhergehend auch eine 
große Zahl an Patienten mit reaktivem Infektionsstatus vorstellig wird und somit eine potentielle Gefährdung für das Personal in Ambulanz und OP entsteht.

Vergleicht man die Prävalenz der Patienten in Göttingen mit dem reaktiven Hepatitis C-Status der deutschlandweit erhobenen Studie DEGS1, so ergibt sich ein Wert von 2,5\% im Vergleich zu Deutschland mit 0,3\%. Dabei muss man jedoch bedenken, dass für die DEGS1-Studie ein Querschnitt der Bevölkerung im Alter von 18-79 Jahren erhoben wurde und Risikogruppen, wie beispielsweise Drogenabhängige und MSM (Männer, die Sex mit Männern praktizieren), ausgeschlossen wurden (Poethko-Müller et al. 2013). Daraus ergibt sich die weittragende Konsequenz, dass dieser erhobene Wert durch Ausschluss von Risikogruppen eine zu geringe Prävalenz widerspiegeln könnte.

Wegen der hohen Anzahl von Patienten in unserer Studie, welche sich infolge von Verletzungen als zufälliges Ereignis und demnach ohne Selektion in medizinische Behandlung begeben haben, gehen wir davon aus, einen repräsentativen Schnitt durch die Gesellschaft untersucht zu haben. Hierbei wurden Patienten im Alter von 0 bis 103 Jahren berücksichtigt.

Für Hepatitis-B-Mono-Infektionen ohne Co-Infektion liegt Göttingen mit einem Wert von $0,45 \%$ Prävalenz etwas über dem deutschlandweiten Durchschnitt einer HBsAg-Prävalenz von 0,3\% (Poethko-Müller et al. 2013).

Die HIV-Prävalenz lag für Göttingen mit 0,08\% im deutschlandweiten Rahmen von $0,12 \%$ (Marcus et al. 2010). Diese Zahlen repräsentieren jedoch nur die Monoinfektionen. Addiert man die Prozentzahlen der Göttinger Patienten mit reaktiven Blutentnahmen, so ergibt sich eine Gesamtprävalenz von 3,195\% für reaktive Status. Davon ausgehend, dass das vorliegende Patientenkollektiv aufgrund der Größe einen repräsentativen Schnitt durch die Gesamtbevölkerung darstellt, ergibt sich im Vergleich zur offiziellen Gesamtstatistik für die Bundesrepublik Deutschland ein deutlich erhöhter Wert.

Es ergeben sich drei mögliche Schlussfolgerungen:

- Basierend auf der Annahme eines repräsentativen Kollektivs ist es möglich, dass die offizielle Statistik für Deutschland einen zu niedrigen Wert ausgibt. 
- Eine weitere Schlussfolgerung ist, dass die Anzahl infizierter Personen im Klinikum der Maximalversorgung in Göttingen höher ist als das Vergleichskollektiv.

- Eine dritte Erklärung ist, dass Göttingen im Vergleich zum bundesdeutschen Durchschnitt eine erhöhte Prävalenz für Hepatitis B und C aufweist.

Es ergibt sich eine Wahrscheinlichkeit von 3,195\% als potentielle Gefahr einer Ansteckung mit einer oder mehreren viralen Infektionskrankheiten bei der Behandlung von Patienten der Klinik für Unfallchirurgie der Universitätsmedizin Göttingen. Resultierend aus diesen Zahlen ergibt sich eine deutlich höhere Infektionsgefahr, als offizielle Stellen veröffentlicht haben.

Ein detaillierter Vergleich unserer Daten der Hepatitis- und HIV- Infektionen mit den statistischen Erhebungen der einzelnen Bundesländer, insbesondere Niedersachsen, war nicht möglich, da für die einzelnen Bundesländer hauptsächlich die Inzidenzen erhältlich waren und lediglich eine Gesamtprävalenz der Erkrankungen für die Bundesrepublik verfügbar war. Zur genaueren Bestandsaufnahme dieser Daten wurde seitens des Robert Koch-Instituts Ende 2014 das „HEP-Epi-Projekt“ ins Leben gerufen (Robert Koch-Institut 2015d).

Generelle Schutzmaßnahmen

Standardhygienemaßnahmen wie hygienische Händedesinfektion und Verwendung persönlicher Schutzausrüstung sollten sich von selbst verstehen (Heininger et al. 2015). Als Basisschutzmaßnahme sollte bereits mit Operationsbeginn ein disziplinierter Ablauf eingehalten werden und keine unnötigen stressprovozierenden Faktoren, wie Lärm oder unnötiges Personal, vorhanden sein (Geiss 1998). In einer Studie aus Finnland konnte gezeigt werden, wie wichtig das Tragen von doppelten Handschuhen in der orthopädischen Chirurgie ist. So konnte nachgewiesen werden, dass die Wahrscheinlichkeit, sich mit Blut zu kontaminieren, bei einfachem Handschuhgebrauch um das bis zu Dreizehnfache im Vergleich zum Tragen doppelter Handschuhe erhöht war (Laine und Aarnio 2004).

Durch unterschiedliche Studien konnte belegt werden, dass bereits durch Einhalten einfacher Regeln die Infektionsgefahr während Operationen zu verringern ist. Dazu 
gehört das Einhalten der „No-touch-Technik“, was bedeutet, dass nie zwei Personen gleichzeitig einen potentiell gefährlichen Gegenstand berühren (Schulze-Röbbecke 2006). Scharfe Instrumente sollten, wenn möglich, vermieden werden (Kirsch et al. 2011) und persönliche Schutzausrüstung wie wasserdichte Schutzkleidung sollte getragen werden (Joint Working Party 1992). Des Weiteren sollten Handschuhe bei längerer Operationsdauer nach 2 Stunden gewechselt werden (Kojima und Ohashi 2005). Das Tragen von Schutzbrillen und Sichtschutz wird empfohlen (Sundaram und Parkinson 2007).

\section{Das Göttinger Modell}

Im Schnitt hat ein Arzt der chirurgischen Notaufnahme der Universitätsmedizin Göttingen ca. fünf Minuten Zeit für die Behandlung eines Notfallpatienten. Wochentags stellen sich pro Tag 100-140 Patienten dort vor, an den Wochenenden 80-100 Patienten. Im Tagdienst arbeiten drei bis fünf Ärzte mit zwei bis drei Pflegekräften in der Notaufnahme. In der Universitätsmedizin Göttingen gibt es, wie in vielen anderen Kliniken auch, keine elektronische Patientenakte, die dem Arzt oder Pflegepersonal die Möglichkeit gibt, sich über relevante Vorerkrankungen, wie ansteckende Infektionskrankheiten, zu informieren. Ein Durchsuchen von mikrobiologischen Befunden von vorherigen Krankenhausaufenthalten nimmt so viel Zeit in Anspruch, dass dies routinemäßig nicht machbar ist. Dadurch müssen die Ärzte, auch um sich selbst sowie das nachgeordnete Personal abzusichern, bei Verdacht auf eine Infektion ein Screening durchführen. Wäre eine elektronische Patientenakte vorhanden, so wären potentiell Informationen schneller verfügbar, da viele Patienten mit Infektionen ihren Status nicht kommunizieren, um nicht stigmatisiert zu werden (Nyblade et al. 2009). Ein bereits gesicherter Infektionsstatus müsste somit nicht erneut überprüft werden.

Bei Patienten, die in das Risikoprofil von Hepatitis C, B und HIV passen, wie zum Beispiel Drogensüchtige oder Personen mit sexuellem Risikoverhalten, sollten weiterhin Blutentnahmen zum Schutz von Patient und Personal erfolgen. Es muss bedacht werden, dass beispielsweise ein drogenabhängiger Patient mit initialer HIVInfektion sich im Verlauf seines Abusus auch mit Hepatitis C infiziert haben kann und so weitere Infektionen potentiell übertragen könnte (Fleig et al. 2004). 
Im Programm SAP der Universitätsmedizin Göttingen werden bereits bei Anmeldung des Patienten Infektionen mit den bakteriellen Erregern MRSA (Methicillinresistenter Staphylococcus aureus) und VRE (Vancomycin-resistente Enterokokken) speziell markiert. Dem Personal ist in diesen Fällen somit bekannt, welche Schutz- und Hygienemaßnahmen ergriffen werden müssen. Auf dem Boden der festgestellten Tatsachen sollte dies auch für Hepatitis C, B und HIV möglich sein. Dabei geht es nicht um Isolation und Stigmatisierung des Patienten, sondern Ärzte und Pfleger darauf aufmerksam zu machen, in der Behandlung und dem Umgang mit dem Patienten ein Augenmerk auf die eigene Sicherheit zu legen, um sich nicht zu infizieren. Gegen eine elektronische Patientenakte spricht das „Recht auf Nichtwissen" des Patienten, wenn er nicht über etwaige Krankheiten aufgeklärt werden möchte. Ebenso kann der Patient selbstständig entscheiden, welche Daten er dem betreuenden medizinischen Personal zugänglich machen möchte (Müller 2008). Die Angst aus Sicht des Patienten, dass der Datenschutz verletzt wird und die Gefahr vor möglichen Hackerangriffen auf die eigenen Gesundheitsdaten bleibt bestehen. Aber es kann diskutiert werden, welches Gut höher zu bewerten ist: der Schutz des Patienten oder der Schutz des Personals.

Finanzieller Aspekt der Screeningmaßnahmen

Die Kosten für das Screeningverfahren auf Hepatitis $B$ und HIV mittels ARCHITECT HBsAg Qualitative II, sowie ARCHITECT HIV Ag/Ab Combo betragen nach Verrechnungspreis der Universitätsmedizin Göttingen inkl. Personalkosten und Overhead jeweils 9,63 $€$. Für das Screening auf Hepatitis $C$ mittels ARCHITECT AntiHCV ergeben sich Kosten von 12,84€

Bei einem Preis von 32,10€ für den gemeinsamen Nachweis oder Ausschluss von Hepatitis B, C und HIV bei 18659 getesteten Patienten ergibt sich ein Gesamtbetrag von ungefähr 600.000 Euro im Zeitraum Oktober 2001 bis Januar 2015. Somit betragen die Kosten pro Jahr, je nach Patientenaufkommen, im Durchschnitt 45.000 Euro. Die genauen Zahlen der Kostenaufstellung sind im Anhang ersichtlich. Die Kosten für das Testverfahren sind gegen den potentiellen Nutzen der Zusatzinformationen, auch in Hinblick auf ökonomische Faktoren, abzuwägen. Hierbei sind Be- 
handlungskosten für infiziertes Personal und Kosten für der Volkswirtschaft entgangene Arbeitskraft infizierter Patienten sowie die Kosten für die Sozialversicherungen zu nennen.

Die Kosten der Behandlung bei Infektion können sich schnell auf mehrere tausende Euro kumulieren. Geht man von einer Hepatitis-C-Infektion aus, so können sich alleine die Kosten für eine Ein-Jahrestherapie für einen Patienten auf bis zu 59.790 Euro belaufen (Grandt und Schubert 2016).

In mehreren Studien wurde versucht, die Kosteneffektivität von Screeningverfahren zu überprüfen. Im Fokus der Betrachtung stand dabei, ob bei frühzeitiger Entdeckung einer der genannten Infektionskrankheiten die Krankheitsbelastung des Patienten gemindert und die Kosten für das Gesundheitssystem gesenkt werden könnten. Die meisten dieser Studien beziehen sich dabei auf spezielle Risikogruppen, wie Personen mit Infektionskrankheiten, Männer, die Sex mit Männern praktizieren oder Migranten. Im Falle der Migranten wurde festgestellt, dass bezogen auf das Hepatitis B-Virus eine positive Kosteneffektivität für das Screening besteht, wenn diese aus Risikogebieten mit einer HBsAg-Prävalenz von über 2\% stammen (Hahné et al. 2013). Dazu zählen Länder und Regionen mit einer mittleren Prävalenz von 2$7 \%$ wie Südwestasien, Israel und Staaten der ehemaligen Sowjetunion. Zu Ländern mit hoher Prävalenz werden unter anderem auch der Mittlere Osten, Indonesien und die Philippinen gezählt (Hadem et al. 2004). Es besteht nach Eckman et al. für die Gesamtpopulation einer Nation eine Kosteneffektivität, sofern die Prävalenz des Landes für Hepatitis-B-Virus-Infektionen über 0,3\% lag (Eckman et al. 2011). Unter Berücksichtigung der höheren Prävalenz der Hepatitis-C-Infektion im Vergleich zu Hepatitis B kann somit auch für das Screening auf Hepatitis $C$ eine positive Kosteneffektivität angenommen werden (Hahné et al. 2013).

In Bezug auf die Effektivität des HIV-Screenings zeigte eine 2014 für Großbritannien veröffentlichte Analyse von Long et al., dass ca. $25 \%$ der HIV-reaktiven Personen nichts von ihrem Status wissen (Long et al. 2014). Long et al. fanden heraus, dass sich 4 bis $15 \%$ der Neuinfektionen verhindern lassen würden, wenn man die bekannten Risikogruppen, wie Personen mit Infektions-Krankheiten, Männer, die Sex mit Männern praktizieren und Migranten aus Hochrisikogebieten einer jährlichen Testung, sowie alle anderen Erwachsenen einer einmaligen Testung zuführen würde. 
Dies ließe sich auch auf andere Niedrigprävalenz-Länder mit hohem Einkommen anwenden (Long et al. 2014).

Anhand der Studien und einem Vergleich zu den Prävalenzen in Deutschland und Göttingen ergibt sich für Göttingen und das klinikrelevante Einzugsgebiet eine Kosteneffektivität für das Hepatitis-B- und C-Screening.

In Hinblick darauf, dass sich im Rahmen von HIV-Erkrankungen 4 bis 15\% der Neuinfektionen durch einmalige Testungen von Nicht-Risiko-Patienten und jährliche Testung bei Risikopatienten, wie in Großbritannien, verhindern lassen würden, spricht auch dies für ein Screening. Somit empfiehlt es sich, den Ablauf des Screenings in der Unfallchirurgie der Universitätsmedizin Göttingen beizubehalten und fortzuführen und dies in allen Kliniken bundesweit zu etablieren. Die Kosten müssten in der DRG mitberücksichtigt werden.

Patientenklientel und Konsequenzen aus der Kenntnis des Infektionsstatus

Für das Jahr 2005 zeigte sich in Göttingen ein Maximum mit 45 Hepatitis-B-Patienten und 12 Hepatitis-B- und HIV-Mehrfachinfektionen. Dies lässt sich nicht schlüssig erklären, da weder der Test geändert wurde noch sonstige Auffälligkeiten bestanden. Die erhobenen Daten betrachten wir somit als normale Schwankung ohne statistische Relevanz.

Die Altersverteilungen in den jeweiligen Diagnosekategorien ergibt sich anhand der typischen altersrelevanten Verletzungen. Hierunter lassen sich beispielsweise Beckenverletzungen bei älteren Personen zusammenfassen, was sich an den Altersschnitten über 60 Jahren, bei erhöhtem Sturzrisiko und dem Auftreten von Komorbiditäten wie Osteoporose zeigt (Fuchs et al. 2011), wohingegen Polytraumen eher bei jüngeren Patienten festzustellen sind (Wedegärtner et al. 2004). Dies ist meist auf den Auslösemechanismus des Unfalles zurückzuführen, da Polytraumen sehr oft mit Verkehrsunfällen, wie Motorradunfällen, assoziiert sind (Mauritz 1998).

Bis auf die Kategorien C (Abdominalverletzungen), F (Wirbelsäulenverletzungen) und $\mathrm{G}$ (Polytraumen) zeigte sich bei den reaktiven Frauen ein höherer Altersschnitt als bei den Männern. Im Schnitt, berechnet in allen Verletzungskategorien, ergab sich eine Altersdifferenz von 2,31 Jahren. 
Bei Betrachtung der Abszesse zeigt sich, dass diese regelmäßig mit Drogenabusus in Verbindung gestellt werden. Somit sind Abszesspatienten oft Risikopatienten für Infektionserkrankungen (Fink et al. 2011). Mit zehn behandlungsnotwendigen Abszessen gab es im Jahre 2006 einen Peak zu verzeichnen. Dafür lässt sich keine Erklärung finden. Die beiden Patienten mit Doppelinfektionen wurden im Jahr 2012 vorstellig. 47 der Abszesse wurden durch wahlweise Spaltung, Inzision oder Wunddebridement versorgt. Zwei der Patienten verließen vor Einleiten einer operativen Behandlung die Universitätsmedizin. In neun von 47 Operationsberichten (19,15\%) wurden die reaktiven Infektionsstadien erwähnt.

Die initial 102 falsch-positiven Getesteten zeigen die Wichtigkeit der ScreeningTests. Für das behandelnde Personal sowie den Patienten selbst ist es sicherer, initial falsch-positiv getestet zu werden und durch weitere Testungen einen negativen Status zu bekommen, als durch die Tests als falsch-negativ deklariert zu werden und so keiner frühzeitigen medizinischen Versorgung zugeführt werden zu können. Jedoch muss bedacht werden, dass bei einer falsch-positiven Testung der Patient des Längeren im Ungewissen darüber gelassen wird, ob er nun eine Infektionskrankheit hat, die erst durch eine spätere Testung als negativ gesichert wird.

Bei der Patientenversorgung im Schockraum besteht eine erhöhte Gefahr für Ansteckungen mit übertragbaren Infektionskrankheiten, da bei der medizinischen Versorgung ein zeitgleiches Arbeiten von mehreren medizinischen Disziplinen wie Unfallchirurgie, Anästhesie und Radiologie stattfindet und Untersuchungen parallel durchgeführt werden (Krueger et al. 2013).

Bei Übergabe des Patienten durch Notarzt und Rettungsdienst ist der Infektionsstatus des Patienten meist unklar, sofern dieser sich nicht selber dazu äußern kann und wird auch selten erfragt. Darum muss schon bei Übernahme und Beginn der Maßnahmen erhöhte Vorsicht, im Umgang mit medizinischem Material und potentiell kontagiösen Körperflüssigkeiten, eingehalten werden und bis zum Beweis des Gegenteils von einer Infektion ausgegangen werden.

51 von 593 Entnahmen kamen von Patienten, die über den Schockraum eingeliefert wurden. Dies entspricht 8,6\% der reaktiven Blutentnahmen. Betrachtet man das Verhältnis von reaktiven Blutproben zu allen im Schockraum getätigten Abnahmen, im Vergleich zu den restlichen 542 reaktiven Proben in Bezug auf die Patienten, die nicht über den Schockraum liefen, so ergibt sich ein Wert von 1:56,59 für den 
Schockraum und 1:28,94 für den Rest. Somit ergibt sich für Patienten aus der Poliklinik ein doppelt so hohes Risiko, an einer Infektionskrankheit zu leiden und diese auf das Personal übertragen zu können.

Laut Paragraph 630f „Dokumentation der Behandlung“ des Bürgerlichen Gesetzbuches ist der behandelnde Arzt verpflichtet, unter anderem alle relevanten Maßnahmen, Therapien, Aufklärungen und Einwilligungen zu dokumentieren und schriftlich in der Patientenakte festzuhalten (BGBI I 2002, S. 42, 2909; 2003 I S. 738). Dies gilt nicht nur zur Absicherung für den Arzt, sondern auch für weiterführend notwendige Therapien für den Patienten.

Im Falle von Extremitätenverletzungen, die weitergehender Versorgung wie Gipsanlagen oder Operationen bedurften, wurden nur in 15 Operationsberichten von 155 Behandlungen mit positivem Infektionsstatus die Infektionen erwähnt. Dies entspricht einem Prozentsatz von 9,68\%. Bei 64 der 155 reaktiven Entnahmen behandlungsbedürftiger Verletzungen war der Status im Computerprogramm IXserv schon bekannt $(41,29 \%)$. Bei Behandlung von Weichteilabszessen waren es neun $(19,15 \%)$ dokumentierte Infektionen von 47 Versorgungen. Das doppelt so hohe Verhältnis von 9,68\% dokumentierten Infektionen bei Extremitätenverletzungen im Vergleich zu 19,15\% dokumentierten Abszessbehandlungen, zeigt, dass sich die Wachsamkeit und die Erwartungshaltung des Chirurgen bei den unterschiedlichen Eingriffen unterscheidet. Diese Erkenntnisse belegen die Notwendigkeit einer verbesserten Dokumentation, auch um langfristig für das Klinikpersonal eine erhöhte Arbeitssicherheit gewährleisten zu können. Eine nicht dokumentierte übertragbare Infektionskrankheit birgt für Mitarbeiter und Patienten das Risiko einer Ansteckung durch Übertragung.

\section{Rechtliche Aspekte}

Aus der klinischen Praxis heraus lässt sich beobachten, dass sich Patienten häufig unsicher sind, ob sie verpflichtet sind, ihre innen bekannte Infektion dem behandelnden Personal gegenüber zu erwähnen oder ob sie, um einer Stigmatisierung und minderwertigen Behandlung zu entgehen, diesen Status lieber verheimlichen sollten. Dazu gibt es keine allgemein gültige Richtlinie, die eine Informationsübermittlung vorschreibt. Nach dem Recht der informationellen Selbstbestimmung im 
Sinne der freien Persönlichkeitsentfaltung, Grundgesetz Art. 2 Abs.1, darf ein jeder selbst über seine Daten und Angaben bestimmen, jedoch gibt es keine explizite Regelung, was das Ausmaß dieser Daten betrifft (BGBI III 1949, GI 100-1). Aus ethischen Gründen darf prinzipiell von einem Patienten erwartet werden, dass dieser den behandelnden Arzt über seine Infektionskrankheit informiert. Ist sich der Patient über seine Infektion bewusst und verheimlicht diese dem Arzt, der invasive Maßnahmen, z. B. eine Operation, zur Behandlung der Verletzungen durchführen muss und somit einem erhöhten Infektionsrisiko ausgesetzt ist, so kann dies möglicherweise als fahrlässige Körperverletzung angesehen werden- nach Definition von $§ 229$ des Strafgesetzbuches-, da sich der Patient der erhöhten Infektionsgefahr für den Arzt bewusst war (BGBI I 1998, S. 3322). Zusammenfassend lässt sich sagen, dass die rechtliche Grundlage in Deutschland schwer zu fassen ist und interindividuell entschieden werden muss.

Da es für den Patienten keine rechtlich bindende Vorschrift gibt, seinen Infektionsstatus offenzulegen, aber dennoch das medizinische Personal ein Recht auf körperliche Unversehrtheit hat, erscheint es somit auch aus juristischer Sicht vernünftig vertretbar ein Screening durchzuführen, um sowohl Rechte des Patienten aber auch des Personals zu wahren.

Bei Einlieferung eines Patienten in die unfallchirurgische Notaufnahme kommt es im Rahmen der Anamneseerhebung zur Entnahme von Blut, wenn weiterführende diagnostische bzw. operative Maßnahmen zu erwarten sind. Das heißt, dass sich der behandelnde Arzt zu diesem Zeitpunkt bereits Gedanken zur weiteren Versorgung machen muss. Im Schnitt erhält der zuständige Arzt 49,7 \pm 5,6 Minuten nach Abnahme des Bluts Informationen, seitens der klinischen Chemie, über den Infektionsstatus des Patienten (Dresing et al. 2003). Zurzeit liegt dieses Intervall bei 34,3 \pm 4,9 Minuten. Zu diesem Zeitpunkt ist bereits die Diagnostik durch den Unfallchirurgen abgeschlossen. Damit steht eigentlich auch eine geplante Behandlungsmaßnahme fest. Von lebensnotwendigen Soforteingriffen abgesehen, liegt die Information über den Infektionsstatus innerhalb eines Zeitraumes, der für die Operationsvorbereitung üblicherweise veranschlagt wird, dem behandelnden Arzt vor. Eine reaktive Infektionsdiagnose dient nunmehr nicht dazu, dem Patienten die notwendige Behandlung vorzuenthalten, sondern möglicherweise eine für Personal und Patienten sicherere Behandlungstechnik zu wählen, um so die Übertragungswahrschein- 
lichkeit einer Infektion zu verringern. Dazu zählt auch, dass im Operationssaal spezielle Vorsichtsmaßnahmen getroffen werden, wie beispielsweise das Tragen von zwei Paar Handschuhen übereinander. Auch wird davon abgesehen, minimalinvasiv zu arbeiten, und sich möglicherweise beim Tasten von Frakturstückchen in minimal inzidierten Bereichen an Knochenfragmenten zu verletzen und somit Handschuh und Haut zu perforieren. Die offen chirurgische Therapie mit freier Sicht auf das Operationsgebiet sollte bevorzugt werden. In keinster Weise erfolgt eine minderwertige Behandlung und somit Benachteiligung oder Stigmatisierung des Patienten.

Auch bei Bekanntwerden eines reaktiven Infektionsstatus darf und wird keine erforderliche Therapie unterlassen werden, jedoch wird jede Indikation sorgfältig überprüft und unerlässliche Maßnahmen zum Schutz von Patient und Personal ergriffen. Dazu gehören kontrollierte OP-Bedingungen im Sinne von Übergabe des OP-Materials nur unter Sichtkontakt, erforderliche Schutzkleidung wie Schutzbrillen und Doppel-Handschuhverfahren (Dresing et al. 2005).

Konsequenzen der Kenntnis des Infektionsstatus bei Verletzungen der oberen Extremitäten

Bei den Verletzungen der oberen Extremitäten wurden 40 statt 44 Verletzungen operativ versorgt und 12 statt zwei konservativ behandelt. Die sechs auf beide Arten behandelbaren Verletzungen wurden alle konservativ versorgt. Analysiert man die Literatur, so ergibt sich, dass sowohl proximale Humerusfrakturen als auch distale Radiusfrakturen mit konservativer Therapie mit gutem Ergebnis behandelt werden können. So zeigten Krettek und Wiebking, dass die Langzeitergebnisse bei konservativer Behandlung der proximalen Humerusfraktur nicht hinter der operativen Therapie zurückstehen (Krettek und Wiebking 2011). In einer Multi-Center-Studie konnte nachgewiesen werden, dass die nicht-operative Therapie von distalen Radiusfrakturen in vielen Items gleichwertig zur operativen Therapie ist (Bartl et al. 2014). Das Spektrum der Indikationen besteht auch leitlinienkonform häufig sowohl aus konservativen als auch operativen Behandlungsoptionen. Das Pendel bei der Abwägung zum operativen als auch nicht-operativen Verfahren kann aufgrund des nachgewiesenen Infektionsstatus mehr zum konservativen Vorgehen schlagen, was aber in keinster Weise gegen medizinische Standards verstößt. Somit ergibt 
sich, dass vier Verletzungen, für die bei objektiver und retrospektiver Betrachtung Operationsindikation bestanden hätte, konservativ behandelt wurden. Dies ergibt ein Verhältnis von 3,33:1 für Operationen zu konservativer Behandlung bei Betrachtung der Verletzungen an der oberen Extremität.

Konsequenzen der Kenntnis des Infektionsstatus bei Verletzungen der unteren Extremität

Bei Verletzungen der unteren Extremität wären 92 Verletzungen operativ zu behandeln gewesen, für zehn Verletzungen hätten beide Optionen bestanden und eine Verletzung hätte konservativ behandelt werden können. Es ergab sich, dass bis auf eine Verletzung alle Verletzungen mit beiden Behandlungsmöglichkeiten operativ versorgt wurden. Von den operativ zu versorgenden Fällen wurden vier Verletzungen konservativ versorgt. Es ergibt sich ein Verhältnis von ca.16:1 bei Betrachtung der unteren Extremität. Dies bedeutet: alle indizierten und notwendigen Operation wurden durchgeführt.

Im Vergleich zur Standardversorgung zeigt sich für die obere Extremität ein Shift zur eher konservativen Therapie bei 9\% der infizierten Patienten.

Bei Verletzungen der unteren Extremität war dieser Trend nicht festzustellen. Hier gab es im Gegenteil einen Shift zur operativen Therapie.

Es zeigte sich somit, dass alle Eingriffe, die als mobilitätserhaltende Eingriffe anzusehen waren, eher operativ behandelt wurden und Eingriffe an den oberen Extremitäten im Verhältnis eher konservativ behandelt wurden.

Allgemeine Konsequenzen für die Arbeitssicherheit

Für Göttingen ergibt sich die Konsequenz, dass Patienten, die einen reaktiven Status haben, immer selbstverständlich auch notfallmäßig behandelt werden. Es werden alle nötigen Eingriffe durchgeführt, aber maximale Schutzmaßnahmen ergriffen und riskante Techniken vermieden, Operationen werden auf höchster Sicherheitsstufe durchgeführt. Dies beinhaltet immer Augenschutz, Doppel-Layering-Verfahren bei Handschuhen (Indikatorsystem) und wasserdichte OP-Kleidung. Die Übergabe 
der OP-Instrumente erfolgt nach dem 4-Augen-Prinzip, d.h. dass der Operateur die Instrumente erst nach klarem Augenkontakt der Schwester überreicht und anders herum. Es findet keine Jet-Lavage statt und es sollten keine minimalinvasiven Verfahren angewandt werden, bei denen die Knochen mit Fingern abgetastet werden.

Diese Verletzungen müssen sehr oft unfallchirurgisch im Rahmen von Operationen oder Wundversorgungen behandelt werden. Das Augenmerk der vorliegenden Dissertation lag auf Frakturen und Verletzungen, die weitere operative Versorgungen nach sich zogen. Dazu zählten auch nötige Metallentfernungen. Somit war eine Filterung der Verletzungen der oberen Extremitäten nötig.

\section{Auswertung der Daten des Betriebsärztlichen Dienstes}

Anhand der Zahlen seitens des Betriebsärztlichen Dienstes lässt sich feststellen, dass es innerhalb von elf dokumentierten Jahren zu 2385 Stichverletzungen beim medizinischen Personal gekommen ist. Im Durchschnitt waren dies 218,18 Verletzungen pro Jahr (179-286). Unter dem betroffenen Personal befanden sich zu 44,40\% ärztliches Personal (Ärzte, Studenten im Praktischen Jahr und Medizin- und Zahnmedizinstudenten) sowie zu 30,26\% pflegerisch tätiges Personal (OP-Personal, examinierte Pflegekräfte und Krankenpflegeschüler). Die Unterteilung in Studenten im praktischen Jahr und „normalen“ Studenten wurde vermutlich unternommen, um zu verdeutlichen, dass ein Teil der Studenten bereits am Ende der Ausbildung standen und für die Tätigkeit an der Universitätsmedizin angestellt waren. Bei 1058 Stichverletzungen bei ärztlichem Personal verletzten sich pro Jahr durchschnittlich 105,8 Personen (56-134) und bei pflegerisch tätigem Personal 72,1 Personen pro Jahr (721, 50-105). Zusammengefasst ergibt dies 177,9 Verletzungen pro Jahr. Es ergibt sich, dass unter den bekannten Serologien der Indexpatienten bzw. Spender eine infektiöse Serologie mit einem Mittelwert von 10,92\% vorlag, unbekannte Serologien mit möglicher Infektion nicht eingerechnet. Es ergibt sich, bezogen auf alle infektiösen Stichverletzungen ein Wert von 8,2\%. Hieraus lässt sich Schlussfolgern, dass die Belegschaft eher dazu neigt, Vorfälle zu melden, bei denen ein positiver Infektionsstatus bereits bekannt ist. Von durchschnittlich 177,9 Verletzungen jährlich innerhalb des Klinikums könnten somit bis zu 15 Personen betroffen sein. 
Beachtet man die Anzahl der Verletzungsmeldungen 2014 in Bezug auf die zum Stichtag 2015 angestellten Personen, so ergibt sich, dass unter den Ärzten und Studenten im Praktischen Jahr sich im Durchschnitt jeder 10. einmal im Jahr an einem möglicherweise kontaminierten Gegenstand verletzt.

Unter den häufigsten Ursachen für Verletzungen führten das Skalpell und die Nahtnadeln. Dies verdeutlicht, dass gerade operativ tätiges Personal einer erhöhten Gefahr für blutübertragbare Krankheiten ausgesetzt ist. Jährlich gibt es im Schnitt 31,78 Verletzungen durch Skalpelle und 30,44 Verletzungen durch die Verwendung von Nahtnadeln. OP-Personal steht an fünfter Stelle der Verletzungen mit jährlich ca. 13,9 Meldungen (Betriebsmedizin Göttingen 2016).

Nach Überprüfen der Patientenserologie und des Impfstatus des Mitarbeiters können weitere Maßnahmen in die Wege geleitet werden (Himmelreich et al. 2013).

\section{Gesamtschlussfolgerung}

Schlussendlich stellt sich die Frage, ob das Screeningverfahren der unfallchirurgischen Patienten aus medizinischer Sicht gerechtfertigt, rechtlich vertretbar und aus gesundheitsökonomischer Sicht sinnvoll ist. Aufgrund der vorliegenden Daten kann die Schlussfolgerung gezogen werden, eine standardisierte Testung zu empfehlen. In Anbetracht dessen, dass 10,92\% der bekannten Serologien nach Stichverletzungen positiv für eine Infektionskrankheit waren und sich im Durchschnitt jährlich 10\% der Ärzte und Studenten im Praktischen Jahr verletzen, so kann durch frühzeitiges Screening der Patienten eine Infektionsgefahr minimiert werden. Allerdings steht hier auch zur Diskussion, ob und wann Personal nach einer Stichverletzung beim betriebsärztlichen Dienst vorstellig wurde. Hofmann et al. schlussfolgerten 2002, dass es bei bis zu $90 \%$ von Verletzungen nicht zu einer Meldung kommen würde (Hofmann et al. 2002). Bei bekannter Serologie mit nachgewiesener Infektion gibt man eine Verletzung eher an, als wenn bewusst ist, dass der Indexpatient eine negative Serologie hatte. Bei gänzlich unbekannter Serologie des Spenders erfolgt eine Untersuchung des Personals, um etwaige Folgen der Verletzungen zu minimieren.

Auch der Patient hingegen profitiert durch das Screening von einer frühzeitigen Entdeckung seiner Infektion, bei unbekannter Erkrankung, noch vor Eintritt möglicher 
Symptome und kann somit einer früheren medizinischen Therapie zugeführt werden. Bedenkt man, dass Göttingen im Vergleich zur deutschlandweiten Prävalenz für Hepatitis C im Schnitt einen achtfach erhöhten Wert aufweist, so sollte durch Screeningmethoden die Möglichkeit einer Übertragung, durch frühzeitiges Bewusstwerden des Infektionsstatus, verhindert werden. Allerdings muss hier aber wieder in Betracht gezogen werden, dass für die Darstellung dieser Werte unterschiedliche Maßstäbe herangezogen wurden. Die Werte der Universitätsmedizin Göttingen werden anhand eines Patientenklientels ohne fest definiertes Einzugsgebiet erhoben, dessen Alter und Risikopotential nicht selektiert wird. Das bedeutet, dass ein Altersbereich von 0,175 Jahren bis zu einem Höchstalter von 102,45 Jahren in Betracht einer möglichen Hepatitis-C-Infektion gezogen wurde, auch mit Herkunft aus anderen Ländern. Die bereits erwähnte DEGS1-Studie bezog Ihre Hepatitis-C-Prävalenz-Werte auf einen Altersbereich von 18-79 Jahren, bei einer in Deutschland lebenden repräsentativen Querschnittprobe durch die Bevölkerung (Kamtsiuris et al. 2013). Zudem wurden Blutentnahmen in der unfallchirurgischen Notaufnahme nur dann angefordert, wenn es zu einer möglicherweise weiterführenden Behandlung, wie einer Operation, hätte kommen können. Patienten, die nicht unter diese Voraussetzungen fielen, bekamen somit kein Screening. Damit besteht die Möglichkeit einer Abweichung der erhobenen Daten für Hepatitis $C$ in Göttingen. Gleiches gilt für Infektionen mit Hepatitis B und HIV.

In Bezug auf die rechtlichen Aspekte der Blutentnahme gilt der Hinweis, dass Patienten im Vorfeld über das Screening aufgeklärt wurden, wobei sich ein nahezu hundertprozentiges Einverständnis zeigte. Bei bewusstlosen oder nicht einwilligungsfähigen Patienten wurde von einem mutmaßlichen Einverständnis im Sinne einer frühzeitigen Erkennung und der Möglichkeit einer schnellstmöglichen Behandlung, noch vor Auftreten erster Symptome, ausgegangen.

In den USA wird von Seiten der U.S. Preventive Services Task Force eine Empfehlung für HIV-Screenings bei Personen im Alter von 15-65 Jahren ausgesprochen. Bei gegebenem Anlass auch bei jüngeren oder älteren Personen mit Risikoprofil (Moyer 2013).

Zusammenfassend lassen sich zahlreiche positive Aspekte für ein generelles Screening auf HIV, Hepatitis B und C sammeln. Bei positivem Testergebnis verrin- 
gert sich ein mögliches Übertragungsrisiko von Patient auf Personal durch Bewusstheit des Status. Darüber hinaus ermöglicht dem Chirurgen ein positives Testergebnis eine Therapieentscheidung über konservative oder operative Versorgung und es können suffiziente Schutzmaßnahmen für das operativ tätige Personal ergriffen werden. Im Falle einer Nadelstichverletzung des Personals kann direkt auf die Serologie des Indexpatienten geschlossen werden und sofortige Maßnahmen können ergriffen werden. Im Weiteren kann dem Patienten durch ein positives Ergebnis bei unbekanntem Infektionsstatus frühzeitig eine adäquate Behandlung empfohlen werden.

Bei deutlich überwiegenden Vorteilen des Screenings, gestützt durch die positiven Erfahrungen aus 14 Jahren Infektionsstatuserhebung an der Universitätsmedizin Göttingen, kann abschließend ein standardisiertes Screening generell empfohlen werden. Bei vertretbarer finanzieller Belastung der Klinik konnte ein erheblich verbesserter Personalschutz bei gleichzeitigem medizinischen Benefit für die Patienten erreicht werden. Das Göttinger Modell kann Kliniken, die bisher kein Screeningprogramm durchführen, als Beispiel dienen. Die Qualitätssicherungsmaßnahme „Gesundheitsschutz für das Personal“" kann damit als erfolgreich eingestuft werden. 


\section{Zusammenfassung}

HIV, Hepatitis B und Hepatitis C sind auch heutzutage noch ernstzunehmende Infektionskrankheiten, die über Blut und weitere Körperflüssigkeiten durch Kontakt übertragbar sind.

Es sollte der vorbeugende Gesundheitsschutz für pflegerisches und ärztliches Personal evaluiert werden. Des Weiteren wurde überprüft, wie Behandlungsabläufe von Verletzungen und Frakturen bei Vorliegen einer reaktiven Blutprobe geändert werden können, ohne die Qualität der Versorgung zu vernachlässigen, um für Patienten und Personal größtmögliche Sicherheit vor Übertragung von Infektionskrankheiten bieten zu können.

Von Oktober 2001 bis Januar 2015 wurden alle Patienten der unfallchirurgischen Notaufnahme der Universitätsmedizin Göttingen per Schnelltest auf die Infektionskrankheiten HIV, Hepatitis B und C gescreent. Ebenso wurden Arbeitsunfälle und Stichverletzungen an der Universitätsmedizin Göttingen untersucht, kategorisiert und analysiert.

Die Ergebnisse der Screeningverfahren der 18569 Blutproben wurden nach Infektions-, Verletzungs- und Behandlungsart sortiert, analysiert und einer umfassenden statistische Auswertung unterzogen. Insbesondere wurde dabei überprüft, ob ein bekannter reaktiver Status ein anderes Therapieregime nach sich zog. Die Arbeitsunfälle wurden nach Material, durch welches die Verletzung entstand, und betroffenes Personal gegliedert.

Unter den 18569 Blutproben des Screeningverfahrens waren 593 (3,19\%) der Entnahmen reaktiv für eine oder mehrere Infektionskrankheiten. Davon gab es an Monoinfektionen 465 Hepatitis-C-Infektionen, 84 Hepatitis-B-Infektionen und 14 HIVInfektionen. Bei den Arbeitsunfällen erfolgten die häufigsten Verletzungsmeldungen durch Ärzte und examinierte Pflegekräfte. Die meisten der Verletzungen erfolgten hierbei an Skalpellen und Nahtnadeln.

Es zeigte sich eine Kosteneffizienz für das Screeningverfahren an der Universitätsmedizin Göttingen, und ein standardisiertes Screening kann generell empfohlen werden. Es konnte ein verbesserter Personalschutz bei gleichzeitigem medizinischen Benefit für die Patienten erreicht werden. 


\section{Literaturverzeichnis}

Abbott Laboratories (2009): Beschreibung ARCHITECT Anti-HCV: Überarbeitung Oktober 2009, REF $6 \mathrm{C} 37$

Abbott Laboratories (2011a): Beschreibung ARCHITECT HIV Ag/Ab Combo: Überarbeitung Februar 2011, REF 4J27

Abbott Laboratories (2011b): Beschreibung ARCHITECT HbsAg Qualitative II: Überarbeitung Mai 2011, REF 2 G22

Baggaley RF, Boily M-C, White RG, Alary M (2006): Risk of HIV-1 transmission for parenteral exposure and blood transfusion: a systematic review and meta-analysis. AIDS $\underline{20}$, 805-812

Barasa SS (2011): True story about HIV: theory of viral sequestration and reserve infection. HIV AIDS (Auckl) $\underline{3}, 125-133$

Bartl C, Stengel D, Bruckner T, Gebhard F (2014): The treatment of displaced intra-articular distal radius fractures in elderly patients. Dtsch Arztebl Int $\underline{111}$,779-787

Becker N (2002): Screening aus epidemiologischer Sicht. Radiologe 42, 592-600

Berger A, Sturmer M, Doerr HW (2012): Case report: risk of virus infection after accidental blood inoculation from a multi-infected AIDS patient. J Med Virol $\underline{84}, 897-900$

Betriebsmedizin Göttingen (2016): Daten aus dem Programm BASIS der Betriebsärzlichen Abteilung, Universitätsmedizin Göttingen

BGBI I (1998) S.3322: Strafgesetzbuch (StGB). Strafgesetzbuch in der Fassung der Bekanntmachung vom 13. November 1998 (BGBI. I S. 3322), das zuletzt durch Artikel 1 des Gesetzes vom 1. März 2017 (BGBI. I S. 386) geändert worden ist

BGBI I (2002) S.42, 2909; 2003 I S.738: Bürgerliches Gesetzbuch (BGB): Bürgerliches Gesetzbuch in der Fassung der Bekanntmachung vom 2. Januar 2002 (BGBI. I S. 42, 2909; 2003 I S.738), das zuletzt durch Artikel 2 des Gesetzes vom 21. Februar 2017 (BGBI. I S. 258) geändert worden ist

BGBI I (2013) S. 2514: Verordnung über Sicherheit und Gesundheitsschutz bei Tätigkeiten mit Biologischen Arbeitsstoffen (Biostoffverordnung -BioStoffV. Biostoffverordnung vom 15. Juli 2013 (BGBI. I S. 2514), die zuletzt durch Artikel 146 des Gesetzes vom 29. März 2017 (BGBI. I S. 626) geändert worden ist

BGBI III (1949) GI 100-1: Grundgesetz für die Bundesrepublik Deutschland. Grundgesetz für die Bundesrepublik Deutschland in der im Bundesgesetzblatt Teil III, Gliederungsnummer 100-1, veröffentlichten bereinigten Fassung, das zuletzt durch Artikel 1 des Gesetzes vom 23. Dezember 2014 (BGBI. I S. 2438) geändert worden ist

Bundesärztekammer (2016): Richtlinie gemäß § 16 Abs. 1 S. 1 Nrn. 2 u. 5 TPG für die Wartelistenführung und Organvermittlung zur Lebertransplantation. Dtsch Arztebl 113: A-1947 / B-1635 / C1623 [http://www.bundesaerztekammer.de/fileadmin/user_upload/downloads/pdf-Ordner/RL/RiliOrgaWIOvLeberTx2016042122.pdf]

Bundesgesundheitsblatt Hepatitis-B-Virus (HBV) (2000): Stellungnahmen des Arbeitskreises Blut des Bundesministeriums für Gesundheit. Bundesgesundheitsbl- Gesundheitsforsch- Gesundheitsschutz $\underline{43}, 240-248$ 
Centers for Disease Control (CDC) (1992): 1993 revised classification system for HIV infection and expanded surveillance case definition for AIDS among adolescents and adults. MMWR Recomm Rep $41,1-19$

Chan DC, Kim PS (1998): HIV Entry and Its Inhibition. Cell 93, 681-684

Cornberg M, Protzer U, Petersen J, Wedemeyer H, Berg T, Jilg W, Erhardt A, Wirth S, Sarrazin C, Dollinger MM et al. (2011): Aktualisierung der S 3-Leitlinie zur Prophylaxe, Diagnostik und Therapie der Hepatitis-B-Virusinfektion. Z Gastroenterol 49, 871-930

Davies CG, Khan MN, Ghauri ASK, Ranaboldo CJ (2007): Blood and body fluid splashes during surgery--the need for eye protection and masks. Ann R Coll Surg Engl 89, 770-772

Deterding K (2014): Berufsausübung von Virusträgern. HepNetJournal $\underline{8}, 8-9$

Deutsche Aids-Gesellschaft e.V (2014): Deutsch-Österreichische Leitlinien zur antiretroviralen Therapie der HIV-Infektion (konsentierte Version 2014): Version 1.0, 13.5.2014

Deutsche Gesetzliche Unfallversicherung (2010): Handlungsanleitung für die arbeitsmedizinische Vorsorge nach dem Berufsgenossenschaftlichen Grundsatz G 42 „Tätigkeiten mit Infektionsgefährung" (DGUV Information 504-42)

Dresing K, Pouwels C, Bonsack S, Oellerich M, Schwörer H, Uy A, Stürmer KM (2003): HCV-, HBVund HIV-Infektionen: Gefahren für Arzt und Pflegepersonal. Chirurg $\underline{74}$, 1026-1033

Dresing K, Lumpp B, Stürmer K (2005): Prävention von Verletzungen und Erkrankungen im OP. OPJournal $\underline{21}, 28-37$

DVV (2007): Empfehlungen der Deutschen Vereinigung zur Bekämpfung der Viruskrankheiten (DVV) zur Prävention der nosokomialen Übertragung von Hepatitis B Virus (HBV) und Hepatitis C Virus (HCV) durch im Gesundheitswesen Tätige 2007

Eckman MH, Kaiser TE, Sherman KE (2011): The Cost-effectiveness of Screening for Chronic Hepatitis B Infection in the United States. Clin Infect Dis $\underline{52}$, 1294-1306

Engelman A, Cherepanov P (2012): The structural biology of HIV-1: Mechanistic and therapeutic insights. Nat Rev Micro $\underline{10}$, 279-290

Fink B, Landthaler M, Hafner C (2011): Hautveränderungen durch Missbrauch illegaler Drogen. J Dtsch Dermatol Ges $\underline{9}, 633-638$; quiz 639

Fleig WE, Krummener P, Lesske J (2004): Indikationsstellung akute/ chronische Hepatitis C. Z Gastroenterol $\underline{42}, 707-713$

Fry DE (1993): Occupational risks of infection in the surgical management of trauma patients. Am J Surg 165, 26

Fry DE (2005): Occupational blood-borne diseases in surgery. Am J Surg 190, 249-254

Fuchs T, Rottbeck U, Hofbauer V, Raschke M, Stange R (2011): Beckenringfrakturen im Alter. Die unterschätzte osteoporotische Fraktur. Unfallchirurg $\underline{114}$, 663-670

Geiss HK (1998): Empfehlungen für chirurgische Therapieplanung und Eingriffe bei Patienten mit AIDS. Chirurg $\underline{69}, 503-510$

Gerlich WH (2004): Hepatitis B und C. Übertragungsgefahr auf Patienten durch infiziertes medizinisches Personal. Bundesgesundheitsbl- Gesundheitsforsch- Gesundheitsschutz $\underline{47}$, 369-378 
Girke J, Wedemeyer H, Wiegand J, Manns MP, Tillmann HL (2008): Akute Hepatitis B: Ist eine antivirale Therapie indiziert? Zwei Fallberichte. Dtsch Med Wochenschr 133, 1178-1182

Grandt D, Schubert I: Arzneimittelreport 2016: Analysen zur Arzneimitteltherapie und Arzneimittelsicherheit. Schriftenreihe zur Gesundheitsanalyse Band 39. BARMER GEK, Berlin 2016

Grimm D, Thimme R, Blum HE (2011): HBV life cycle and novel drug targets. Hepatol Int $\underline{5}, 644-$ 653

Hadem J, Wedemeyer H, Manns MP (2004): Hepatitis als Reisekrankheit. Internist (Berl) $\underline{45}$, 655668

Hahné SJM, Veldhuijzen IK, Wiessing L, Lim T-A, Salminen M, van de Laar M (2013): Infection with hepatitis $B$ and $C$ virus in Europe: a systematic review of prevalence and cost-effectiveness of screening. BMC Infect Dis $\underline{13}, 181$

Hasselhorn H-M, Hofmann F (2000): Übertragung von HBV, HCV und HIV durch infektiöses medizinisches Personal - eine Übersichtsdarstellung. Chirurg 71, 389-395

Hatzakis A, Wait S, Bruix J, Buti M, Carballo M, Cavaleri M, Colombo M, Delarocque-Astagneau E, Dusheiko G, Esmat G et al. (2011): The state of hepatitis B and C in Europe: report from the hepatitis B and C summit conference*. J Viral Hepat 18 Suppl 1, 1-16

Heininger A, Frank U, Schnitzler P (2015): Maßnahmen zum Schutz vor kontaktübertragenen Virusinfektionen. Krankenh.hyg. up2date 09, 233-253

Hildt E, Bleifuß E, Brandenburg B, Bürckstümer T, Foerste R, Hillemann A, Huser H, Kriegs M, Löffelbein F, Malkowski B et al. (2003): Molekulare Virologie am Beispiel des Hepatitis-B-Virus. Bundesgesundheitsbl- Gesundheitsforsch- Gesundheitsschutz $\underline{46}$, 508-513

Himmelreich H, Rabenau HF, Rindermann M, Stephan C, Bickel M, Marzi I, Wicker S (2013): The management of needlestick injuries. Dtsch Arztebl Int 110, 61-67

Hoffmann C, Rockstroh JK (Hrsg.): HIV 2011. Medizin Fokus Verlag, Hamburg 2011

Hofmann F (2015): Zur nosokom Übertragung von Hep B C und HIV durch HCW. ASU Arbeitsmed Sozialmed Umweltmed $\underline{50}$,439-445

Hofmann F, Kralj N, Beie M (2002): Kanülenstichverletzungen im Gesundheitsdienst- Häufigkeit, Ursachen und Präventionsstrategien. Gesundheitswesen 64, 259-266

Hugle T, Fehrmann F, Bieck E, Kohara M, Krausslich HG, Rice CM, Blum HE, Moradpour D (2001): The hepatitis $C$ virus nonstructural protein $4 B$ is an integral endoplasmic reticulum membrane protein. Virology $\underline{284}, 70-81$

Jilg W (2000): Epidemiologie, Diagnostik und Prophylaxe der Virushepatitiden. Chirurg $\underline{71}$, 374380

Joint Working Party (1992): Risks to surgeons and patients from HIV and hepatitis: guidelines on precautions and management of exposure to blood or body fluids. Joint Working Party of the Hospital Infection Society and the Surgical Infection Study Group. BMJ 305, 1337-1343

Kamradt T, Ferrari-Kühne K (2011): Das adaptive Immunsystem. Dtsch Med Wochenschr $\underline{136}$, 1678-1683 
Kamtsiuris P, Lange M, Hoffmann R, Schaffrath Rosario A, Dahm S, Kuhnert R, Kurth BM (2013): Die erste Welle der Studie zur Gesundheit Erwachsener in Deutschland (DEGS1): Stichprobendesign, Response, Gewichtung und Repräsentativität. Bundesgesundheitsbl $\underline{56}, 620-630$

Kirsch B, Klinker H, Huber R (2011): HIV in der Gefäßchirurgie. Gefässchirurgie 16, 38-43

Kojima Y, Ohashi M (2005): Unnoticed glove perforation during thoracoscopic and open thoracic surgery. Ann Thorac Surg 80, 1078-1080

Krettek C, Wiebking U (2011): Proximale Humerus Fraktur: ist die winkelstabile Plattenosteosynthese der konservativen Behandlung überlegen? Unfallchirurg 114, 1059-1067

Krueger A, Frink M, Kiessling A, Ruchholtz S, Kühne CA (2013): Schockraummanagement. Chirurg 84, 437-450

Kwong PD, Wyatt R, Robinson J, Sweet RW, Sodroski J, Hendrickson WA (1998): Structure of an HIV gp120 envelope glycoprotein in complex with the CD4 receptor and a neutralizing human antibody. Nature $\underline{393}, 648-659$

Laine T, Aarnio P (2004): Glove perforation in orthopaedic and trauma surgery. A comparison between single, double indicator gloving and double gloving with two regular gloves. J Bone Joint Surg $\mathrm{Br} \underline{86}, 898-900$

Lauer GM, Walker BD (2001): Hepatitis C virus infection. N Engl J Med 345, 41-52

Lavanchy D (2009): The global burden of hepatitis C. Liver Int 29 Suppl 1, 74-81

Li HC, Lo SY (2015): Hepatitis C virus: Virology, diagnosis and treatment. World J Hepatol 7 , 13771389

Long EF, Mandalia R, Mandalia S, Alistar SS, Beck EJ, Brandeau ML, Caylà JA (2014): Expanded HIV Testing in Low-Prevalence, High-Income Countries: A Cost-Effectiveness Analysis for the United Kingdom. PLoS ONE $\underline{9}$, e95735

Marcus U, Rockstroh J, Schmidt RE (2010): HIV-Testung: Empfehlungen zur Verbesserung der aktuellen Situation. Ergebnisse eines Expertenworkshops. Dtsch Med Wochenschr 135, 1201-1202

Mauritz W (1998): Der polytraumatisierte Patient. I. Anasthesiol Intensivmed Notfallmed Schmerzther $\underline{33}$, 441-456

Mischke C, Verbeek JH, Saarto A, Lavoie MC, Pahwa M, ljaz S (2014): Gloves, extra gloves or special types of gloves for preventing percutaneous exposure injuries in healthcare personnel.

Cochrane Database of Syst Rev, CD009573

Mohd Hanafiah K, Groeger J, Flaxman AD, Wiersma ST (2013): Global epidemiology of hepatitis C virus infection: new estimates of age-specific antibody to HCV seroprevalence. Hepatology $\underline{57}$, 1333-1342

Moyer VA (2013): Screening for HIV: U.S. Preventive Services Task Force Recommendation Statement. Ann Intern Med 159, 51-60

Müller JH (2008): Elektronische Patientenakte: Schlüsselrolle für den Datenschutz. Dtsch Arztebl $\underline{105}(11)$, A $571-573$

Nyblade L, Stangl A, Weiss E, Ashburn K (2009): Combating HIV stigma in health care settings: what works? J Int AIDS Soc $\underline{12}, 15$ 
Offergeld R, Stark K, Hamouda O (2003): Infektionen bei Blutspendern. Bundesgesundheitsbl- Gesundheitsforsch- Gesundheitsschutz $\underline{46}, 775-779$

Peliska J, Benkovic S (1992): Mechanism of DNA strand transfer reactions catalyzed by HIV-1 reverse transcriptase. Science $\underline{258}, 1112-1118$

Plettenberg A, Dettke T, Meigel W (1990): Klinik und Therapie des HIV-assoziierten Kaposi-Sarkoms. Dtsch Med Wochenschr $\underline{115}, 106-113$

Poethko-Müller C, Zimmermann R, Hamouda O, Faber M, Stark K, Ross RS, Thamm M (2013): Die Seroepidemiologie der Hepatitis A, B und C in Deutschland: Ergebnisse der Studie zur Gesundheit Erwachsener in Deutschland (DEGS1). Bundesgesundheitsbl $\underline{56}, 707-715$

Popejoy SL, Fry DE (1991): Blood contact and exposure in the operating room. Surg Gynecol Obstet $\underline{172}, 480-483$

Potthoff A, Brockmeyer N (2007): HIV-Infektion 2007. Med Klin (Munich) 102, 531-539

Rabenau HF, Gottschalk R, Gürtler L, Haberl AE, Hamouda O, Himmelreich H, Korn K, Mertens T, Schmidt KW, Schmiedel S et al. (2012): Prävention der nosokomialen Übertragung von humanem Immunschwächevirus (HIV) durch HIV-positive Mitarbeiterinnen und Mitarbeiter im Gesundheitswesen. Empfehlungen der Deutschen Vereinigung zur Bekämpfung der Viruskrankheiten (DVV) e.V. und der Gesellschaft für Virologie (GfV) e.V. Bundesgesundheitsbl $\underline{55}$, 937-943

Rabenau HF, Bannert n, Berger A, Donoso Mantke O, Eberle J, Enders M, Fickenscher H, Grunert H-P, Gürtler L, Heim A et al. (2015): Nachweis einer Infektion mit Humanem Immundefizienzvirus (HIV): Serologisches Screening mit nachfolgender Bestätigungsdiagnostik durch Antikörper-basierte Testsysteme und/oder durch HIV-Nukleinsäure-Nachweis: Stellungnahme der Gemeinsamen Diagnostikkommission der Deutschen Vereinigung zur Bekämpfung von Viruskrankheiten e. V.(DVV e. V.) und der Gesellschaft für Virologie e. V. (GfV e. V.). Bundesgesundheitsbl $\underline{58}, 877-886$

Read JS, Newell MK (2005): Efficacy and safety of cesarean delivery for prevention of mother-tochild transmission of HIV-1. Cochrane Database Syst Rev, CD005479

Richtlinie Nr.54/2000 EG, ABI. EU Nr. L 262 S. 21: Richtlinie 2000/54/EG des Europäischen Parlaments und des Rates über den Schutz der Arbeitnehmer gegen Gefährdung durch biologische Arbeitsstoffe bei der Arbeit (Siebte Einzelrichtlinie im Sinne von Artikel 16 Absatz 1 der Richtlinie 89/391/EWG). Vom 18. September 2000 (ABI. EU Nr. L 262 S. 21)

Robert Koch-Institut (Hrsg.) (2006): HIV und AIDS (Gesundheitsberichterstattung des Bundes 31); Robert Koch-Inst, Berlin 2006

Robert Koch-Institut (Hrsg.) (2007): Hepatitis C (Gesundheitsberichterstattung des Bundes 15), Nachdr; Robert Koch-Inst, Berlin 2007

Robert Koch-Institut (2014a): Berufsbedingte HIV-Infektionen in Deutschland und anerkannte Berufskrankheiten. Epid Bull 39, 385-390

Robert Koch-Institut (2014b): HIV/AIDS in Deutschland- Eckdaten der Schätzung. https://www.rki.de/DE/Content/InfAZ/H/HIVAIDS/Epidemiologie/Daten_und_Berichte/EckdatenDeutschland.pdf;jsessionid=0B3ED0A801E540C592D251181C91A16B.2_cid372?_blob=publicationFile; Zugriff am 28.07.2016 
Robert Koch-Institut (2014c): HIV/AIDS in Niedersachsen- Eckdaten der Schätzung. https://www.rki.de/DE/Content/InfAZ/H/HIVAIDS/Epidemiologie/Daten_und_Berichte/EckdatenNiedersachsen.pdf;jsessionid=0B3ED0A801E540C592D251181C91A16B.2_cid372?_blob=publicationFile; Zugriff am 28.07.2016

Robert Koch-Institut (2015a): Infektionsepidemiologisches Jahrbuch meldepflichtiger Krankheiten für 2014. Datenstand 1. März 2015. Berlin.

Robert Koch-Institut (2015b): Impfquoten bei der Schuleingangsuntersuchung in Deutschland 2013. Epid Bull 16, 131-138

Robert Koch-Institut (2015c): Virushepatitis B und D im Jahr 2014. Epid Bull 29, 271-288

Robert Koch-Institut (2015d): Hepatitis C im Jahr 2014. Epid Bull 30, 289-302

Robert Koch-Institut (2015e): Schätzung der Prävalenz und Inzidenz von HIV-Infektionen in Deutschland, Stand Ende 2014. Epid Bull 45, 475-490

Robert Koch-Institut (2016): Empfehlungen der Ständigen Impfkommission (STIKO) am Robert Koch-Institut/Stand: August 2015. Epid Bull 34, 327-362

Royce RA, Sena A, Cates W, JR, Cohen MS (1997): Sexual transmission of HIV. N Engl J Med 336, 1072-1078

Sadlowski N, Drewes J, Kleiber D (2011): Aufsuchende HIV-Test- und Beratungsangebote für MSM in Deutschland. Ergebnisse einer qualitativen Expertenbefragung (Schriftenreihe des Instituts für Prävention und psychosoziale Gesundheitsforschung Nr. 05/P11). Freie Universität Berlin.

Sarrazin C, Berg T, Buggisch P, Dollinger MM, Hinrichsen H, Hofer H, Hüppe D, Manns MP, Mauss S, Petersen J et al. (2015): Aktuelle Empfehlung zur Therapie der chronischen Hepatitis C. Z Gastroenterol $\underline{53}, 320-334$

Sarrazin U, Brodt R, Sarrazin C, Zeuzem S (2003): Postexpositionsprophylaxe nach beruflicher Exposition mit HBV, HCV und HIV. Urologe A $\underline{42}, 1497-1512$

Sarrazin U, Brodt H-R, Sarrazin C, Zeuzem S (2005): Prophylaxe gegenüber HBV, HCV und HIV nach beruflicher Exposition. Dtsch Arztebl 102, A 2234-2239 [Heft 33]

Schädler S, Hildt E (2009): HBV life cycle: entry and morphogenesis. Viruses $\underline{1}, 185-209$

Schell W (2002): Infektionsgefahr aus der Kanüle - Hepatitis-Anzeigen nehmen zu - Medizinisches Personal und Fernreisende besonders betroffen -. intensiv 10, 190-191

Schirmacher P, Fleig WE, Dienes HP (2004): Bioptische Diagnostik der chronischen Hepatitis- Ergebnisse einer evidenzbasierten Konsensuskonferenz der Deutschen Gesellschaft für Pathologie(DGP) der Deutschen Gesellschaft für Verdauungs- und Stoffwechselkrankheiten (DGVS) und des Kompetenznetzwerkes Hepatitis. Z Gastroenterol $\underline{42}$, 175-185

Schulze-Röbbecke R (2006): Prävention der intraoperativen HBV-, HCV- und HIV-Übertragung. Krankenh.hyg. up2date 1, E1-E18

Seeger C, Mason WS (2000): Hepatitis B Virus Biology. Microbiol Mol Biol Rev $\underline{64}$, 51-68

Sharp PM, Bailes E, Chaudhuri RR, Rodenburg CM, Santiago MO, Hahn BH (2001): The origins of acquired immune deficiency syndrome viruses: where and when? Philos Trans R Soc Lond B, Biol Sci $\underline{356}, 867-876$ 
Shepard CW, Simard EP, Finelli L, Fiore AE, Bell BP (2006): Hepatitis B virus infection: epidemiology and vaccination. Epidemiol Rev $\underline{28}, 112-125$

Sitzmann F (2014): Keime im Keim ersticken. intensiv 22, 123-129

Sundaram RO, Parkinson RW (2007): Universal precaution compliance by orthopaedic trauma team members in a major trauma resuscitation scenario. Ann R Coll Surg Engl $\underline{89}, 262-267$

Sundaram V, Kowdley K (2015): Management of chronic hepatitis B infection. BMJ 351, h4263

Thomas S, Agarwal M, Mehta G (2001): Intraoperative glove perforation--single versus double gloving in protection against skin contamination. Postgrad Med J $\underline{77}, 458-460$

Thurau K, Friedrich A, Schleicher C, Senninger N (2010): Krankenhaushygiene - Teil der modernen Patienten- und Personalsicherheit. Allg Viszeralchir up2date $\underline{4}$, 313-324

UNAids (2016): Fact Sheet. http://www.unaids.org/sites/default/files/media_as-

set/20150901_FactSheet_2015_en.pdf; Zugriff am 27.07.2016

Unfallchirurgie Göttingen (2017): Leistungs-Kennzahlen Klinik für Unfallchirurgie, Orthopädie, Plastische Chirurgie. http://cuop-umg.de/klinik/ueber-uns; Zugriff am 19.04.2017

van Sighem A, Gras L, Reiss P, Brinkman K, Wolf F de (2010): Life expectancy of recently diagnosed asymptomatic HIV-infected patients approaches that of uninfected individuals. AIDS $\underline{24}, 1527-$ 1535

Vogel M, Schwarze-Zander C, Wasmuth JC, Sprengler U, Sauerbruch T, Rockstroh J (2010): Therapie der HIV-Infektion. Dtsch Arztebl Int 2010; 107(28-29): 507-516, 2010

Wedegärtner U, Lorenzen M, Nagel HD, Weber C, Adam G (2004): Radiologische Bildgebung beim Polytrauma: Dosisvergleich von Ganzkörper MSCT-und konventionellem Röntgen mit organspezifischer CT. Rofo $176,1039-1044$

Wild C, Dellinger J (2013): HIV-Testung an der Allgemeinbevölkerung. Internationale Empfehlungen und reale Risken für HIV-Infektionen für Gesundheitsberufe. Wien Med Wochenschr 163 , 519-527

World Health Organization (2015): Hepatitis C in the WHO European Region Fact Sheet July 2015. http://www.euro.who.int/_data/assets/pdf_file/0010/283357/fact-sheet-en-hep-c.pdf?ua=1; Zugriff am 29.07.2016

World Health Organization (2016a): Hepatitis B Fact sheet Updated July 2016. http://www.who.int/mediacentre/factsheets/fs204/en/; Zugriff am 29.07.2016

World Health Organization (2016b): Hepatitis C Fact Sheet Updated July 2016. http://www.who.int/mediacentre/factsheets/fs164/en/; Zugriff am 29.07.2016

World Health Organization (2016c): HIV/AIDS Fact Sheet Updated July 2016. http://www.who.int/mediacentre/factsheets/fs360/en/; Zugriff am 27.07.2016 


\section{Anhang}

\subsection{Abkürzungsverzeichnis}

\begin{tabular}{ll} 
AIDS & acquired immune deficiency syndrome \\
Anti-HBc & HBc-Antikörper \\
Anti-HBe & HBe-Antikörper \\
BGB & Bürgerliches Gesetzbuch \\
CD4 & cluster of differentiation 4 \\
CDC & Centers For Disease Control \\
DEGS1 & Studie zur Gesundheit der Erwachsenen in Deutschland \\
DNA & deoxyribonucleic acid \\
dsDNA & Doppelstrang-DNA \\
ELISA & enzyme linked immunosorbent assay \\
HAART & highly active antiretroviral therapy \\
HBc-AG & hepatitis B core antigen \\
HBeAg & hepatitis B envelope antigen \\
HBsAg & hepatitis B surface antigen \\
HBV & Hepatitis-B-Virus \\
HCV & Hepatitis-C-Virus \\
HIV & human immunodeficiency virus \\
HIV-1 & human immunodeficiency virus 1 \\
HIV-2 & human immunodeficiency virus 2 \\
IgM & Immunglobulin M \\
MRSA & Methicillin-resistenter Staphylococcus aureus \\
MSM & Männer, die Sex mit Männern praktizieren \\
NS5A & nonstructural protein 5A \\
NS5B & nonstructural protein 5B \\
OP & Operation \\
\hline
\end{tabular}


RNA ribonucleic acid

Rt-PCR Reverse Transkriptase-Polymerase-Kettenreaktion

S3 Leitlinie Leitlinie, hat alle Elemente einer systematischen Entwicklung durchlaufen

STIKO Ständige Impfkommission

UMG Universitätsmedizin Göttingen

VRE Vancomycin-resistente Enterokokken 


\subsection{Abbildungsverzeichnis}

Abbildung 1: Unterteilung des Gesamtkollektives von 18569 Untersuchungen nach Geschlecht auf Alterskategorie

Abbildung 2: Verteilung der reaktiven Ergebnisse nach Alter und Geschlecht Seite 31

Abbildung 3: Anzahl der reaktiven Blutentnahmen, Mono- und Mehrfachinfektionen

Abbildung 4: Box Plot, Gesamtverteilung des Infektionsstatus von 593 Blutentnahmen auf Alter und Geschlecht

Abbildung 5: Anzahl der falsch-positiven Testergebnisse bezogen auf die im Schnelltest initial festgestellte Infektion

Abbildung 6: Anzahl Abszesspatienten pro Jahr

Abbildung 7: Lokalisation der Extremitätenverletzungen

Abbildung 8: Verteilung der Infektionen in Bezug auf Verletzungen der oberen Extremität

Abbildung 9: Infektion bei Verletzungen der unteren Extremität 


\subsection{Tabellenverzeichnis}

Tabelle 1: $\quad$ Unterteilung der Status auf die Jahre 2001-2015 Seite 35

Tabelle 2: $\quad$ Verteilung Geschlecht, Alterskategorie (in Jahren) und Diagnosekategorie A-S (Definition siehe 2.3.2)

Tabelle 3: $\quad$ Obere Extremität, Vergleich der Maßnahmen in Bezug auf übliche Behandlung und Verletzungskategorie

Tabelle 4: $\quad$ Untere Extremität, Vergleich der Maßnahmen in Bezug auf übliche Behandlung und Verletzungskategorie

Tabelle 5: $\quad$ Anzahl der Stichverletzungen an der Universitätsmedizin Göttingen, unterteilt in Berufsgruppen

(Betriebsmedizin Göttingen 2016).

Seite 52

Tabelle 6: Material, anhand dessen es in der Universitätsmedizin Göttingen zu Stichverletzungen kam

(Betriebsmedizin Göttingen 2016).

Tabelle 7: $\quad$ Unterteilung der Serologien in Bezug auf Stichverletzungen an der Universitätsmedizin Göttingen

(Betriebsmedizin Göttingen 2016). 
7.4 Kostenaufstellung Screeningverfahren

Kosten der einzelnen Testverfahren:

Hepatitis B $9,63 €$

Hepatitis C $12,84 €$

HIV $\quad 9,63 €$

Gesamtkosten $\quad 32,10 €$

Kosten für das Screening der 18659 Patienten

$598.953,9 €$

Ungefähre monatliche Kosten bei 160 Monaten

(errechnet an Monaten, nicht Patientenaufkommen) $3.743,46 €$

Ungefähre jährliche Kosten

$44.921,54 €$ 


\section{Danksagung}

Mein Dank gebührt Herrn Prof. Dr. Dresing für die Konzeptionierung des Themas und die hervorragende Betreuung des Promotionsvorhabens.

Weiterer Dank geht an Herrn Priv.-Doz. Dr. Jung aus dem Institut für Medizinische Statistik für die beratende Hilfe bei der Bearbeitung der statistischen Daten.

Aus dem Institut für klinische Chemie gilt mein Dank Frau Dr. Loderstädt und Herrn Dr. Binder, kommissarischer Leiter, für die Durchführung der laborchemischen Analysen.

Ferner danke ich dem stellvertretenden Leiter des betriebsärztlichen Dienstes der Universitätsmedizin Göttingen, Herrn Stamer, sowie der Leitung Frau Dr. Reimers, für die Unterstützung der Analyse der betriebsmedizinischen Daten. 